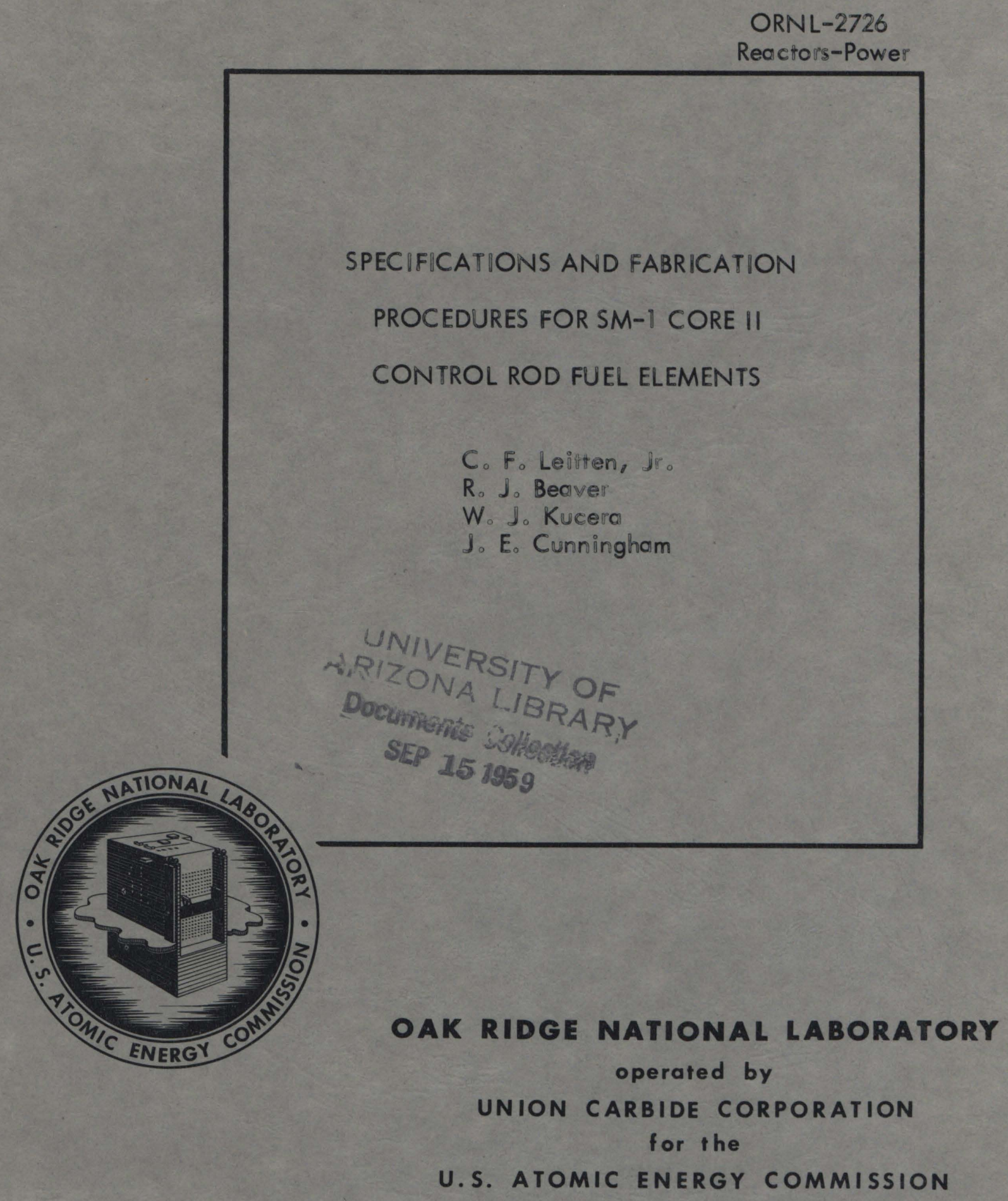

metadc100282 


\section{Printed in USA. Price $\$ 2.50$}

Available from the

Office of Technical Services

Department of Commerce

Washington 25, D.C.

\section{LEGAL NOTICE}

This report was prepared as an account of Government sponsored work. Neither the United States, nor the Commission, nor any person acting on behalf of the Commission:

A. Makes any warranty or representation, expressed or implied, with respect to the accuracy, completeness, or usefulness of the information contained in this report, or that the use of any information, apparatus, method, or process disclosed in this report may not infringe privately owned rights; or

B. Assumes any liabilities with respect to the use of, or for damages resulting from the use of any information, apparatus, method, or process disclosed in this report.

As used in the above, "person acting on behalf of the Commission" includes any employee or contractor of the Commission, or employee of such contractor, to the extent that such employee or contractor of the Commission, or employee of such contractor prepares, disseminates, or provides access to, any information pursuant to his employment or contract with the Commission, or his employment with such contractor. 
Contract No. W-7405-eng-26

METALLURGY DIVISION

SPECIFICATIONS AND FABRICATION PROCEDURES

FOR

SM-I CORE II CONTROL ROD FUEL ELEMENTS

\author{
C. F. Leitten, Jr. \\ R. J. Beaver \\ W. J. Kucera \\ J. E. Cunningham
}

DATE ISSUED

\title{
JUL 291959
}

\author{
OAK RIDGE INATIONAL LABORATORY \\ Oak Ridge, Tennessee \\ operated by \\ UNION CARBIDE CORPORATION \\ for the \\ U.S. ATOMIC ENERGY COMMISSION
}


CONTENTS

$\underline{\text { Page }}$

ABSTRACT

I. INTRODUCTION-_. 2

II. DESCRIPTION OF THE COMPONENT

III. GENERAL REQUIREMENTS- 3

IV. DESIGN CRITERIA

A. Basic Requirements

B. Material Selection-1

1. Uranium Dioxide-_. 11

2. Boron Carbide-14

3. Austenitic Stainless Steel-14

4. Flux Suppressor-15

5. Brazing Alloy-a 15

V. CONTROL ROD FUEL ELEMENT SPECIFICATIONS

A. Fuel Core Material Requirements

1. Fuel-15

2. Burnable Poison-_. 16

3. Matrix Material-a 16

B. Suppressor Core Material Requirements-16

1. Suppressor Material-16

2. Matxix Material-16

C. Material Specifications 17

1. Fuel Core-17

2. Flux Suppressor Core-17

3. Wrought Stainless Steel-18

4. Brazing Alloy-18

5. Handle and Gusset Plates-_. 18

6. Extraneous Materials-_. 18

D. Dimensional Requirements-19

E. Finish Requirements- 19

F. Qualification of Fabrication Procedure

1. Methods of Qualification-... 19

2. Qualification of Master Suppressor Compacts_...... 20 
3. Qualification on Fuel Plate Fabrication-_... 20

4. Qualification of Component Brazing-(22

5. Control of Boron Losses 25

6. Liaison and Inspection-_. 27

7. Certification-10 27

VI. MANUFACTURING PROCEDURES- 27

A. Introduction-1 27

B. Records-a 29

C. Fuel Core Manufacture-1 29

1. Calculations-_- 29

2. Weighing of Component Powders 30

3. Blending 33

4. Cold Pressing of the Core Ingredients-_.-. 33

5. Sintering of Green Compacts-a 36

6. Coining of Sintered Compacts- 37

7. Inspection-1 37

8. Core Storage-1 37

D. Flux Suppressor Core-18

1. Preparation of $\mathrm{Eu}_{2} \mathrm{O}_{3}$

2. Manufacture of the Dispersion of $\mathrm{Eu}_{2} \mathrm{O}_{3}$ in Stainless Steel-- 39

E. Billet Assembly-_ 41

1. Material Preparation-1 4

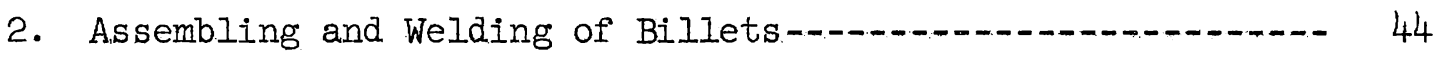

F. Composite Plate Fabrication-_. 44

I. Hot Rolling-- 44

2. Fluoroscopic Examination-_.- 46

3. Cold Rolling-_. 46

4. Radiographic Examination and Marking-_. 46

5. Shearing-- 48

6. Machining-- 48

7. Inspection-1

G. Flatten Annealing of Machined Fuel Plates-_. 51

H. Manufacture of Side Plates and Combs 54

I. Side Plates-a 54 
$\underline{\text { Page }}$

2. Combs

3. Attachment of Gusset Plates to Side Plates............... 58

I. AssembIy of Fuel Unit_... 58

1. Brazing Jig-....... 58

2. Procedure -nan- 61

J. Brazing of Fuel Assemblies -...

1. Procedure

2. Dimensional Inspection-1. 66

3. Cleaning- 68

4. Visual Inspection-_. 68

K. Attachment of Handle -

VII. PREPARATION FOR SHIPMEIVI _

ACKNOWLEDGMENTS - $\ldots 2 \ldots 9$

BIBLIOGRAPHY 70

APPENDIX A

APPENDIX B-

APPENDIX C $\times-\ldots$ 
SPECIFICATIONS AND FABRICATION PROCEDURES FOR SM-I

CORE II CONTROL ROD FUEL ELEMENTS

SUMMARY

Stainless steel-base fuel elements of thin plate-type construction, containing a dispersion of enriched uranium dioxide, have been successfully employed in powering the Army Package Power Reactor. This report is concerned with the control rod fuel element proposed for operation in the second core loading of SM-1, formerly designated as APPR-1.

The general characteristics of the component engineered for radioactive service in pressurized water at $450^{\circ} \mathrm{F}$ are described. An important feature of the new component is a built-in flux suppressor to minimize flux peaking at the void junction between the fuel and absorber sections of the control rod assembly. The underlying criteria which guided the design are presented. The technological factors, such as compatibility, corrosion resistance, and irradiation behavior, which led to the selection of $\mathrm{UO}_{2}$ as the fissile compound, boron carbide as the burnable poison, europium oxide as the flux suppressor, and austenitic stainless steel as the cladding and matrix material, are reviewed.

The fabrication procedures developed and adopted for manufacturing the component are presented in detail. Included are powder metallurgy processing of $\mathrm{UO}_{2}$ and $\mathrm{B}_{4} \mathrm{C}$ in stainless steel fuel compacts and $\mathrm{Eu}_{2} \mathrm{O}_{3}$ in stainless steel flux suppressor compacts, cladding of the fuel by roll bonding, and joining of the thin plates into an integral unit by brazing. Quality-control measures adopted to produce components, on a pilot plant basis, consistently within dimensional tolerances are described.

The general requirements for manufacturing Core II control rod fuel elements are outlined for the purpose of informing prospective fabricators with the nature and scope of the undertaking. Detailed material specifications and dimensional requirements which the manufacturer is expected to meet are also provided.

Since the components have not been prepared along normal commercial lines where quality is assured by nondestructive testing to industry-wide standards, the supplier should qualify his fabrication procedure before initiating work. The method for qualification of procedure is given. Requirements include the preparation and testing of full-sized plates and elements to demonstrate trouble-free operation from such problems as inhomogeneity, sensitization, excessive fragmentation and stringering, surface contamination, and lack of bonding. 


\section{INTRODUCTION}

The control rod fuel element manufactured at ORNL for the second loading of SM-I (formerly the APPR-I) is essentially the same as the prototype component employed in operation of Core I, except for one distinct feature. An integral flux suppressor containing a small europium-bearing segment has been incorporated directly into the core at one end of the composite fuel plate. The internal suppressor replaces the external Haynes -25 combs utilized in Core $I$. This innovation improves coolant flow and eliminates one potential source of gamma activity in the primary loop due to $\mathrm{Co}^{60}$. In addition, the integral suppressor still serves the primary function of minimizing flux peaking caused by the Wilkins' effect in the axial void junction at the fuel-absorber interface in the control rod assembly.

This report is prepared specifically to aid the A.rmy Reactors Branch of the Division of Reactor Development in procuring replacement control rod fuel elements from a commercial source. The specifications and fabrication procedures developed and adopted for the Core II control rod fuel elements are presented in sufficient detail to enable an industrial manufacturer to undertake the task with only a minimum of development effort. Similar data on the absorber section, which constitute an important segment of the control rod, are reported in ORNL-2733.

The Army Package Power Reactor was built and placed into operation on April 12, 1957, to demonstrate the feasibility of supplying heat and power at remote locations by nuclear energy generated in smal.1, compact reactors. The plant has a rated thermal capacity of $10 \mathrm{Mw}$ and delivers $2 \mathrm{Mw}$ of electrical power at the turbo generator. The reactor is cooled and moderated by pressurized water and powered with highly enriched uranium. The fuel is loaded into the reactor core in the form of uranium dioxide dispersed in stainless steel.

The utilization of stainless steel-uranium dioxide fuel components for this application was the culmination of a five-year-program effort of general materials and component development work at the Oak Ridge National Laboratory. The program was motivated by the limitations of aluminum and zirconium and by the advantages offered by stainless steel with its excellent corrosion resistance, its attractive physical and mechanical properties, and its amenability to simple and inexpensive fabrication practice. The final engineering design data covering material content requirements as well as dimensional specifications were established and furnished by A.jso Products, Inc. 


\section{DESCRIPTION OF THE COMPONENT}

As illustrated in Fig. 1, the control rod fuel element is one of two major components which are positioned in a stainless steel control rod housing or "basket:" The fuel element consists of sixteen composite fuel plates, joined by brazing into a pair of side plates to form an integral assembly. The core of each composite fuel plate consists of two 0.020 -in.-thick sections: (1) a fuelbearing section containing enriched $\mathrm{UO}_{2}$ and a small quantity of $\mathrm{B}_{4} \mathrm{C}$ uniformly dispersed in a matrix of stainless steel powder and (2) a neutron-absorbing section containing a homogeneous dispersion of $\mathrm{Eu}_{2} \mathrm{O}_{3}$ in stainless steel. The fuel-bearing portion occupies approximately 95\% of the core volume of the plate while the flux suppressor component accounts for the balance.

The cores are encased in a thin jacket of stainless steel. These composites are prepared by roll bonding to promote heat transfer across the core-clad interface and to hermetically seal the fuel and resultant fission products from the coolant.

Representative cross sections of the stalnless clad composite fuel and flux suppressor sections are shown in Figs. 2 and 3, respectively. A radiograph showing the physical arrangement at the flux suppressant end of the fuel plate is illustrated in Fig. 4. The finished control rod fuel element with accessory handle, for loading is shown in Fig. 5.

\section{GENERAI REQUIREMENTS}

A. The fuel component is designed for radioactive service in pressurized water. Once placed in operation it cannot be subjected to maintenance, repair, or salvage. It is imperative, therefore, that only the highest degree of quality obtainable with respect to materials of construction and workmanship be incorporated into the finished component. In addition, the product is intended for service in an existing system and cannot be altered. Hence, the component must be manufactured in strict accordance with the specifications and fabrication procedures described in this report.

B. Satisfactory performance of the control rod fuel elements during their operating life requires that special precautions be taken to ensure the following:

1. Accurate incorporation of the desired quantity of fuel burnable poison, and flux suppressant into the component is mandatory. A nuclear imbalance resulting from improper loading of critical constituents can potentially lead to a serious nuclear incident. 


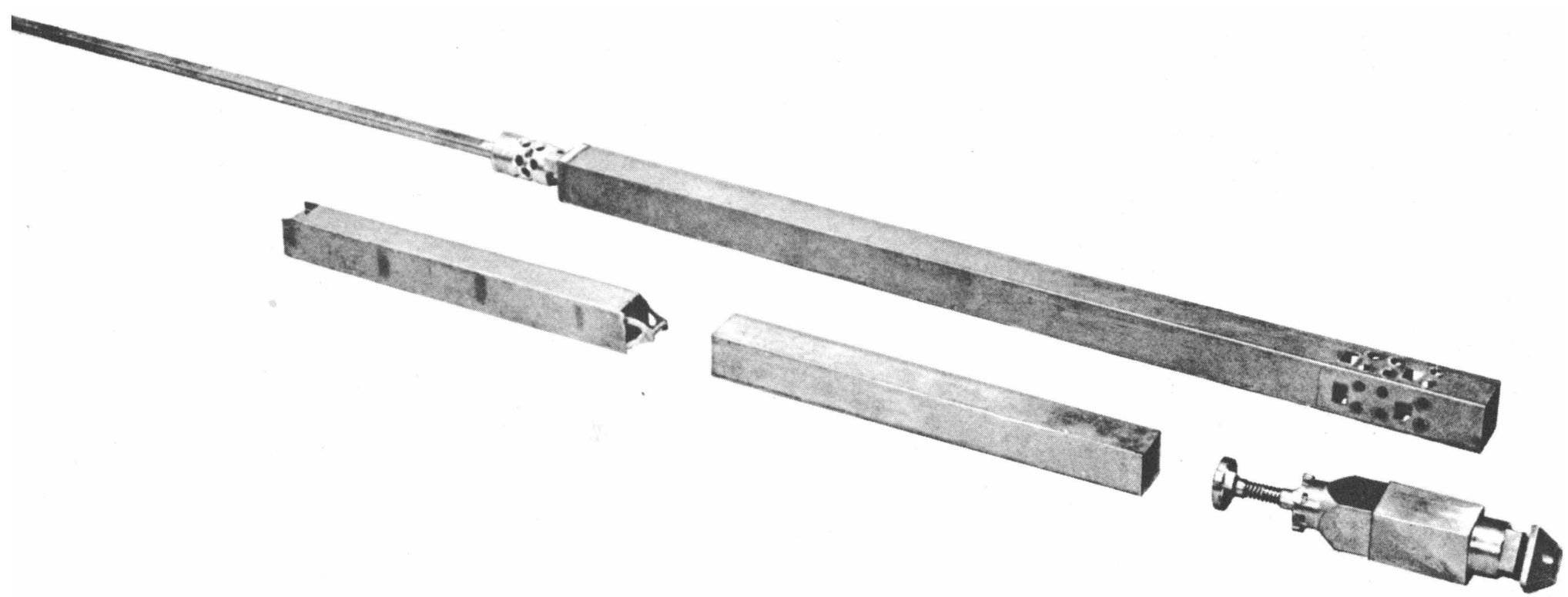

Fig. 1. The Control Rod Components. 
UNCLASSIFIED

Y-28336

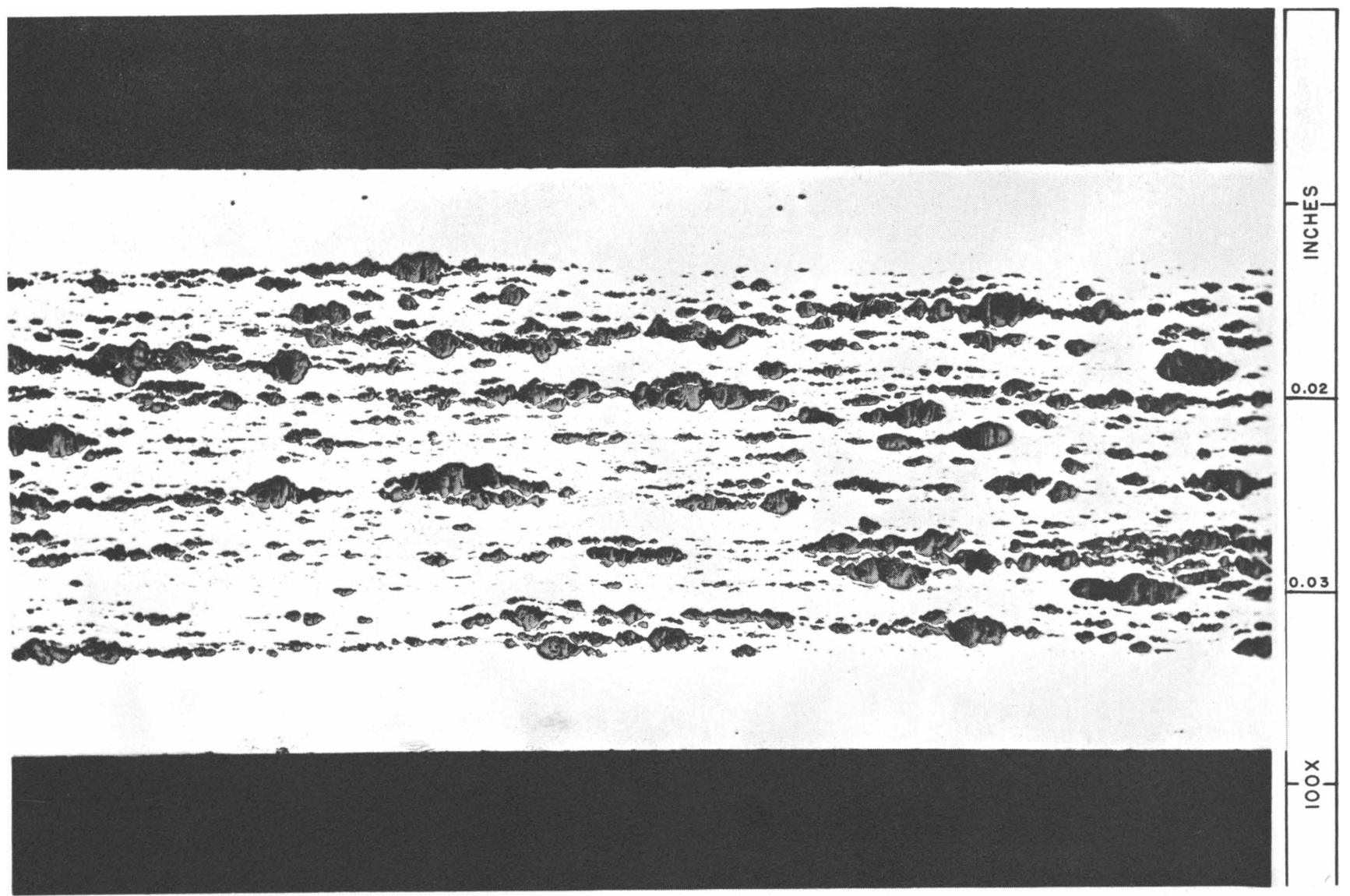
Plate.

Fig. 2. Cross Section of the $\mathrm{UO}_{2}$-Stainless Steel Control Rod Fuel 
UNCLASSIFIED

Y-29588

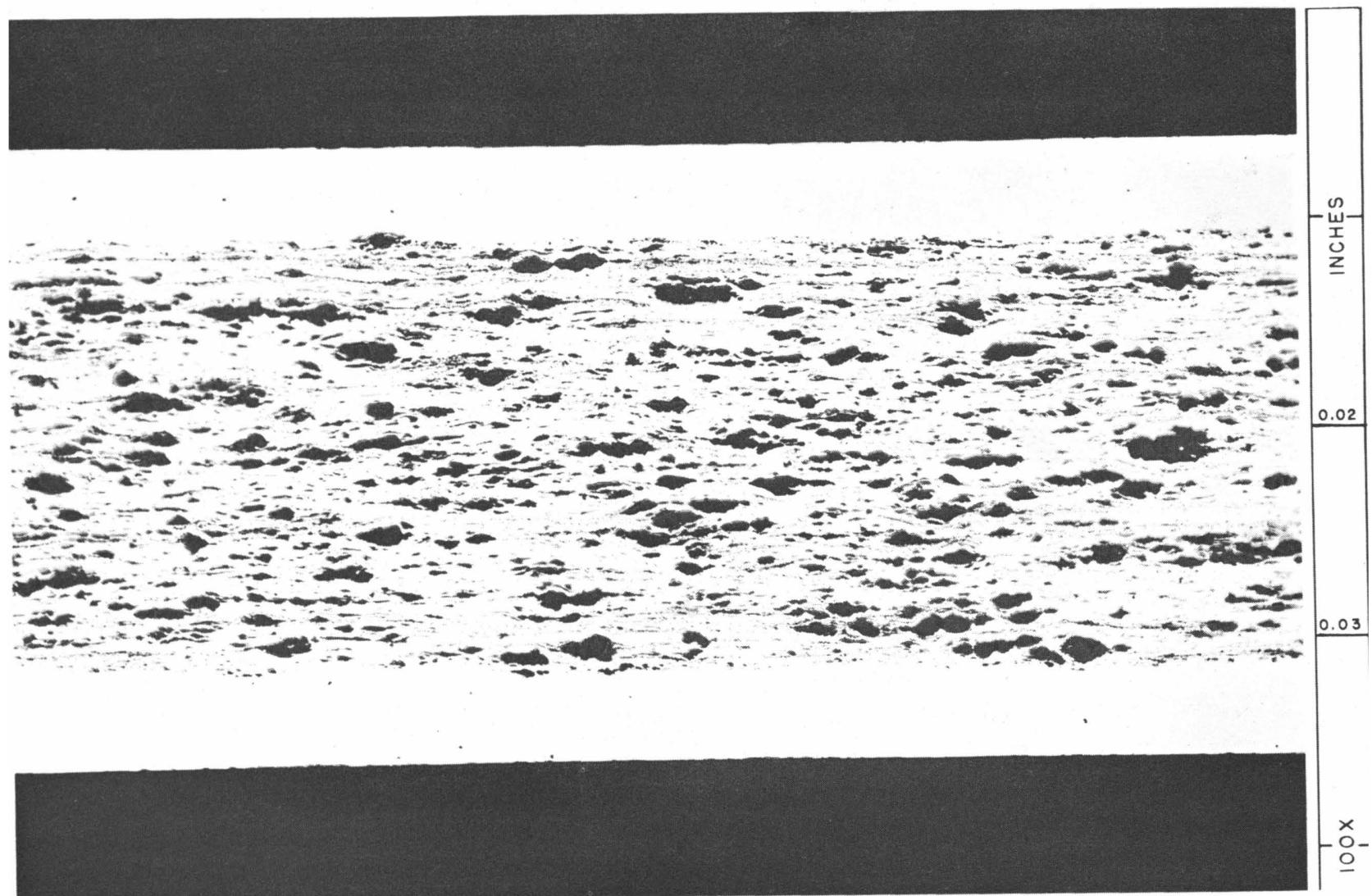

Fig. 3. Cross Section of $\mathrm{Eu}_{2} \mathrm{O}_{3}$-Stainless Steel Flux Suppressor. 
UNCLASSIFIED

Y-29589

Fig. 4. Radiograph Showing the Internal $\mathrm{Eu}_{2} \mathrm{O}_{3}$-Stainless Steel Flux Suppressant Section at the $\mathrm{TIp}$ End of the $\mathrm{UO}_{2}$-Stainless Steel Fuel section in the Core II Control Rod Fuel Plate. 


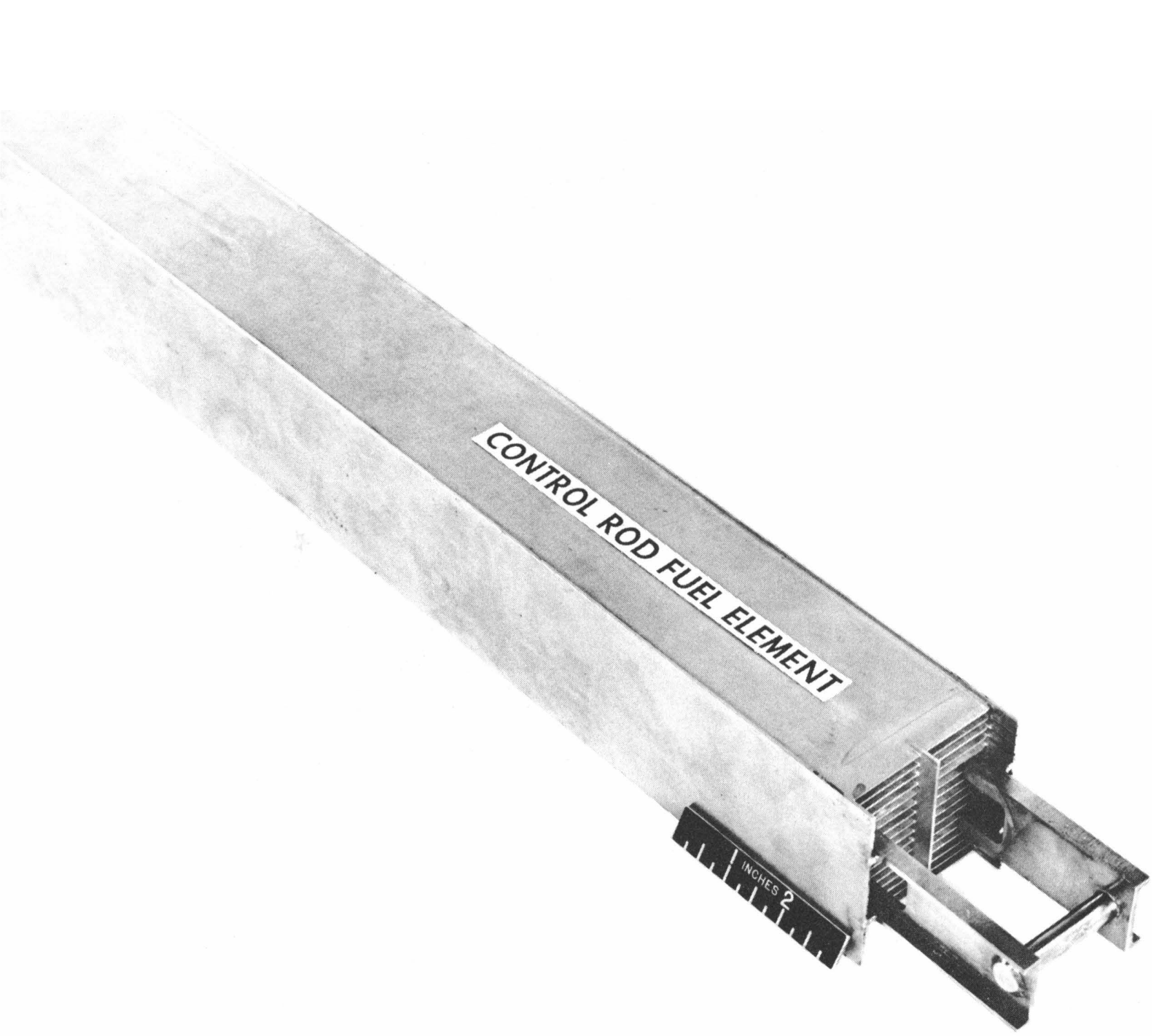

Fig. 5. Control Rod Fuel Element. 
2. Uniform distribution of the $\mathrm{UO}_{2}$ and $\mathrm{B}_{4} \mathrm{C}$ in the fuel core and $\mathrm{Eu}_{2} \mathrm{O}_{3}$ in the flux suppressor of the composite plate must be achieved. Inhomogeneity of these important ingredients could lead to hot spots and ultimate failure.

3. A continuous metallurgical bond between clad and frame material às well as clad and core-matrix material must be obtained to: (a) protect the fuel, burnable poison and flux suppressant from corrosion by the coolant, (b) contain the highly radioactive by-products of fission, and (c) promote efficient heat removal. The resulting bond should be free of defects, such as blisters, which may release fission products to the coolant.

4. Uniformity in thickness of clad and core material must be maintained to ensure proper corrosion protection as well as to achieve the required concentration of fuel over the entire area of the active portion of the fuel plate.

5. It is important that all plates be identified and assembled properly to assure that the $\mathrm{Eu}_{2} \mathrm{O}_{3}$-bearing tips of each plate are located at the end of the fuel element which will be adjacent to the absorber section.

6. The composition and processing of materials must be controlled to minimize the presence of contaminants which may (a) accelerate corrosion, (b) contribute to parasitic absorption of neutrons, (c) reduce mechanical integrity, (d) promote diffusion or migration of fuel or burnable poison, (e) impair heat transfer, (f) promote swelling or blistering by gas release which could restrict coolant flow and ultimately result in cladding failure, and (g) increase the level of radioactivity in the primary coolant loop by contaminating the fuel element surfaces with fissionable or other materials capable of undergoing transmutation and giving rise to gamma-activity buildup.

7. The various sequences of framing, cladding, shearing, machining, and brazing must be carried out and inspected in a manner to preclude the presence of fissionable material at the clad-frame interface as well as to ensure that no portion of the fuel and/or suppressant-bearing core is exposed to the coolant.

C. Experience at ORNL in the manufacture of the stationary and control rod fuel elements for Core I as well as the control rod elements for Core II has demonstrated the feasibility of fabricating components which consistently meet 
the product standards required. Assurance that the component meets these standards cannot be accomplished exclusively by nondestructive testing of random or control samples. Instead, these must be combined with the estabishment of and rigid adherence to proven fabrication procedures, materials inspection, and cleanliness standards. Industrial utilization of the detailed processing procedures presented in Section VI (Manufacturing Procedures) does not relieve a manufacturer from any responsibility associated with the fabrication of a product satisfactory for service.

D. Sufficient and proper supervisory and production controI must be provided by a manufacturer: (I) to ensure that all details of the fabrication procedure conform at all times with the approved procedure, (2) to maintain rigid adherence to a.l specifications, (3) to protect personnel against human intake of airborne activity from alpha-emitting $\mathrm{UO}_{2}$ by inhalation or ingestion in compliance with the requirements of the International Commission on Radiation Protection, (4) to enforce safety measures to prevent a criticality incident, and (5) to safeguard and account for all fissionable material in accordance with the Atomic Energy Commission Iicensing agreement, or other arrangements with the AEC, as defined under the Atomic Energy Act.

E. It will be necessary to maintain sufficient and proper records to supply complete metallurgical history, fuel accountability, inspection, quality control, and other pertinent data required in the fabrication of the fuel elements.

F. In adaition to the identification numbers specified in the fabrication procedure for components and fuel elements, a symbol indicative of the manufacturer shall be added to each fuel element.

IV. DESIGN CRITERIA

\section{A. Basic Requirements}

The design of the control rod fuel element for service in Core II is based on the following criteria: (1) operation at a high specific power density and reduction of core volume by utilizing enriched fuel, (2) dispersion of the fuel in a suitable diluent to maximize heat transfer and prevent structural damage to the materials of construction by overheating, (3) extension of reactivity lifetime by the addition of a burnable poison to compensate for reactivity changes due to fuel. consumption and to permit utilization of heavier investments of fuel, (4) utilization of $\mathrm{Eu}_{2} \mathrm{O}_{3}$ dispersed in stainless steel as an internal flux suppressor, (5) cladding with stainless steel, for corrosion protection and retention of fission products, 
(6) selection of inexpensive materials of construction and low-cost methods of processing to minimize fuel cycle costs, and (7) employment of a metallurgical bond and thin plate-type construction to promote efficient heat removal.

The active core is composed of thirty-eight stationary fuel components and seven movable control rod assemblies immersed in water, which serves as moderator, reflector, and coolant. The system is pressurized to 1200 psia and water flows through the channels between adjacent fuel plates at an average velocity of 4.3 fps.

The control rod fuel component consists of sixteen flat composite plates joined to a pair of side plates by brazing to form an integral assembly with a nominal watergap spacing of 0.133 in. A line drawing with dimensional requirements of the component is shown in Fig. 6. This drawing is for reference only and should not be used for fabrication.

Other pertinent design and operating data are listed in Table I. The data listed for make-up of the core section of each composite plate are for information only and are based on utilizing materials of the following specifications: (I) $\mathrm{UO}_{2}$ with a total uranium content of 87.63 wt $\%$ and a uranium-235 isotopic enrichment of 93.07 wt \%, (2) $\mathrm{B}_{4} \mathrm{C}$ containing a total boron content of 75.90 wt $\%$ and boron-10 isotopic concentration of 18.09 wt $\%$, and (3) $\mathrm{Eu}_{2} \mathrm{O}_{3}$ with a total europium content of 85 wt $\%$.

\section{B. Material Selection}

In general, alloys of uranium with stainless steel or with any of the elemental constituents of stainless steel cannot be considered as fuel materials because of the presence of low-melting eutectics and brittle intermetallic compounds. Therefore, the development of stainless steel fuel elements has centered on the selection of a uranium-bearing compound which is metallurgically compatible and chemically inert when dispersed in stainless steel and processed at elevated temperatures.

1. Uranium Dioxide - The refractory compound $\mathrm{UO}_{2}$ with its excellent high-temperature properties meets these general requirements. The compound is chemically inert in contact with stainless steel at temperatures as high as $2550^{\circ} \mathrm{F}$ and exhibits moderate resistance to corrosion in pressurized water. Furthermore, it can be produced in an economical manner and has a relatively high assay of fuel compared to most uranium-bearing compounds. In contrast to uranium metal, uranium dioxide is relatively insensitive to radiation damage and 
UNCLASSIFIED
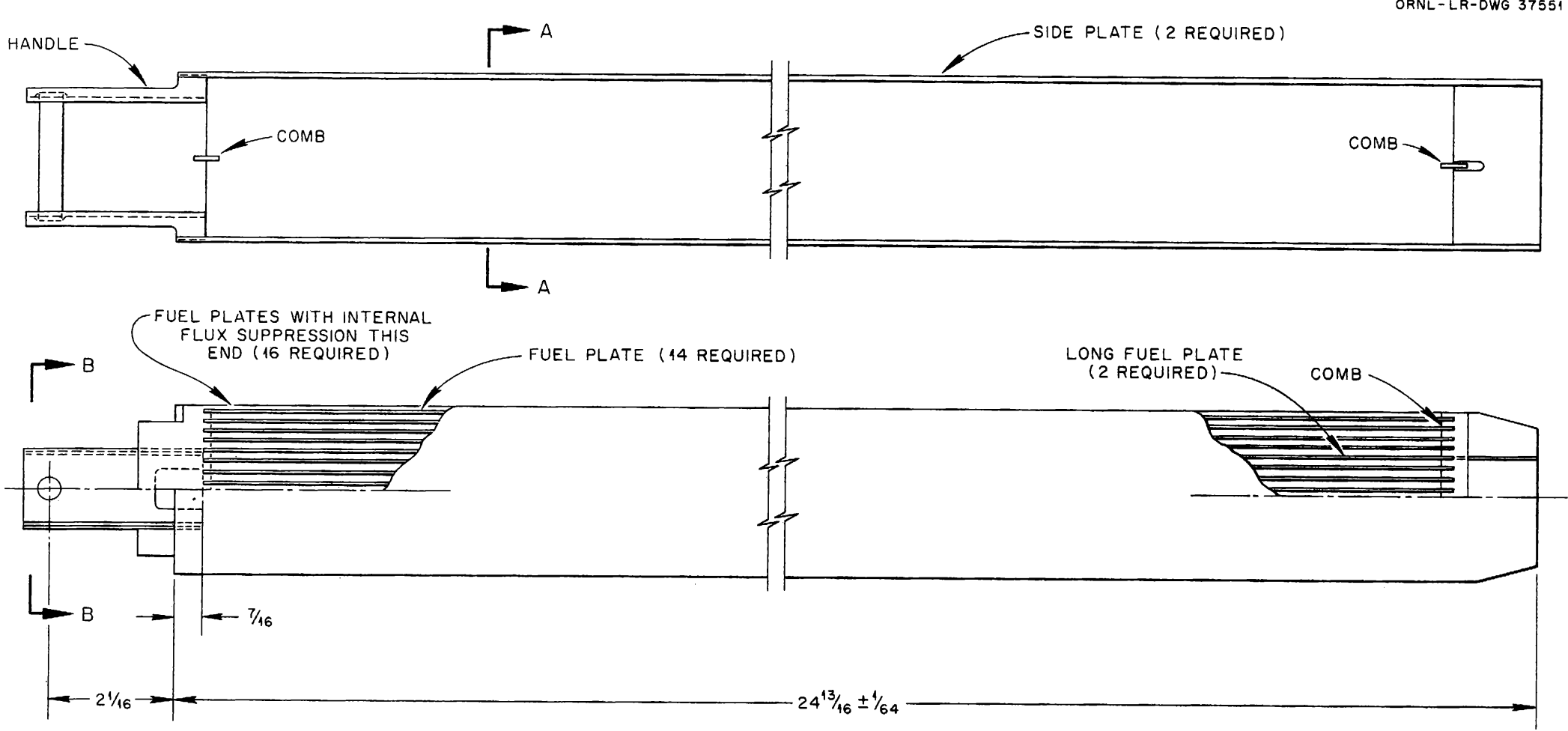

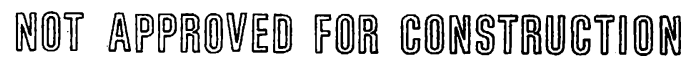

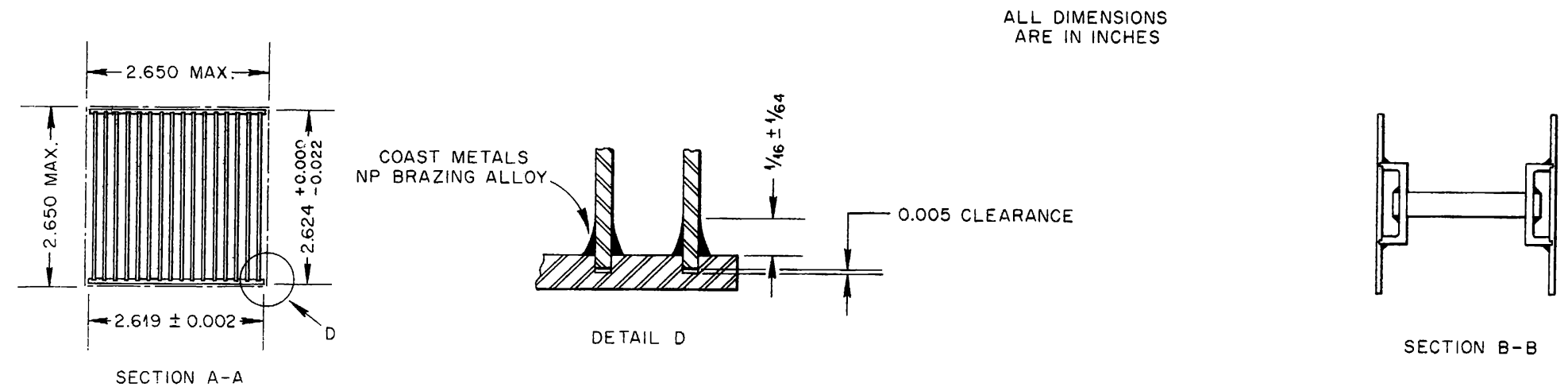

Fig. 6. Dimensional Drawing of the Control Rod Fuel Element. 
TABLE I

DESIGN DATA ON APPR-I CORE II CONTROL ROD FUEL ELENENT

General Description

Number of Fuel Plates Per Assembly

Fuel Plate Clad-Core-Clad Thickness, mil

$5-20-5$

Water Gap Spacing, mil

$\mathrm{B}^{10}$ Content Per Assembly, g

0.362

Europium Content Per Assembly, g

16.0

$\mathrm{u}^{235}$ Content Per Assembly, g

401.12

Metal-to-Water Ratio

0.25

Materials Make-Up Data

Fuel Core Composition Per Plate

$\mathrm{UO}_{2}(44-88 \mu)$

$B_{4} C(<44 \mu)$

304IB Stainless Steel $(<149 \mu)$

Suppressor Core Composition

Per Master Compact

$$
\mathrm{Eu}_{2} \mathrm{O}_{3}(<44 \mu)
$$

8.058

27.68

28.96

Stainless Steel (prepared from $<44 \mu$ elemental powders $71 \% \mathrm{Fe}-18 \% \mathrm{Cr}-11 \% \mathrm{Ni}$ )

\begin{tabular}{|c|c|c|}
\hline$g$ & wt $\%$ & vol $\%$ \\
\hline 30.82 & 25.16 & 19.39 \\
\hline 0.165 & 0.13 & 0.48 \\
\hline 91.51 & 74.71 & 80.13 \\
\hline 8.058 & 27.68 & 28.96 \\
\hline 21.05 & 72.32 & 71.04 \\
\hline
\end{tabular}


does not undergo deformation at low temperatures when subjected to reactorinduced radiation. Uranium dioxide also offers the advantage of good fission-gas retention which is attributed to its defective lattice structure. The chief disadvantages of low-thermal conductivity and brittleness, which are characteristic of $\mathrm{UO}_{2}$, are largely overcome by the nature of the dispersion-type fuel component.

Although $\mathrm{UO}_{2}$ can be prepared by a variety of methods to yield a product with various characteristics, a fairly dense and inert grade of oxide with an oxygentowranium ratio near stoichiometry is desirable as a dispersoid in stainless steel. The product should be free of agglomerates, platelets, rods, and clinging surface fines which lead to excessive fragmentation and stringering during processing. In addition, particles larger in size than $44 \mu$ are desirable to minimize fission-fragment damage to the matrix stalnless steel. The hydrothermal process yields a product that generally meets these requirements and was used in the Core I and Core II control rod fuel elements.

2. Boron Carbide - Boron-10 was selected as the burnable poison because Its nuclear burnout characteristics closely match those of the fuel. It is added. as natural boron in the form of boron carbide $\left(\mathrm{B}_{4} \mathrm{C}\right)$. This compound was selected in preference to other boron compounds because of its high concentration in boron.

3. Austenitic Stainless Steel - Wrought austenitic stainless steel, AISI type 304L, was selected as the cladding and structural material for the fuel components. This material is relatively cheap, readily available in the desired form, and amenable to most mechanical working and welding operations. It has excellent corrosion resistance in high-temperature water and adequate strength and ductility to withstand the thermal stresses and gradients encountered in operation. The alloy also has fair heat-transfer properties, and is not subject to serious structural damage under irradiation. On the other hand, stainless steel would impose a severe nuclear penalty if substituted for zirconium on an atom-formatom basis. This penalty can be partly overcome by judicious design utilizing the full potential of the high-strength properties of stainless steel. Care should be taken to use a steel with low-cobalt content in order to minimize the radio-chemical transport problem associated with high-activity cobalt-60 which enters the primary-loop system as a corrosion product.

A low-carbon grade of wought stainless steel is specified for the cladding and frame material to minimize the precipitation of chromium carbide at the grain 
boundaries and, thereby, avoid excessive sensitization on cooling after brazing.

Prealloyed stainless steel powder of type AISI 304LB with maximum carbon content of 0.03 wt $\%$ and silicon content of approximately 2.5 wt $\%$ is stipulated as the matrix material for the fuel core section. The silicon content is added primarily to prevent oxidation during preparation; however, it does result in particles with an irregular shape which leads to higher green strengths on cold pressing.

The stainless steel for the matrix of the flux suppressor is prepared from iron, nickel, and chromium elemental powders with a composition of 71 wt $\% \mathrm{Fe}-18$ wt $\% \mathrm{Cr}-1 \mathrm{l}$ wt $\% \mathrm{Ni}$. The silicon content of each of the elemental powders is restricted to a maximum of 0.03 wt $\%$.

4. Flux Suppressor - Europium oxide $\left(\mathrm{Eu}_{2} \mathrm{O}_{3}\right)$ is specified as the flux suppressant because of its nuclear-worth characteristics and its expected stability under irradiation. The material is received as a fluffy white powder "dead burned" from the oxalate and is subsequently densified and strengthened by a high-firing operation.

5. Brazing Alloy - Coast Metals N. P. is specified for joining the fuel plates into integral units because of its superior corrosion resistance. Coast Metals N. P. is a brittle nickel-base alloy containing 50 wt $\% \mathrm{Ni}-27$ wt $\% \mathrm{Fe}-\mathrm{Il}$ wt $\% \mathrm{Si}-8$ wt $\% \mathrm{Mo}-4$ wt $\% \mathrm{P}$. The alloy flows at $2066^{\circ} \mathrm{F}$. Stainless steel joints prepared with this brazing alloy have exhibited excellent resistance to corrosion in $570^{\circ} \mathrm{F}$ water and strengths of $28,000 \mathrm{psi}$ in shear and 62,000 psi in tension.

V. CONTTROL ROD FUEL ELEMENT SPECIFICATIONS

A. Fuel Core Material Requirements

1. Fuel

$$
\begin{array}{ll}
\mathrm{U}^{235} \text { Content Per Plate, g } & 25.07 \\
\mathrm{U}^{235} \text { Isotopic Concentration, wt \% } & 93 \pm 1 \\
\quad \text { Allowable tolerances } & \\
\text { Weighing } & \pm 0.03 \% \\
\mathrm{U}_{\mathrm{TT}} / \mathrm{UO}_{2} & \pm 0.25 \% \\
\mathrm{U}^{235} / \mathrm{U}_{\mathrm{T}} \text { Limit of Error at 95\% Confidence Level } & 0.05 \% \\
\text { Handling Loss } & -0.19 \%
\end{array}
$$

*Allowable tolerances were established by ORNL as a resilt of evaluation of uncertainties involved in fabricating the control rod fuel element for core II. 
2. Burnable Poison

$\mathrm{B}^{10}$ Content Per Plate, $g$

0.02264

$\mathrm{B}^{10}$ Isotopic Concentration, wt \%

$18.5 \pm 1.5$

Allowable tolerances ${ }^{*}$

Weighing

$\pm 0.30 \%$

$\mathrm{B}_{\mathrm{N}} / \mathrm{B}_{4} \mathrm{C}$

$\pm 1.00 \%$

$\mathrm{B}^{10} / \mathrm{B}^{11}$ Limit of Error at $95 \%$ Confidence Level

$\pm 0.05 \%$

Handling Loss

$-0.20 \%$

Average Processing Loss

$-25.00 \%$

3. Matrix Material

Type 304LB Stainless Steel Powder, g

91.51

Allowable tolerances ${ }^{*}$

Weighing

$\pm 0.01 \%$

Handling Loss

$-0.20 \%$

B. Suppressor Core Material Requirements ${ }^{* *}$

1. Suppressor Material

Europium Content Per Plate, g

Allowable tolerances ${ }^{*}$

Weighing

$\pm 0.3 \%$

$\mathrm{Eu} / \mathrm{Eu}_{2} \mathrm{O}_{3}$

$\pm 0.5 \%$

Handling Loss

$-0.1 \%$

2. Matrix Material

Stainless: Steel Prepared from Iron-Nickel-Chromium Elemental Powders (in the weight ratio of $71 \mathrm{Fe}-18 \mathrm{Cr}-1 \mathrm{lNi}$ ) Allowable tolerances ${ }^{*}$

Weighing $\pm 0.9 \%$

Handling Loss $-0.3 \%$

*Allowable tolerances were established by ORNL as a result of evaluation of uncertainties involved in fabricating the control rod fuel element for core II.

**

In actual practice, the suppressor component is machined from a master compact. The loading per plate is based upon homogeneity of the master compact and dimensional requirements of the suppressor component. 
C. Material Specifications

1. Fuel Core

(a) Fuel - The fuel shall be in the form of enriched $\mathrm{UO}_{2}$ powder of high density and virtually free of clinging fines and agglomerates. Uranium dioxide prepared from the thermal decomposition of $\mathrm{UO}_{3} \cdot \mathrm{H}_{2} \mathrm{O}$ in a hydrogen atmosphere was used for the Core II control rod fuel elements. A material with comparable quality is acceptable in the event this type of $\mathrm{UO}_{2}$ is not available. The $\mathrm{UO}_{2}$ shall contain approximately 88 wt $\%$ total uranium and have a $\mathrm{U}^{235}$ isotopic concentration of $93 \% \pm 1 \%$. A particle size of 44 to $88 \mu$ is specified to minimize fission-product damage to the stainless steel matrix.

(b) Burnable Poison - The burnable poison material shall be natural $\mathrm{B}_{4} \mathrm{C}$ powder equivalent to that supplied by Norton Chemical Company as High Purity Grade containing approximately $76 \%$ natural boron. Particle size shall be less than $44 \mu$.

(c) Matrix Material - The matrix material shall be type 304LB stainless steel powder with maximum carbon content of 0.03 wt $\%$ and a silicon content of approximately 2.5 wt \%, equivalent to that supplied by Vanadium Alloys Steel Company. Particles shall be of irregular shape and ranging from 10 to $149 \mu$ in size. Typical distribution of various sized particles in this range for type $304 \mathrm{LB}$ stainless steel is as follows:

$\begin{array}{cc}\text { Particle Size, in } \mu & \text { Fraction, in } \% \\ >149 & 1.9 \\ 105-149 & 23.9 \\ 74-105 & 26.1 \\ 44-74 & 17.0 \\ <44 & 31.1\end{array}$

2. Flux Suppressor Core

(a) Flux Suppressant - The flux suppressant shall be thoria-free dead-burned europium oxide $\left(\mathrm{Eu}_{2} \mathrm{O}_{3}\right)$ which has been densified by a high-firing treatment in hydrogen at $3090^{\circ} \mathrm{F}$. The $\mathrm{Eu}_{2} \mathrm{O}_{3}$ shall contain approximately 85 wt $\%$ europium and the particle size of the material shall be less than $44 \mu$.

(b) Matrix Stainless Steel - The stainless steel matrix is a product of the blending of electrolytic iron, nickel, and chromium elemental powders and 
subsequent alloying during sintering of the suppressor core. Each of the elemental powders shall be limited to a maximum of 0.03 wt $\%$ silicon. The composition of the elemental powders shall be 71 wt $\% \mathrm{Fe}-18$ wt $\% \mathrm{Cr}-1 \mathrm{l}$ wt $\% \mathrm{Ni}$.

3. Wrought Stainless Steel - A special grade of low-cobalt type 304L wrought stainless steel with a 0.01 wt \% (max) cobalt and 0.01 wt \% (max) tantalum content shall be used as the clad and frame material for the fuel plates as well as for the side plates and combs of the fuel element.

Typical analyses of this type of steel is listed below:

$\begin{array}{ccc}\text { Element } & & \text { Wt } \% \\ \mathrm{C} & & 0.018 \\ \mathrm{Mn} & & 1.72 \\ \mathrm{P} & 0.010 \\ \mathrm{~S} & & 0.020 \\ \mathrm{Cr} & 18.70 \\ \mathrm{Ni} & 9.57 \\ \mathrm{Co} & & 0.004 / 0.005 \\ \mathrm{Al} & & 0.062 \\ \mathrm{Mo} & & 0.0097 \\ \mathrm{Cu} & & 0.10 \\ \mathrm{~N} & & 0.05 \\ \mathrm{~Pb} & 0.001 \\ \mathrm{Ta} & 0.001 \\ \mathrm{Sn} & 0.009\end{array}$

4. Brazing Alloy - The brazing material shall be Coast Metals N. P. powder of less than $88 \mu$ size, and can be obtained from Coast Metals, Incorporated, Little Ferry, New Jersey. This material shall be free of boron.

5. Handle and Gusset Plates - The handling pin and gusset plates required to facilitate loading and unloading the component in the reactor core shall be of low-cobalt type 304 stainless steel.

6. Extraneous Materials - Care must be exercised in utilizing extraneous materials, such as electrodes, filler rod, cleaning agents, and lubricants which come into contact with the product during processing. All lubricants, for instance, shall be of non-halogen-bearing type. Pickling of the fuel plates in any solution containing a halide ion, or which is reducing in nature, is not permissible 
subsequent to removal of scale from the hot-rolled fuel plates. The use of any processing agent that may have a deleterious effect on the finished product is prohibited.

D. Dimensional Requirements

The component parts shall be manufactured and assembled in accordance with the dimensional specifications set forth on the Alco Drawings listed below:

APPR CONTROI ROD FUEL ETEMENTT

Description of Item

1. Fuel Element Assembly

2. Composite Fuel Plates Detail

3. Side Plate and Comb Detail

4. Gusset Plate Detail

5. Handle Detail
Reference Drawing

Alco Drawing D9-13-1011

Alco Drawing D9-13-2073

Alco Drawing D9-13-2011

Alco Drawing A.9-13-2078

Alco Drawing A9-13-2077

E. Finish Requirements

All machined surfaces in contact with the coolant shall have a finish of at least 125 RMS unless otherwise noted. Rolled surfaces shall have a surface finish of at least 32 RMS.

F. Qualification of Fabrication Procedure

Quality control of the fuel elements is primarily attained by rigid adherence to proven fabrication procedures. Thus, specifications for the control rod fuel elements cannot be prepared along the lines normally used for industrial products, in which quality is assured by nondestructive inspection to industrywide standards. Consequently, the fuel element manufacturer will be required to qualify the fabrication procedure which is to be employed in the fabrication of the control rod fuel elements.

1. Methods of Qualification - Three qualifications are required. The manufacturer must demonstrate ability to (a) prepare homogeneous master flux suppressor compacts, (b) fabricate fuel plates, and (c) braze fuel elements of the quality described and specified. Six sample fuel plates shall be fabricated and subjected to the tests outlined in Part " 3 " of this section. In addition, one full-size element consisting of composite plates containing depleted or normal $\mathrm{UO}_{2}$ shall be brazed to the dimensions specified in Alco Drawing (D9-13-1011) and subjected to the tests described in Part "4" of this section. The manufacturer 
must exercise special care to minimize boron losses incurred during fabrication. Consistency of boron loss shall be demonstrated by the results of tests described in Part " $5 "$ of this section.

2. Qualification of Master Suppressor Compacts - Two sample master compacts prepared in accordance with Section VI, Item D shall be sectioned into three I/4-in. wide strips taken from the midale and each end of the compacts. The average europium content of the six samples expressed in wt $\%$ must be within \pm 0.2 wt $\%$ of the required concentration.

\section{Qualification on Fuel Plate Fabrication}

(a) The six sample fuel plates shall be prepared in conformance with the exact and complete fabrication procedure which is proposed to be used in the manufacture of the control rod fuel elements. Depleted uranium oxide, identical in every respect wi.th the material to be used in the control rod fuel element except in enrichment, shall be used in the sample fuel plates. The sample fuel plates shall be subjected to the maximum number of exactly duplicated hightemperature treatments which will be encountered in the proposed procedure for fabrication of completed fuel elements. Approval of qualification must be obtained prior to inception of the manufacture of enriched fuel plates unless otherwise specifically authorized by the Contracting Agency or its authorized representative. Approval by the Contracting Agency or its authorized representative of the procedure as used in establishing qualification or of any modification thereof will not relieve the manufacturer of any responsibility for any phase of the fabrication of the control rod fuel elements or for conformity to specification requirements.

\section{(b) Tests}

(1) Visual Inspection - The six sample fuel plates shall be inspected for over-all width, length, and thickness dimensions and shall be inspected for pitting, surface condition, and finish. The six sample fuel plates shall meet all dimensional requirements and shall not exhibit any oxide indentations or pits over 0.001 in. deep, scratches over 0.001 in. deep, blisters, scale, and dents, or discrete color changes over the core area.

(2) Radiographic Examination - The six sample fuel plates shall then be radiographed to delineate the fuel-bearing core area and to reveal any fuel segregation and voids or other internal defects. The radiographs shall be made using proper techniques with a fine-grained film such as Eastman "M," exposed and processed to yield a gamma density of $1.0-1.25$ over the core area. 
The radiographs shall be used as the basis of measuring core length, core width, and inactive edges and ends.

The samples shall meet all dimensional requirements and shall exhibit no evidence of fuel segregation, voids, or other internal defects.

(3) Surface Contamination - The six sample fuel plates shall be subjected to a smear test on both sides of the fuel plates. Alpha counting of the absorbing material shall exhibit no evidence of contamination by fissionable material.

(4) Clad Sensitization and Intergranuilar A.ttack - Some increase in carbon content of the clad material must be expected due to diffusion of carbon from the core material during the various high-temperature treatments to which the fuel plates are subjected. Experience has shown that a relatively small increase in carbon content of the clad material causes no deleterious effect during reactor operation. However, it is mandatory that no additional carbon from external sources contaminate the cladding.

The degree of external carbon contamination can be evaluated by testing samples from the inactive portion of the composite fuel plate. Two transverse specimens of the full-plate width shall be taken (one at each end) from each of the six sample fuel plates and subjected to the Strauss Test. The samples shall not exhibit any evidence of cracking after bending $180 \mathrm{deg}$ around a 1/8-in.-dia mandrel or evidence of serious intergranular attack when examined metallographically at I.00X in the as-polished condition.

(5) Homogeneity - If the six sample fuel plates exhibit satisfactory homogeneity, as evidenced by examination of the radiographs, two of the six shall be further examined. Five miniature samples of full-plate thickness, approximately one-inch square, shall be extracted from each of the two fuel plates on a diagonal between the fuel core corners and approximately equally spaced. The end samples should be taken at a minimum of two inches from the core-frame interface. These samples shall be chemically analyzed for total uranium and boron contents, and the results expressed on a weight per cent basis. For each of the two plates, variation from location to location shall not exceed $2 \%$ of the uranium content and $20 \%$ of the boron content.

(6) Bond Integrity - Five transverse samples, equally spaced along the plate length, and three longitudinal samples from each end, equally spaced across the width, shall be removed from two of the six sample fuel plates. 
After proper preparation and electrolytic etching with 5\% chromic acid reagent, the samples shall show no evidence of lack of bond at the clad-frame interface or at the clad-core interface upon metallographic examination at 100 diameters.

(7) Clad-Core-Clad Thickness - The ten transverse samples used in (6) shall be metallographically measured to determine clad-core-clad thickness. As measured by filar micrometer, the thickness at all points, in the samples, shall show compliance with specified thicknesses.

(8) End Conditions - The twelve longitudinal samples used in (6) shall be examined metallographically. These samples shall show no evidence of the presence of $\mathrm{UO}_{2}$ and/or $\mathrm{Eu}_{2} \mathrm{O}_{3}$ in the inactive portions as dimensionally specified or the presence of voids at the core-frame interface.

(9) Fuel Fragmentation and Stringering - One longitudinal sample at least one-half inch long shall be taken from the core of each of four remaining sample fuel plates. When examined metallographically, none of these samples shall exhibit fragmentation and stringering of $\mathrm{UO}_{2}$ and $\mathrm{Eu}_{2} \mathrm{O}_{3}$ greater than that illustrated in Figs. 7 and 8.

(c) Conformance of Fabrication Procedure - The exact procedure used in fabricating the sample fuel. plates and which is proposed to be used in fabricating the active fuel plates shall be furnished to the Contracting Agency or its authorized representative at the conclusion of fabrication of qualification plates and at least one week in advance of the request for approval of qualification. Unless otherwise specifically authorized in writing by the Contracting Agency or its authorized representative, the procedure used in fabricating the sample fuel plates shall be strictly adhered to in fabricating the fuel plates and the stationary fuel elements.

4. Qualification of Component Brazing - Examination of the brazed joints of a full-size fuel element consisting of composite plates containing depleted or normal $\mathrm{UO}_{2}$ must demonstrate ability to braze efficiently and within the specifications shown on Alco Drawing (D9-13-1011). After sectioning the 16-plate fuel element longitudinally into four 4-plate sections, the following examination shall be made. 


\section{UNCLASSIFIED \\ $\because-18927$}

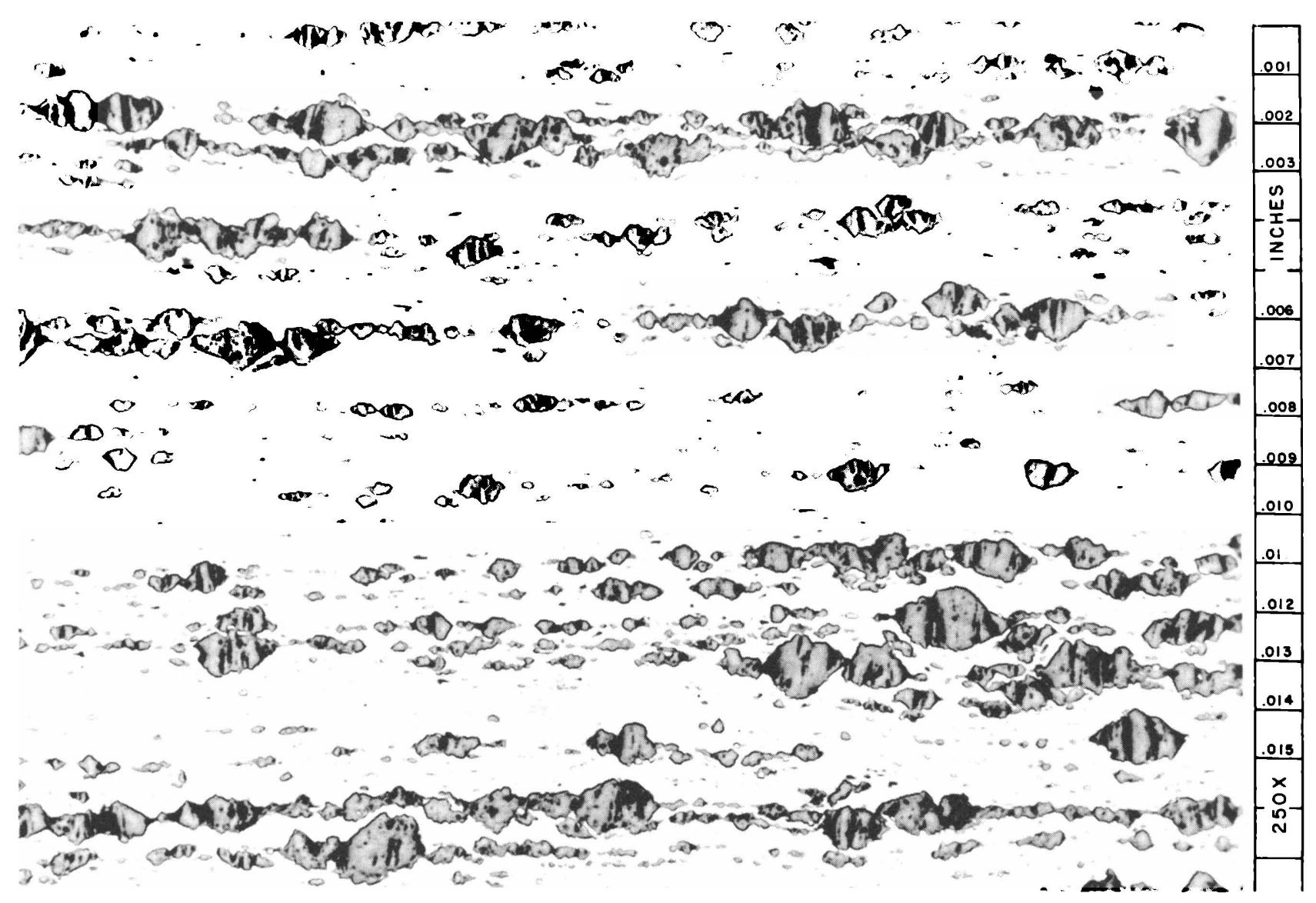

Fig. 7. Typical Longitudinal Section of Finished Core II Fuel Plate Showing Distribution of 25 wt $\% \mathrm{UO}_{2}$ in Stainless Steel. 


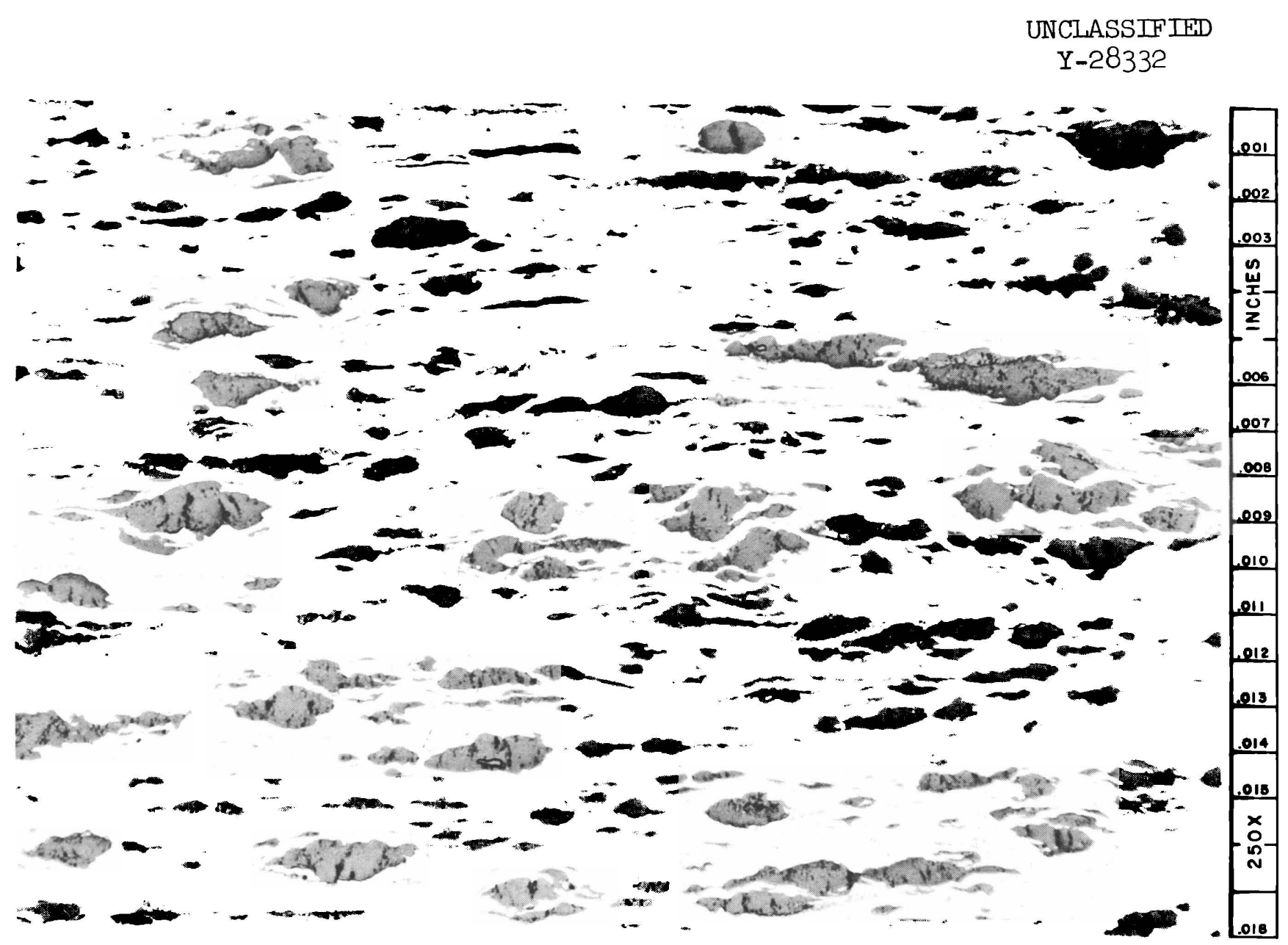

Fig. 8. Typical Longitudinal Section of Flux Suppressor End of the Core II Control Rod Fuel Plate Showing Distribution of 28 wt of $\mathrm{Eu}_{2} \mathrm{O}_{3}$ in
Stainless Steel. 
(a) Visual Inspections for Joint Continuity Along the Plate Iength: The following fillets shall be inspected:

$\begin{array}{ll}\text { Top Fillets } & \text { Bottom Fillets } \\ \text { Plate No. } 1 & \text { Plate No. } 4 \\ \text { Plate No. } 5 & \text { Plate No. } 8 \\ \text { Plate No. } 9 & \text { Plate No. } 12 \\ \text { Plate No. } 13 & \text { Plate No. } 16\end{array}$

Any discontinuity (lack of brazing alloy between the fuel plate and top or bottom land of the side plate groove) along the length greater than two inches shall be cause for rejection.

(b) Microscopic Examination of the Brazed Fillet - Twenty-four joints shall be examined. Specimens shall be obtained from the fuel element sections containing plates No. I to No. 4. Transverse cuts shall be made at distances of $3 \mathrm{in.,} 12 \mathrm{in.,}$ and $20 \mathrm{in.} \mathrm{from} \mathrm{the} \mathrm{end} \mathrm{of} \mathrm{the} \mathrm{fuel} \mathrm{element} \mathrm{containing}$ the flux suppressor. The joints shall be examined to determine the length of brazing alloy overlaying the fuel plate as measured from the inner edge of the side plate. Any overlay in excess of $0.063 \mathrm{in}$. is cause for rejection. It is desirable that a transverse cross section of the brazed joint be similar to that shown in Fig. 9.

5. Control of Boron Losses - Boron losses occur during hydrogen sintering of the fuel cores and in subsequent fuel plate processing. Since this loss is a function of variables in the material and procedures used, it is important that the manufacturer determine the average boron content in the completely finished fuel composite. This average value shall be a result of ten independent determinations; i.e., the complete dissolution and analysis of ten fuel plates prepared from fuel cores which were loaded with the specified amounts of $\mathrm{UO}_{2}$ and boron. Each of these fuel plates is to be fabricated and heat treated under the exact manufacturing procedures which will be followed in the production of enriched plates. The laboratory selected to conduct boron analyses must have demonstrated its ability to analyze boron in stainless steel within an accuracy of $\pm 5 \%$ in the range of $0.04-0.1$ wt $\%$ boron, and must be approved by the Contracting Agency or its authorized representative. Any changes in boron requirements resulting from this qualification must be approved by the Contracting Agency or its authorized representative. 
$-26-$

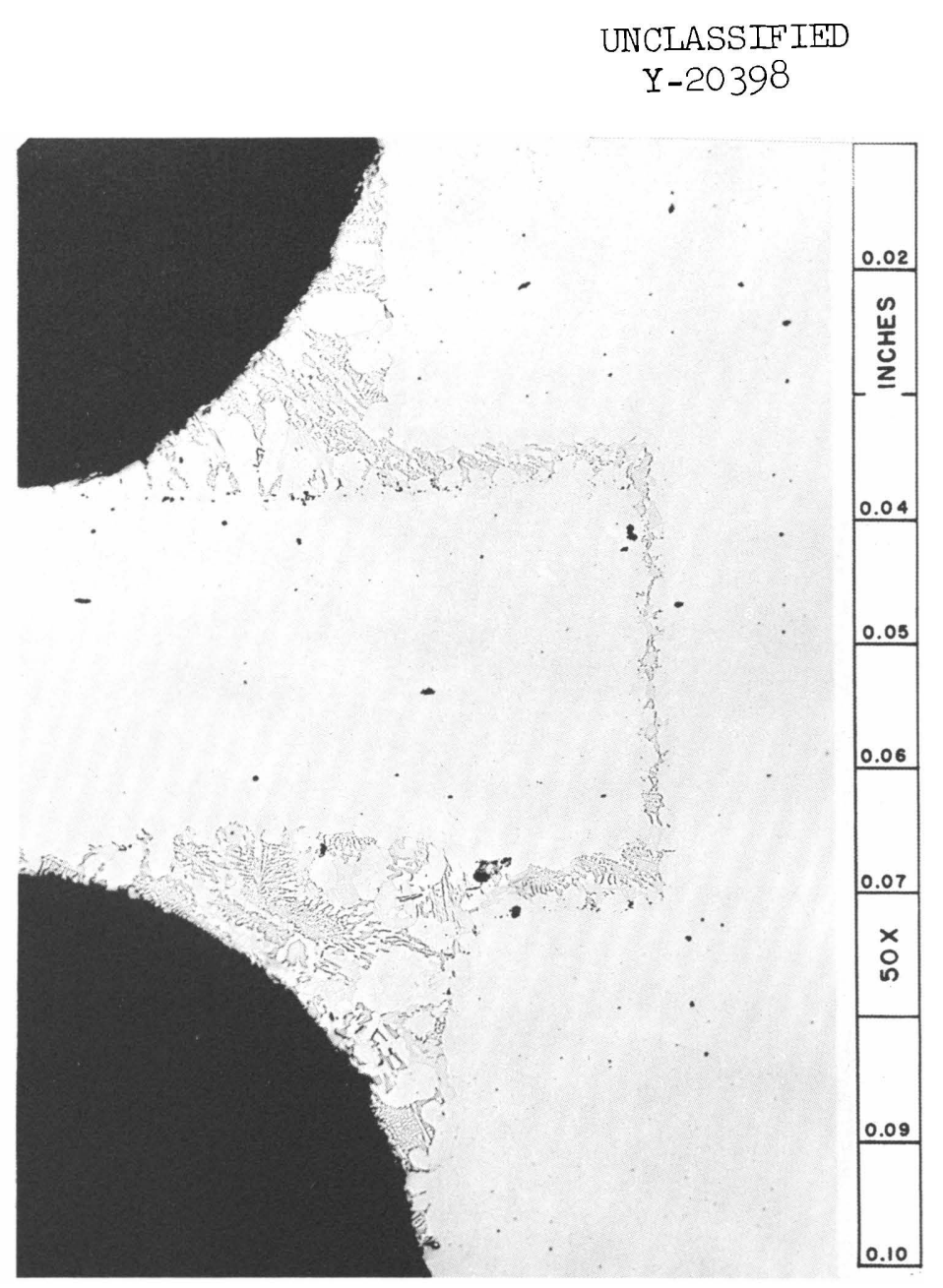

Fig. 9. Transverse Section of a Stainless Steel Fuel Element Joint Brazed with Coast Metals N.P. 
6. Liaison and Inspection - Free entry shall be given to the Contracting Agency or its authorized representative to all areas of the manufacturer's plant at any time during the term of the contract for fabricating the control rod fuel elements. The manufacturer shall provide all reasonable assistance, facilities, and co-operation to the Contracting Agency or its authorized representative for determination of compliance with specification or procedure requirements or for inspection purposes as may be required.

The Contracting Agency or its authorized representative will maintain liaison with the manufacturer for the duration of the contract for the following purposes: (a) to provide necessary and reasonable technical assistance as may be required, and (b) to inspect for compliance to the specifications and the approved fabrication procedure. The Contracting Agency or its authorized representative shall have the right at any time during the term of the contract to reject any and all pieces, parts, components, and products which do not meet the requirements of the specifications, or which have not been fabricated in accordance with the approved procedure, or which fail in any way to meet any of the requirements set forth in this document. Such inspection shall not relieve the manufacturer of any responsibility in any phase of fuel element fabrication or furnishing thereof.

7. Certification - Certification shall be furnished to the Contracting Agency or its authorized representative that all materials used in the fabrication and furnishing of the fuel elements are in accordance with the requirements of these specifications.

\section{MANUFACTURTING PROCEDURES}

\section{A. Introduction}

The flow of material in processing control rod fuel elements for Core II is illustrated in the simplified diagram shown in Fig. 10. The essential operations required in processing are: (I) weighing and blending of the component powders for each individual fuel core, (2) pressing, sintering, and coining into a fuel compact of the required dimensions, (3) weighing and blending of the component powders for the flux suppressor material, (4) pressing, sintering, and coining into a compact, (5) sectioning from the coined compact the dimensionally specified flux suppressor, (6) encapsulation of fuel core and flux suppressor within a welded billet, (7) cladding by roll bonding, 


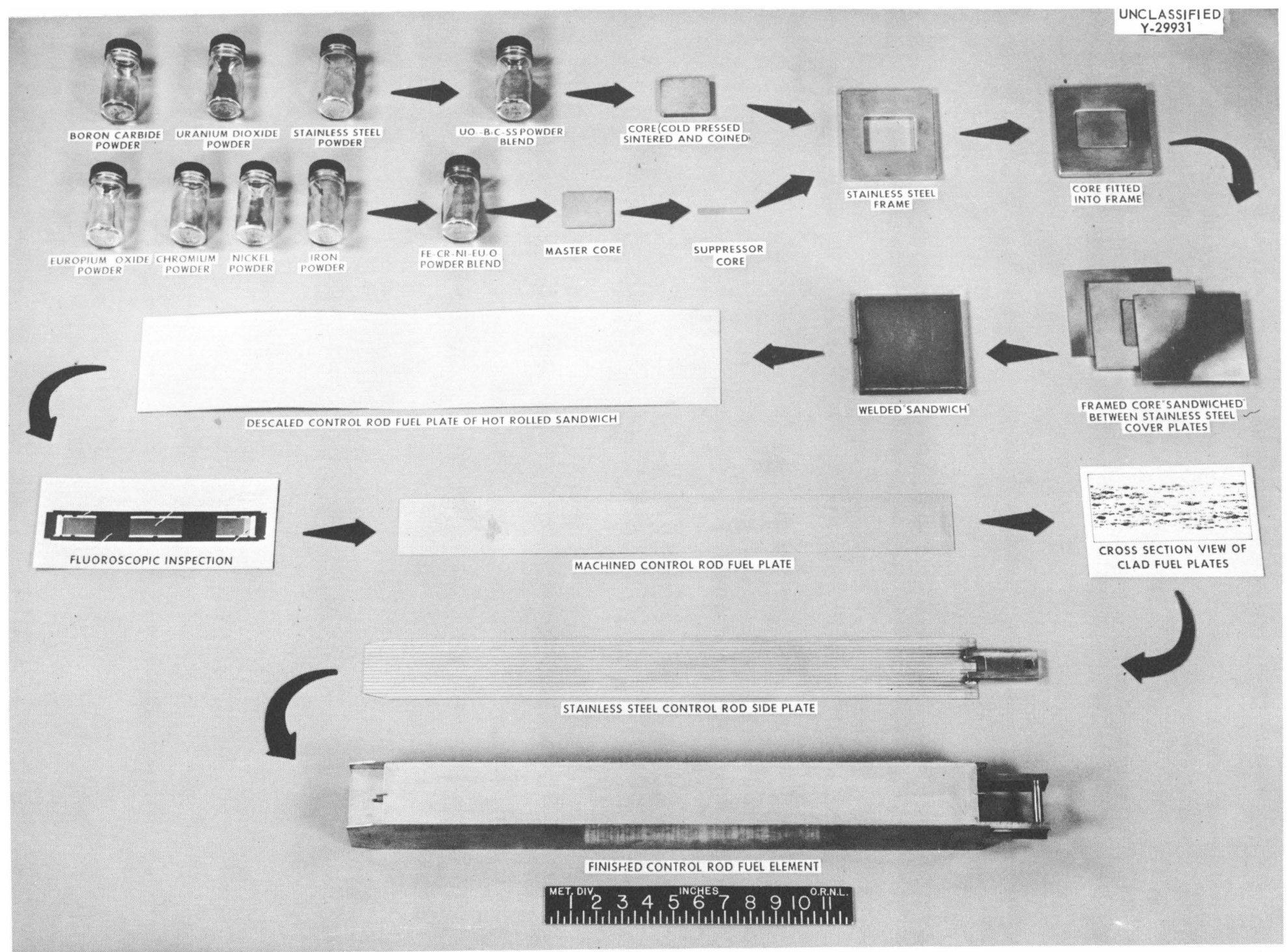

Fig. 10. Fabrication Procedure for Manufacturing Control Rod Fuel Elements for Core II. 
(8) descaling of the hot-rolled plate, (9) cold rolling to specified thickness, (10) marking and shearing of the plate, (11) machining to finished length and width dimensions, (12) flatten annealing, (13) assembling and brazing, (14) inspection of the brazed fuel element, and (15) packaging for shipment. These general procedures and the more specific details, which will be described later, represent methods developed and adopted by the Oak Ridge National Laboratory for manufacturing stainless steel-uranium dioxide control rod fuel elements for service in Core II. Because of differences in equipment, it is recognized that other fabricators may be required to modify some of the detailed procedures to arrive at an equivalent finished product.

B. Records

During processing, positive identification of each fuel plate must be maintained along with appropriate data in order to ensure: (1) proper process control, (2) quality control, (3) metallurgical history, (4) removal of rejected material, and (5) fuel, burnable poison, and $\mathrm{Hu}_{2} \mathrm{O}_{3}$ accountability. Records of the following items are maintained: ( 1 ) identification of each lot of $\mathrm{UO}_{2}$ received from the $\mathrm{UO}_{2}$ processing plant, (2) master log containing materials make-up data and the detailed processing schedule employed in the manufacturing of each plate, and (3) fuel element inspection record of critical dimensions. To serve as a guide, the forms of the pertinent records are included in Appendix C.

\section{Fuel Core Manufacture}

1. Calculations - The fuel, burnable poison, and matrix powders are specified in terms of grams of uranium-235, boron-10, and stainless steel. Since the uranium and boron is incorporated as $\mathrm{UO}_{2}$ and $\mathrm{B}_{4} \mathrm{C}$, respectively, it is necessary to determine by calculation the quantities of these materials for each core. Each batch of as-recelved $\mathrm{UO}_{2}$ is assayed for total uranium content as well as for isotopic concentration of uranium-235. Likewise, the $\mathrm{B}_{4} \mathrm{C}$ powder is analyzed for isotopic concentration of $\mathrm{B}^{10}$ as well as for total boron content. The isotopic concentration of $\mathrm{B}^{10}$ in natural boron is not fixed or constant as generally thought, but varies between 17 and 19 wt \%.

Sample calculations illustrating the methad utilized in determining the quantities of $\mathrm{UO}_{2}$ and $\mathrm{B}_{4} \mathrm{C}$ required in the make-up of each fuel plate are listed. 
(a) Data required:

$\begin{array}{ll}\text { wt } \% \mathrm{U}^{235} \text { in } \mathrm{U} & 93.17 \\ \text { wt } \% \mathrm{U} \text { in } \mathrm{UO}_{2} & 87.31 \\ \text { wt } \% \mathrm{~B}^{10} \text { in } \mathrm{B}_{\mathrm{N}} & 18.09 \\ \text { wt } \% \mathrm{~B} \text { in } \mathrm{B}_{4} \mathrm{C} & 75.9 \\ \mathrm{~g} \mathrm{U}^{235} \text { per plate } & 25.07 \\ \mathrm{~g} \text { of } \mathrm{B}^{10} \text { per plate } & 0.02264\end{array}$

(b) Determination of grams of $\mathrm{UO}_{2}$ per plate:

Grams of $\mathrm{UO}_{2}=\frac{25.07\left(\mathrm{~g} \mathrm{U}^{235}\right)}{\frac{87.31\left(\mathrm{wt} \% \mathrm{U} \text { in } \mathrm{UO}_{2}\right)}{100} \times \frac{93.17\left(\mathrm{wt} \% \mathrm{U}^{235} \text { in } \mathrm{U}\right)}{100}}=30.82$

(c) Determination of grams of $\mathrm{B}_{4} \mathrm{C}$ per plate:

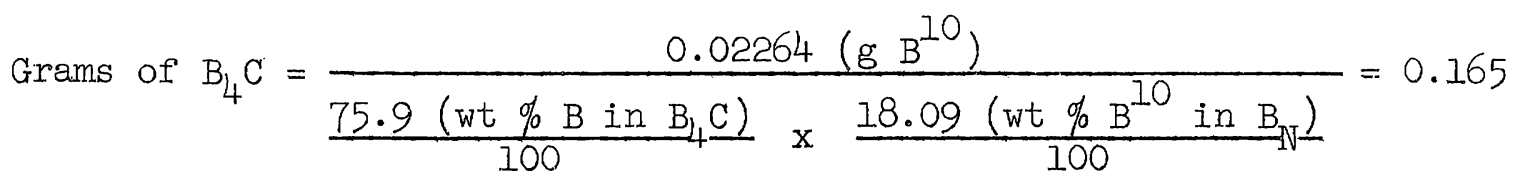

As might be expected, the densification factor ( $\left.\frac{\text { measured volume }}{\text { theoretical volume }}\right)$ of the fabricated core material has a significant effect on the charge of stainless steel powder required to meet dimensional specifications in the finished composite plate. This factor has been determined to be 0.93 for the specific equipment and processing methods utilized at the Oak Ridge National Laboratory. However, any major change in equipment or procedure will probably shift this factor; and under such circumstances, it will be necessary to alter the grams of stainless steel required in the material charge for the fuel compact. Any proposed change in the stainless steel content of the core for this or other reasons necessitates a corresponding change in the boron-10 requirements.

2. Weighing of Component Powders - The component powders for each individual core are separately weighed and combined in a single blending jar. With the exception of possible losses during subsequent pressing and sintering operations, this method offers accurate accounting of the critical ingredients, $\mathrm{U}^{235}$ and $\mathrm{B}^{10}$, in each fuel core within the limits of the accuracy of the weighing balance. Boron carbide is the first material loaded into the blending 
jar, followed by stainless steel. Uranium dioxide is added liast. The sequence permits the boron carbide and stainless steel powders to be handled in a conventional manner, thus eliminating the inconvenience of weighing these materials within a dry box as is required during handling of the radioactive $\mathrm{UO}_{2}$. During processing, ten jars are handled as a unit operation and the individual weighing procedures are as follows:

(a) Weighing of the Boron Carbide - The burnable poison in the form of $\mathrm{B}_{4} \mathrm{C}$ is weighed to an accuracy of at least $0.3 \%$ on a Gram-matic balance of 200-g capacity. A 4-in. x 4-in. sheet of glazed paper with glazed side up and of known weight is placed on the pan. The burnable poison is added to the paper and accurately weighed. The material is then poured into a clean, widemouth, glass jar of $4-0 z$ capacity. A camel's hair brush is used to brush any remaining particles of $\mathrm{B}_{4} \mathrm{C}$ into the jar, which is then capped.

(b) Weighing of the Stainless Steel Powder - The stainless steel is weighed in exactly the same manner as the burnable poison, with the exception that a triple-beam balance is used. It is then transferred to the blending jar containing the previously weighed burnable poison. The jar is immediately recapped.

(c) Weighing of $\mathrm{UO}_{2}$ - Weighing of the fissile compound is accomplished within a protective box in which the atmosphere is under a slight negative pressure. The equipment is illustrated in Fig. 11. Gloves are attached to the ports shown and the hood connected to an exhaust system. The side port permits access to the interior, and the dry box is designed to accommodate a batch of ten jars or more. The box is equipped with a triple-beam balance of $100-g$ capacity. The required quantity of $\mathrm{UO}_{2}$ for one fuel core is weighed directly on the scale pan of the triple-beam balance using a scoopula for fine adjustment of fuel quantity. The specified weight of fuel is added to the jar containing the boron carbide and stainless steel powders. The jar is then capped and placed on the right or exit side.

These operations are repeated until the lot of ten jars has been processed. The jars are cleaned by wiping the outside with tissue paper to prevent the spread of contamination and are then withdrawn through the right side port. After removal from the dry box, the joint between the cap and the jar is sealed with masking tape. The $\mathrm{UO}_{2}$-lot number is then marked on each jar, and the jars 


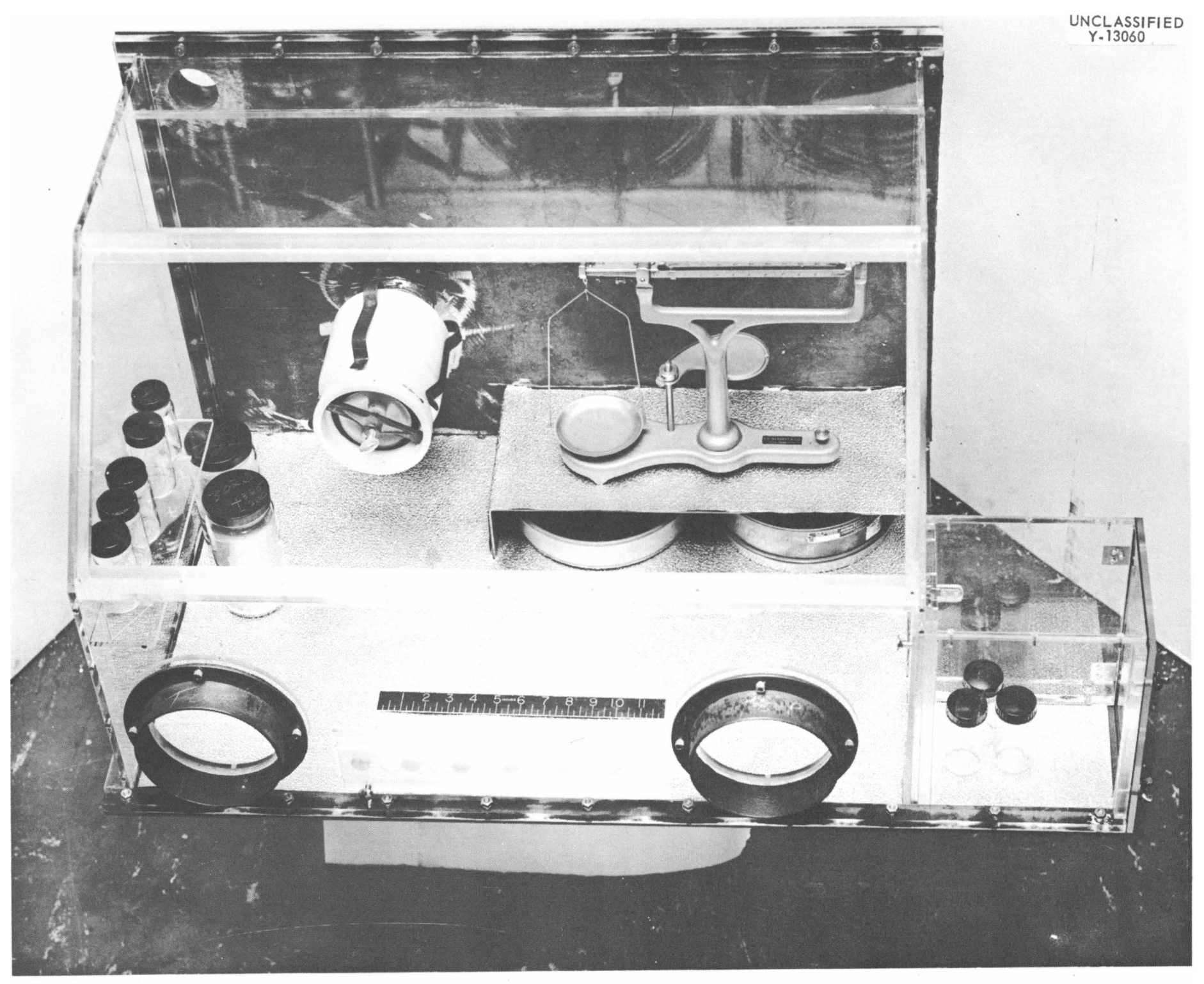

Fig. 1l. Dry Box containing Equipment for Weighing Enriched UO ${ }_{2}$ Powder. 
are placed in a transfer box for removal to the blending area. When the supply of $\mathrm{UO}_{2}$ remaining in the dry box is insufficient to prepare ten cores, it is set aside for later use in smaller lots.

3. Blending - To obtain a homogeneous mixture of fuel, poison, and matrix material, the powders are blended in a modified U. S. Stoneware Company Double Cone Blender, Model 733. The blender cones are replaced by a pair of two-quart steel cans mounted on the motor shaft at an angle of 30 deg with the vertical. Ten jars, each containing the specified quantities of $\mathrm{UO}_{2}, \mathrm{~B}_{4} \mathrm{C}$, and stainless steel, are loaded into each can with sufficient padding to prevent breakage of the jars during the blending operation. The cans are rotated at this oblique angle for two hours, after which the jars are removed and uncapped. Approximately $0.1 \mathrm{~g}$ (two squirts with a hand atomizer) of C. P. dodecyl or lauryl alcohol. is added to each jar. The jars are recapped, resealed with masking tape, and blended for another hour.

4. Cold Pressing of the Core Ingredients - The initial operation in shaping the blended powders into a compact suitable for assembling into a fuel plate billet is to cold press into a "green" compact. A 150-ton Baldwin press with a Vickers hydraulic control system to permit variable movement of the ram is employed for compaction. The press has two rams - an upper fixed ram extending down from the top crosspiece and a lower ram which is movable. On the top of the lower movable ram is fastened a large platen, onto which is placed the dry box containing the die set. The die set, illustrated in Fig. 12, consists of a female die, which is a spring mounted to the movable ram, and a die punch and filler block. The bottom of the die punch contacts the movable ram, while the top of the filler block, inserted into the die cavity after the powder, contacts the stationary ram.

Since pressing of the blended powders again involves handling radioactive $\mathrm{UO}_{2}$, hooding under slightly negative pressure is necessary to prevent human intake of airborne activity by ingestion or inhalation. Figure 13 illustrates the dry box containing the pressing dies. The top of the box, not shown, is designed with a hole in the middle and equipped with a rubber gasket which moves along the stationary ram and prevents leakage.

ren blending jars containing the blended powders, a camel's hair brush, a scoopul.a, and a bottle of 10 wt $\%$ C. P. stearic acid-90 wt \% carbon tetrachioride die lubricant are inserted into the pressing box. By working 


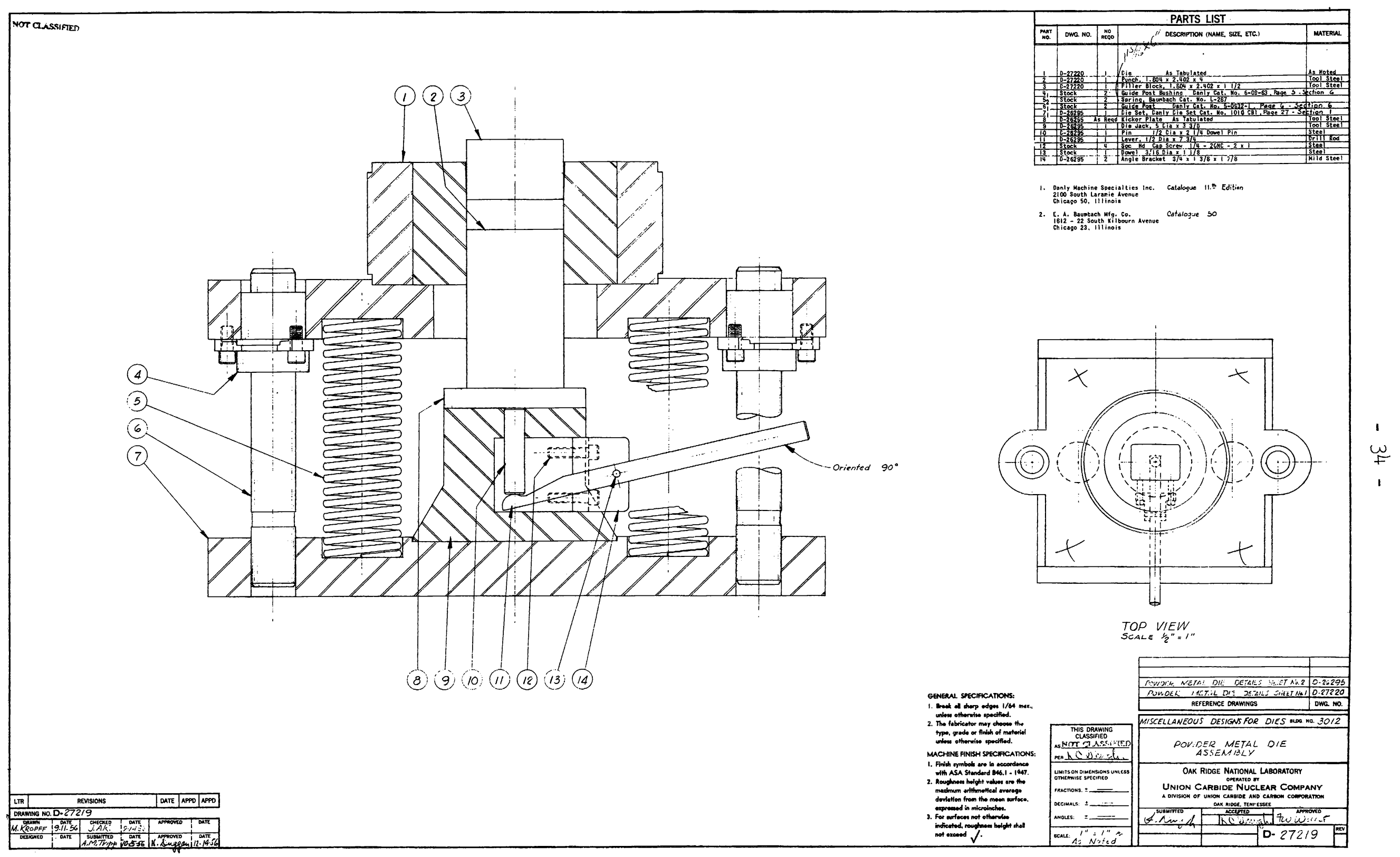

Fig. 12. Powder Metallurgy Die Assembly. 
UNCLASSIFIED

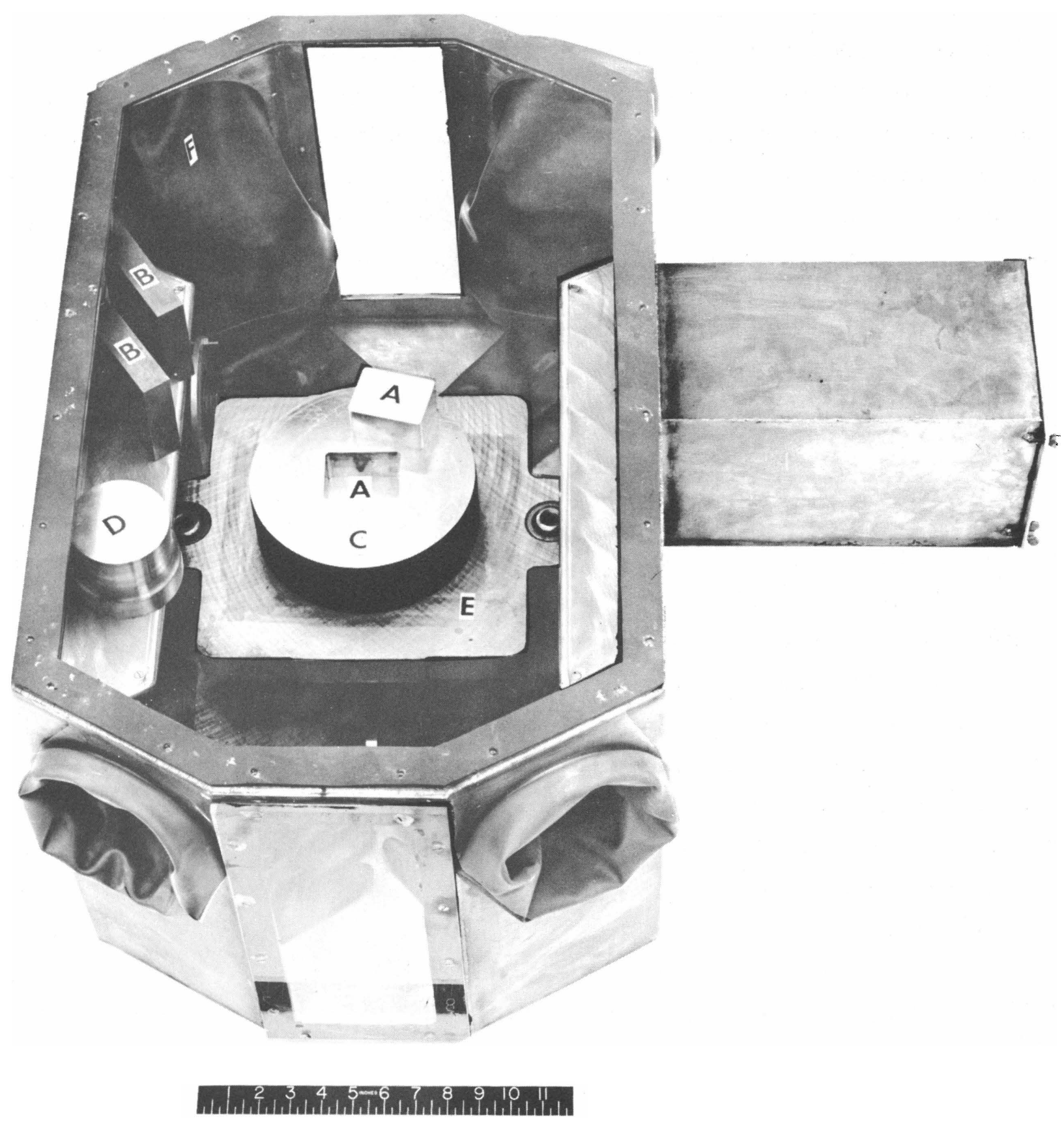

Fig. 13. Dry Box Arrangement Utilized During Pressing of Powder Blends Containing Enriched $\mathrm{UO}_{2}$ Powder. 
through the glove ports, stripes of lubricant for each die charge are applied with the 1/4-in. camel's hair brush around the top of the die cavity and the lower sides of the filler block. The die face is occasionally lubricated if it becomes roughened to the extent that the pressed core adheres to it. The powder is poured from a blending jar into the die cavity. The jar is brushed thoroughly to ensure complete transfer of all powders. Once the core material has been loaded into the die, it is leveled with a scoopula. The filler block is inserted into the die and the lower ram then raised until the die insert contacts the stationary ram. The blended powders are pressed at 33 tsi pressure (approximately 142-ton total pressure) for $15 \mathrm{sec}$ to a thickness of approximately 0.310 in. The filler block is removed and the green compact ejected by elevating the die punch with the hand lever. After ten charges have been pressed, the compacts are loaded into a stainless steel transfer box which is closed and removed from the dry box. A record of the $\mathrm{UO}_{2}$ lot number is maintained.

5. Sintering of Green Compacts - The sintering operation is carried out in a General Electric 20-kw laboratory molybdenum-wound furnace equipped with a 3-in.-dia Inconel muffle. Thirty-six inches of the muffle extends beyond the furnace and acts as a cooling chamber. The sintering temperature is $2150^{\circ} \mathrm{F}$. Uniformity of temperature along the length of compacts is held to $\pm 25^{\circ} \mathrm{F}$. Dry hydrogen with a dew point of $-60^{\circ} \mathrm{F}$, as measured by an Alnor Dewpointer at the gas inlet, is used as atmosphere in the muffle. Hydrogen flow required for this size muffle is approximately $20 \mathrm{cfh}$ under steady-state conditions, although the gas flow is increased when the muffle door is opened during insertion or removal of compacts. The sintered compacts do not exhibit any evidence of oxide formation.

The green compacts are placed in a sintering boat constructed of type 316 stainless steel formed into the shape of an "H." The crossbar between the two vertical sides is $2-1 / 2$ in. wide $x 14 \mathrm{in.} \mathrm{long,} \mathrm{and} \mathrm{is} \mathrm{located} \mathrm{approximately}$ $1 / 2 \mathrm{in}$. above the bottom of the legs. A piece of heavy-gauge No. 12-mesh screen of type 316 stainless steel is placed upon this crossbar. Five compacts are positioned end to end on this screen, and a second screen is laid over the top of the compacts to allow stacking of a second layer of five cores. The screen permits access of hydrogen gas to all surfaces of the compacts.

The sintering boat containing the ten compacts is inserted in the furnace at $2150^{\circ} \mathrm{F}$ and the system is purged with hydrogen. The compacts remain in the 
hot zone for $1-1 / 4 \mathrm{hr}$. The boat is moved to the cooling chamber, allowed to $\operatorname{cool}$ to $450^{\circ} \mathrm{F}$ under the hydrogen atmosphere, removed from the muffle, and air cooled to room temperature. The cores are placed in a covered stainless steel transfer box and moved to the press for coining. A record of $\mathrm{UO}_{2}$-lot number is maintained.

6. Coining of Sintered Compacts - The shrinkage encountered during sintering makes it convenient for reinsertion of the compact into the same die set for coining. After careful loading, the sintered compacts are pressed under a pressure of 33 tsi for $15 \mathrm{sec}$ to obtain destred dimensions and improved densification. The coined compacts are ejected from the die and removed from the ary box.

7. Inspection - Since it is necessary to predict the $U^{235}$ content of the subsequently manufactured fuel element within one gram, it is desirable to weigh the compacts prior to the completion of fuel-core processing. Because of uncertain losses due to the reduction of metal oxides by hydrogen during sintering, it is impractical to consider weight losses of the compact after this final operation. The handling losses are, therefore, determined prior to loading the compacts into the furnace for sintering. As a first order of approximation, all ten cores are weighed together and if the total permissible deviation for a single core is exceeded by the entire batch, each core must be individually weighed for acceptance or rejection. A. weight deviation of more than $0.25 \mathrm{~g}$ from the charged weight for each core is the basis for rejection. Compacts with obvious chips and flaws, of course, are weighed individually and not included in the batch weighing. After sintering, the compacts are examined to determine whether any obvious chipping or spallating has occurred during the handling required for sintering.

Each core is measured with a micrometer after coining to determine whether or not the compact meets the dimensional requirement of $0.276 \pm 0.002$ in. in thickness. Length and width dimensions are established by die design.

8. Core Storage - Each acceptable lot of ten cores is wrapped in paper. These packages are marked with a $\mathrm{UO}_{2}$-lot number and are placed in an ordinary desiccator if storage time is to be less than $48 \mathrm{hr}$. If a storage time of more than $48 \mathrm{hr}$ is required, a vacuum desiccator is used. Criticality limits the number of cores which can be stored in a single desiccator at any one time to a maximum of eighty. 


\section{Flux Suppressor Core}

1. Preparation of $\mathrm{Eu}_{2} \mathrm{O}_{3}$ - The europium oxide obtained from the various vendors is normally of low density and extremely fine particle size. Such material is prone to agglomeration and stringering when dispersed in stainless steel and fabricated into composite plate. Therefore, the material is densified by firing at a high temperature. The various sequences of this operation are: (a) inspection of the received oxide, (b) pressing, (c) firing, and (d) crushing.

(a) Inspaction of received $\mathrm{Eu}_{2} \mathrm{O}_{3}$ - It is recommended for optimum conditioning properties that the oxide be obtained in a "dead burned" or "fluffy" form with no additional intermediate temperature treatments, Each batch of received oxide is analyzed for total europium oxide and thoria content. The material should contain a minimum of $98 \% \mathrm{Eu}_{2} \mathrm{O}_{3}{ }^{\circ}$ The thoria content is determined by alpha-activity measurements. Material with alpha counts in excess of background is considered contaminated and is rejected.

(b) Pressing - Prior to high firing, the received powder is pressed into small cylindrical pellets to facilitate subsequent handing. Approximately $35 \mathrm{~g}$ of the material, measured in a $10-c c$ stainless steel beaker, is poured into the cavity of a double-acting, 0.8-in.-dia die, leveled and pressed into pellet form at a pressure of about 4 ton/in. ${ }^{2}$ The resulting 0.8 -in.-dia $\times 0.8$-in.-long pellets are sufficiently strong to handle without spallation.

(c) Firing - Approximately ten pellets weighing between $300-350 \mathrm{~g}$ comprise the firing batch size. The individual pellets are placed in a tungsten crucible approximately $2 \times 2 \times 7$ in. in size which is constructed by edge welding 1/8-in. sheet stock. The loaded tungsten crucible is inserted in a graphite crucible mounted in the center of an induction coil. Amorphous thermatomic carbon is packed between the graphite crucible and outer quartz furnace tube to serve as an insulator. A graphite cover with attached chimney is placed over the graphite crucible to prevent the thermatomic carbon from contaminating the europium oxide pelilets. The remainder of the quartz tube is then filled with thermatomic carbon and finally capped with a gastight, brass end plug. A hydrogen gas stem is attached to the lid to permit passage of hydrogen to the pellets during the firing operation. The exit hydrogen gas escapes through the chimney attached to the bottom of the quartz tube. The pellet firing is carried out at $3090^{\circ} \mathrm{F}$ for a period of three hours. The power is varied to control the 
temperature rise at a rate of approximately $570^{\circ} \mathrm{F}$ per hour. Temperature measurements are made on the surface of the pellets by sighting an optical pyrometer through the off-gassing stem. Upon completion of the firing, the power is shut off and the furnace air cooled to approximately $300^{\circ} \mathrm{F}$ at which time it is disassembled and the fired pellets removed.

(d) Crushing - The fired pellets are crushed to -325 mesh size in a mortar and pestle using a series of intermediate screening operations. Initially, one-third of the fired batch size is placed in a mortar and crushed using only impact-type strokes. Circular grinding motions were found to produce considerable fines in the crushed oxide. After the initial comminution, the product is placed on a series of vibrating screens which separate the $+100,-100,+270,-270,+325$, and -325 mesh fractions. Each fraction is then recrushed until the entire material passes through a 325 mesh screen. The various sizing separations are necessary to minimize fines. Since the percentage of europium generally changes during high firing, a representative sample of each batch of high-fired oxide is analyzed by wet chemistry for total europium.

2. Manufacture of the Dispersion of $\mathrm{Eu}_{2} \mathrm{O}_{3}$ in Stainless Steel - The flux-suppressor portion of the core is a section obtained from a sintered and coined compact containing approximately 28 wt $\% \mathrm{Eu}_{2} \mathrm{O}_{3}$ homogeneously dispersed in austenitic stainless steel.

(a) Calculations - The flux suppressor and matrix powders are specified in terms of europium and stainless steel. Since the europium is in the form of $\mathrm{Eu}_{2} \mathrm{O}_{3}$, it is necessary to determine by calculation the quantities of these materials which are to be incorporated in each core. Each batch of $\mathrm{Eu}_{2} \mathrm{O}_{3}$ which is treated is analyzed for europium. It has been found from experience at the Oak Ridge National Laboratory that after high firing the compound is approximately 85 wt $\%$ europium. The stainless steel matrix is obtained by sintering of the elemental iron, nickel, and chromium powders. Sample calculations used in determining the quantities of $\mathrm{Eu}_{2} \mathrm{O}_{3}$, iron, nickel, and chromium powders for the $\mathrm{Eu}_{2} \mathrm{O}_{3}$-stainless steel dispersion are listed in Appendix A. 


$$
-40=
$$

Based on the sample calculation, the following weights of constituents were required for one master compact:

$$
\begin{aligned}
& \mathrm{Eu}_{2} \mathrm{O}_{3}-8.06 \mathrm{~g} \\
& \mathrm{Fe} \text { powder }-14.95 \mathrm{~g} \\
& \mathrm{Ni} \text { powder }-2.31 \mathrm{~g} \\
& \mathrm{Cr} \text { powder }-3.79 \mathrm{~g}
\end{aligned}
$$

(b) Weighing of component powders - The $\mathrm{Eu}_{2} \mathrm{O}_{3}$, nickel, iron, and chromium powders are separately weighed in quantities to provide material for one core, $2.1 \times 1.8 \times 0.068$ in. in size. The 2.1-in. dimension was selected for convenient fit into the frame with no subsequent machining; the 1.8-in. dimension was arbitrary; and the 0.068-in. thickness was established experimentally。 The powders are weighed on an analytical balance to within an accuracy of $\pm 0.3 \%$.

(c) Blending - To obtain a homogeneous mixture of the $\mathrm{Eu}_{2} \mathrm{O}_{3}$ and matrix material, the powders are blended in a modified U. S. Stoneware Company Double Cone Blender, Model 733. The blender cones are replaced by a pair of two-quart steel cans mounted on the motor shaft at an angle of $30 \mathrm{deg}$ with the verticle. Five jars, each containing the specified quantities of $\mathrm{Eu}_{2} \mathrm{O}_{3}$, iron, nickel, and chromium are loaded into each can with sufficient padding to prevent breakage of the jars during the blending operation. The cans are rotated at this obliquie angle for three hours.

(d) The blended powders are cold pressed into a compact using the powder metallurgy die described in Section VI, Item C-4. Since no contaminated material is present, this operation is done in a conventional manner. After the powder is carefully leveled in the die cavity, a pressure of 10 tsi is applied to the system for a period of $15 \mathrm{sec}$. Care must be exercised in removing the thin, fragile, green wafers to prevent corner breakage. To avoid unnecessary handling, the pressed compacts are removed from the die and placed directiy on the sintering boat.

(e) Sintering of green compacts - The equipment and procedure utilized is similar to that described in Section VI, Item C-5, for the fuel. compacts. However, the time-temperature sintering condition is $1 \mathrm{hr}$ at $2250^{\circ} \mathrm{F}$, and a molybdenum-lined boat is provided instead of the conventional stainless steel boat to prevent possible reaction of the $\mathrm{Eu}_{2} \mathrm{O}_{3}$.

(f $f^{\circ}$ Repressing of sintered compacts - After careful loading into the original dje, the sintered compacts are pressed under a pressure of 33 tsi for $15 \mathrm{sec}$ to improve densification. 
(g) Resintering of repressed compacts - This operation is identical as that described in (e) above.

(h) Coining of sintered compacts - After careful loading into the original die, the sintered compacts are coined at 33 tsi for $15 \mathrm{sec}$. The resultant density is approximately $84 \%$ of theoretical.

(i) Inspection - The compacts are inspected and if chips and flaws are observed, that portion of the compact is rejected. The compact is also rejected if the thickness measurement of 0.068 in. varies more than \pm 0.003 in.

(j) Shearing - The sintered and coined compact is sheared along the 1.8-in. dimension to produce sections which are 2.1 in. long $x 9 / 32$ in. wide. The width dimension is sheared to within $1 / 16$ in. of nominal.

(k) Machining - The section width is ground dry to 0.274 in. \pm 0.001 in., yielding a section 0.068 in. $x 0.274$ in. $x 2.1$ in.

(1) Weighing - The $\mathrm{Eu}_{2} \mathrm{O}_{3}$-stainless steel flux suppressor must be within $5 \%$ of the designed requirement in Section $V I$, Item $D-I(b)$.

E. Billet Assembly

1. Material Preparation - As illustrated in Fig. 14, each fuel plate billet requires two cover plates and one picture frame in addition to fuel and flux suppressor compacts. Cover plates are fabricated from 0.078-in. $\pm 0.005-i n$. stainless steel sheet which is cold rolled to a thickness of $0.067 \mathrm{in} . \pm 0.001$ in. Cover plates are sheared to $4-7 / 16$ in. $x$ in. $\pm 1 / 16$ in. in size. The practice at ORNL was to reduce 9-in. x 36-in. strips of 0.078 -in. sheet to $0.067-i n$. thickness before final shearing.

Picture frames are fabricated from 5/16-in. stainless steel plate which is cold rolled to $0.276 \mathrm{in.} \pm 0.002 \mathrm{in}$. Picture frames are also sheared to 4-7/16 in. $x 4 \mathrm{in.} \pm 1 / 16 \mathrm{in}$. in size. The practice at ORNL was to cross roll 18-in. squares of the 5/16-in. plate to 0.276 -in. thickness before final shearing. A. hole, $1.862-i n . x 2.210-i n$. with $1 / 8$-in. corner radius, is punched in the center of the picture frame to accept both fuel and flux suppressor cores. The blanking die assembly employed for this operation is illustrated in Fig. 15. The 1.862-in. dimension is machined to $1.910 \mathrm{in}$. to allow a snug fit of the suppressor section between the fuel core and the frame. Essentially square corners are required at this end of the frame. 
UNCLASSIFIED

ORNL-LR-DWG 37677

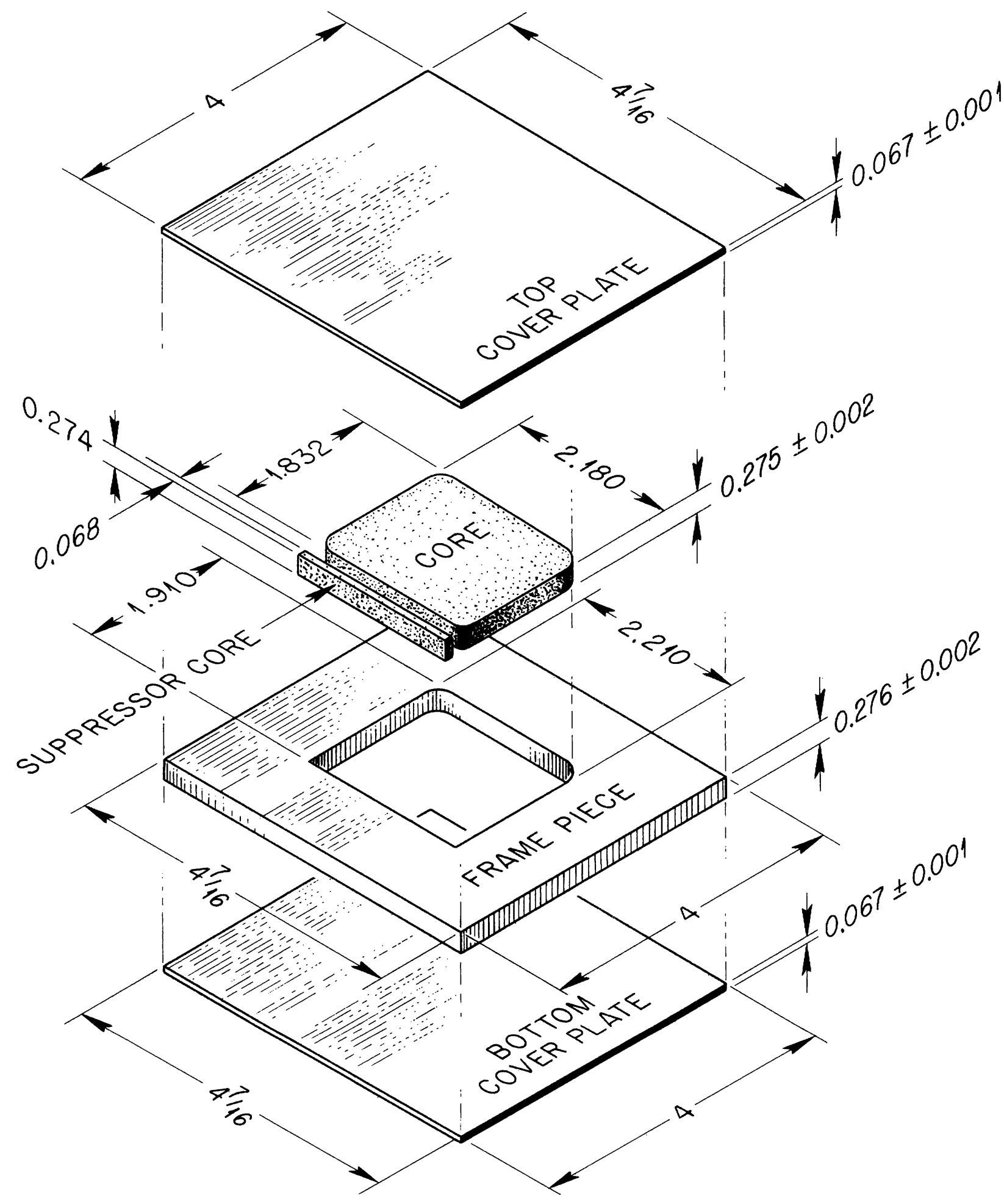

ALL DIMENSIONS IN INCHES

Fig. 14. Components of the Core $\square$ Control Rod Fuel Billet. 


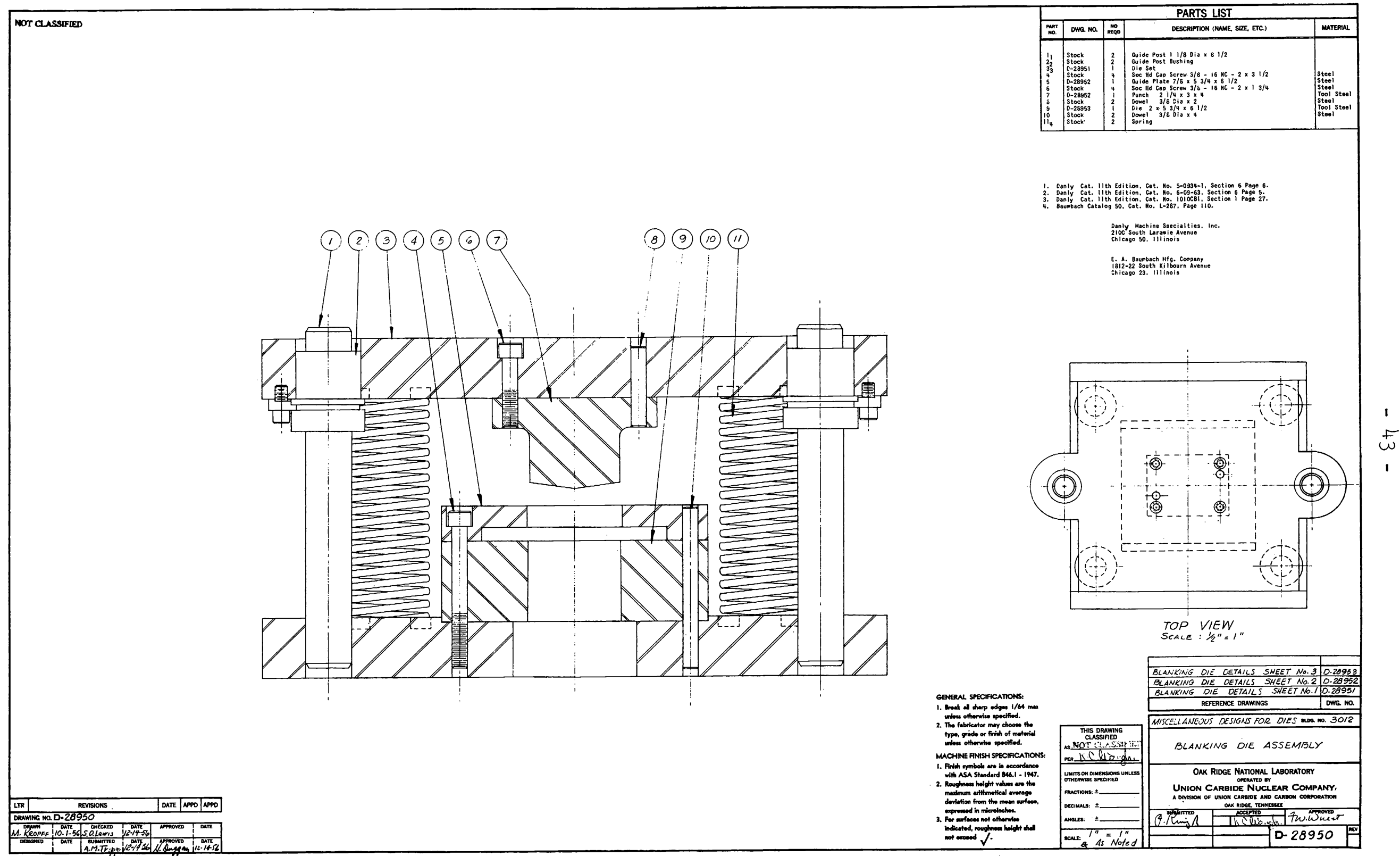

Fig. 15. Blanking Die Assembly. 
2. Assembling and Welding of Billets - To identify the location of the flux suppressor, a small I/4-in.-dia stainless steel rod is welded at the center of the machined edge of the frame which will be trailing during hot rolling. Immediately prior to billet assembly, the stainless steel is degreased and all mating surfaces of the stainless steel are thoroughly cleaned by scratch brushing with a power-driven stainless steel brush. The fuel core is inserted into the cavity followed by the flux suppressor core which fits snugly between the end of the fuel core and the end of the frame which has the attached identification marker. The cover plates are placed on top and bottom to form a sandwich and are immediately resistance spot welded to the picture frame. Four 1/4-in.-dia welds are placed $1 / 2$ in. in from the edge of the billet at the center of each side. A 25-KVA Resistance Welder Corporation Model T-52951. spot-welding machine is used.

The cover plates are also welded to the picture-frame plate by the tungsten inert-gas method. Since the object of the welding is to prevent possible shifting of the billet components during initial hot-rolling operations, high-quality welds are not required. The four corners are left unwelded for a nominal distance of I/4 in. to permit escape of entrapped gases during the initial passes through the bot-rolling mill.

Billets which are not hot rolled immediately are stored in a vacuum desiccator to prevent oxidation. Security, criticality, and accountability regulations dictate careful control during storage. Ordinarily, the billets as well as fabricated plates are stored in a locked safe between processing periods. The shelves of the safe are lined with cadmium. The maximum number of plates that may be stacked in one pile on a shelf is thirty. Minimum separation distance of piles on shelves is four inches.

\section{F. Composite Plate Fabrication}

1. Hot Rolling - The assembled and welded billets are hot rolled to a thickness of 0.040 in. \pm 0.002 in. on a two-high Mesta mill equipped with 20-in.-dia $\times$ 30-in.-wide rolls. The billets are hot rolled in lots of four. However, the lot size is determined by the size of the muffle available for heating the billets. A furnace capable of maintaining $2100^{\circ} \mathrm{F} \pm 25^{\circ} \mathrm{F}$ over a muffle length of at least $32 \mathrm{in.} \mathrm{is} \mathrm{recommended.} \mathrm{The} \mathrm{muffle} \mathrm{is} \mathrm{purged} \mathrm{from} \mathrm{the}$ rear with hydrogen gas with a dew point of less than $-50^{\circ} \mathrm{F}$, as measured at the inlet. A flow rate of $250 \mathrm{cth}$ is generally used. 
The billets are heated to $2100^{\circ} \mathrm{F}$ for at least $20 \mathrm{~min}$ prior to the first pass, and are reheated for at least $2 \mathrm{~min}$ between subsequent passes. A. second lot of billets is introduced into the furnace for preheating after the sixth mill pass of the preceding plates to allow continuous rolling. After the final pass, the plates are replaced in the muffle for a 5-min anneal and are then air cooled.

All billets are fed into the mill after gripping the end marked by the projection. This practice is continued throughout hot rolling to ensure that the flux suppressor portion is always trailing during each pass. The hotreduction schedule, based on mill settings, is:

$\begin{array}{ll}2 \text { passes } & \text { at } 10 \% \text { reduction } \\ 1 \text { pass } & \text { at } 20 \% \text { reduction } \\ 4 \text { passes } & \text { at } 40 \% \text { reduction } \\ 2 \text { passes } & \text { at } 30 \% \text { reduction } \\ 1 \text { pass } & \text { at } 20 \% \text { reduction }\end{array}$

Additional passes are made, as required, to roll to $0.040 \mathrm{in}$. $\pm 0.002 \mathrm{in}$. During the latter stages, and again at the completion of hot rolling, the plate thickness is measured over the core area with a micrometer to determine the actual, thickness of the hot-rolled plate.

The plates while still hot are trimmed in length at both ends by shearing during the hot-rolling schedule, usually after the sixth and eighth passes. At this time, it is important that the trailing end be identified by a scribed mark on the inactive end. The dispersion-type core can be delineated from the wrought stainless steel ends by a difference in heat color. A minimum of four inches of inactive material should remain after trimming.

Special care is exercised during rolling to minimize cambering or "rainbowing" of the plates which tends to decrease the amount of stainless steel. at the inactive edge and, if severe in nature, may be cause for rejection. Cambering of the fuel plate may possibly be corrected, depending on severity, by inserting the plate through the mill at a slight angle. Gross "rainbowing" which may occur during either hot or cold rolling usually cannot be corrected. A. level mill and proper feeding are recommended to circumvent this difficulty.

After cooling and prior to fluoroscopic examination, the hot-rolled plates are numbered consecutively starting with " $I$ " for the first plate processed. Numbers, one-half inch high, are stamped on the inactive section at the end opposite the flux suppressor. Each number is entered into the record. 


$$
-46-
$$

2. Fluoroscopic Examination - After visual inspection, acceptable plates are fluoroscoped to locate internal defects, determine straightness, and delineate the core section of the composite plate. A 175-KVP machine is recommended. A template, illustrated in Fig. 16, is used to scribe locating lines for shearing. The template is constructed to locate scribe lines $1 / 2$ in. beyond the sides of the fuel core and 2-3/4 in. beyond the ends, for either long or short plates. The template is centered over the core before the scribe lines are made. The fuel plate number is then restamped with the same stamp previously used at a location just inside the scribe line at the same end of the plate. A good impression is recommended to assure retention of identification throughout subsequent processing. The scribed dimensions for shearing of the plate are $3-1 / 2$ in. $x$ in.

After shearing, the hot-rolled plates are pickled in a $15 \% \mathrm{HNO}_{3}-5 \% \mathrm{HF}$ aqueous solution until all scale is removed. The cleaned plates are thoroughly washed to remove all traces of acid.

3. Cold Rolling - A Bliss four-high rolling mill with 5-in.-dia x 14-in.wide work rolls is employed in cold rolling the fuel plates to a final thickness of $0.030 \mathrm{in.} \pm 0.001 \mathrm{in}$. To minimize surface contamination of the fuel plates, these rolls should be free of radioactive material. Reduction per pass does not exceed 0.001 in. Level rolls and accurate elevating and indicating mechanisms are recommended. The roll faces are well lubricated with a heavy oil at a.l times. The entering ends of plates are dipped into SAE-90 oil as required before insertion. During cold reduction, it is important that the plates be rotated $180 \mathrm{deg}$ about the transverse and Iongitudinal axes.

The fuel plates are processed in lots of twenty. After a change in mill setting, the thickness of the first few plates rolled is measured at locations over the core area. No guides are used in rolling, but straightness is monitored by checking against a straightedge.

After reducing to a thickness of approximately 0.032 in., the fuel plates are rolled individually to the specified thickness. The heavy lubricating oil is removed from the plates by a kerosene rinse followed by vapor degreasing.

Every 15 th plate is radiographed to monitor the reproducibility of the manufacturing process with respect to homogeneity of the $\mathrm{UO}_{2}$. 


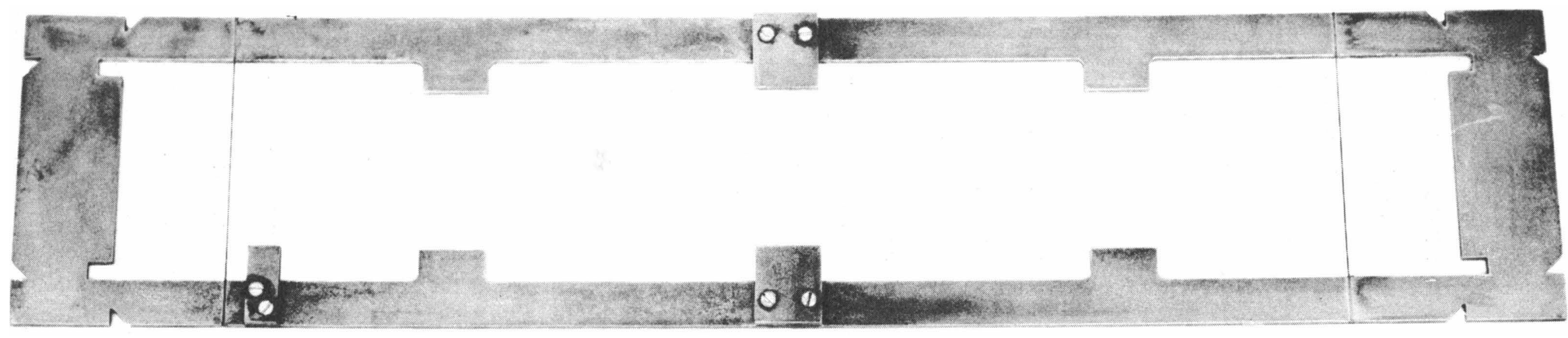

\section{NCHES}

Fig. 16. Rough Shearing Template for the Control Rod Fuel Plate. 
4. Fluoroscopic Examination and Marking -.. The cold rolled fuel piates are then fluoroscoped to delineate both the fuel and flux suppressor area. A 175-KVP machine is recommended. The template used for both long and shor: fuel plates is illustrated in Fig. 17. It is slotted at the ends to determine if the core length lies within the minimum and maximum dimensions. The side slots are spaced to ascertain that the final core width is within tolerance and. that a sufficient width of stainless steel edging is present along the entire length of the plate. The core is centraily located within the template length and side slot boundaries. Short plate lengths are scribed from the inner end of the template. Long plate lengths are scribed from the outer end of the template. The inner width of the template for scribing allows a sheared plate width approximately 0.080 in. wider than the final machined width. Only one side is scribed since sufficiently accurate shearing of the plate width can be obtained by using a fixed reference stop on the shear bed.

Prior to shearing, an identification number about $3 / 8 \mathrm{in}$. high is engraved on the fuel plate with a Burgess Vibro tool inside the scribed line at the plate end opposite the flux suppressor. The number is located far enough on either side of the center line to prevent obstruction by combs located at the plate ends during assembling of the fuel element for brazing.

5. Shearing - The scribed long side is sheared first. Using stops on the shear at a fixed reference, the other long side is sheared to yieid a plate width of $2-11 / 32$ in. $\pm 0.010 \mathrm{in.}$. The ends of the plates are then sheared. from the scribe lines to lengths of $23-1 / 8 \mathrm{in.} \pm 1 / 16 \mathrm{in}$. and $24-1 / 2 \mathrm{in}$. $\pm 1 / 16$ in. for short and long plates, respectively.

6. Machining - The fuel plates are machined to final length and width dimensions by utilizing the machining fixture illustrated in Fig. 18. The fixture consists of a top and base plate, both of which are 0.009 in. Iess in size than the nominal fuel plate width, and removable Iocating brackets for aligning the plates. The base plate is securely clamped to the milling-machine table after proper location. Aluminum cushion plates of $1 / 8$-in. thickness and of the same length and width dimensions as the sheared composites are placed on the top and bottom of the stock of plates in the jig. Plates are usually handled in lots of twenty-five. The plates are aligned securely against the locating brackets on one side of the jig. The top plate is positioned and bolted 


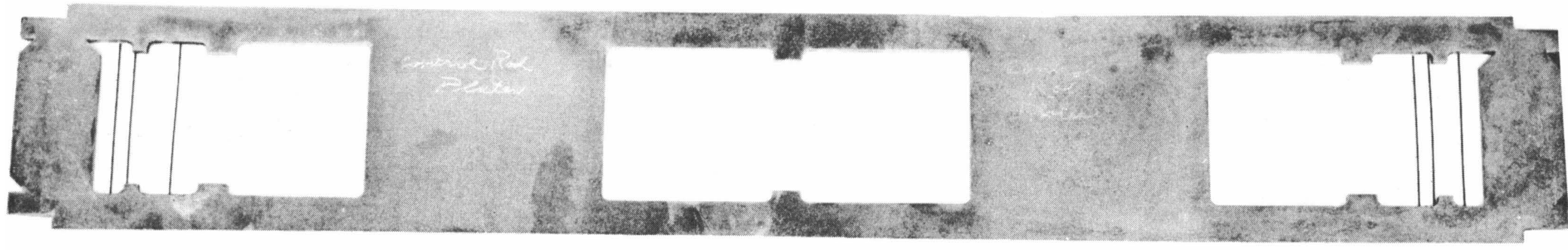

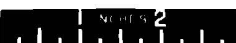

Fig. 17. Final Shearing Template for Either the Short or Long Control Rod Fuel Plate. 


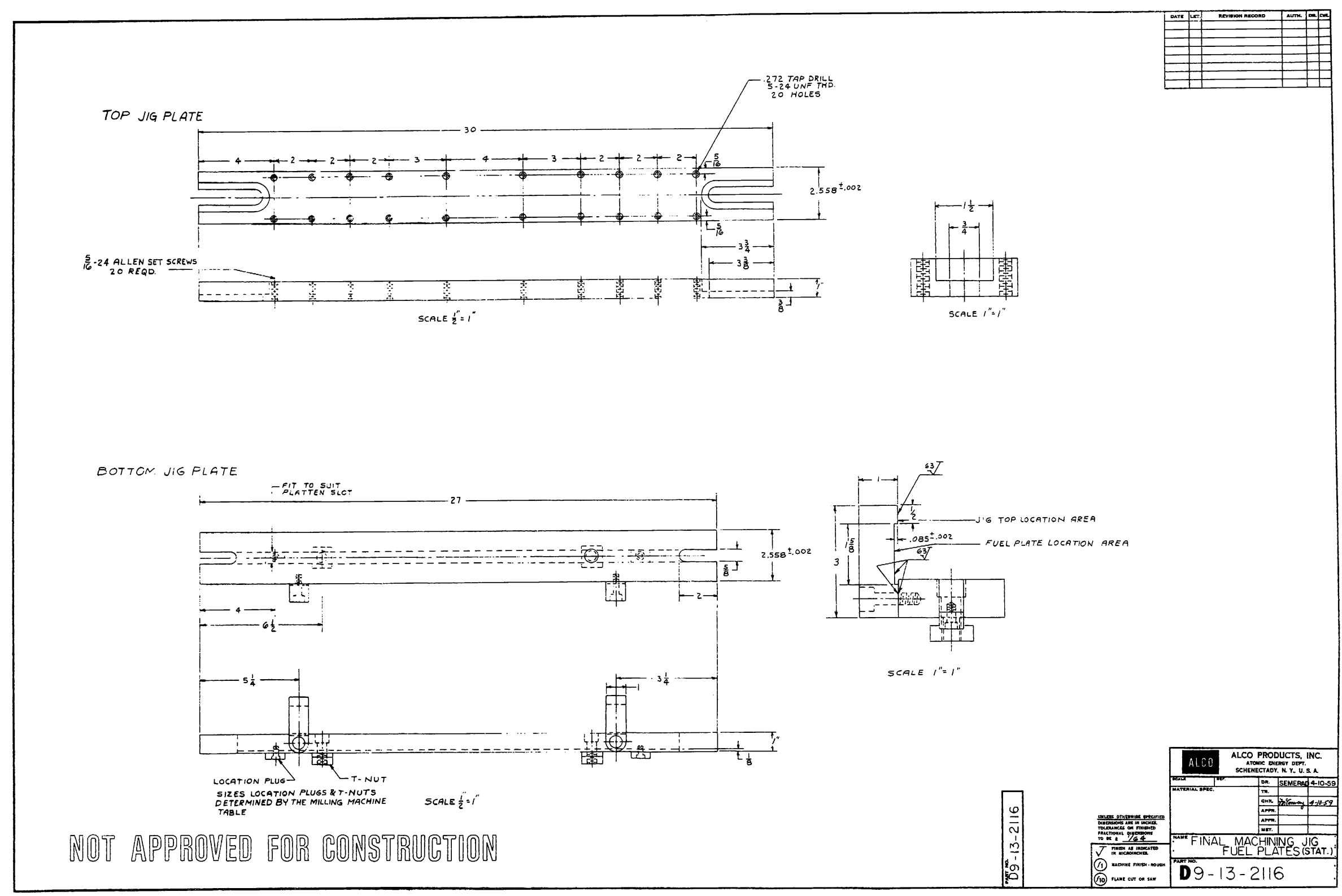

Fig. 18. Fuel Plate Machining Fixture. 
securely at each end through the base plate to the milling-machine table. The Allen screws are tightened to obtain a uniform pressure along the length of the fuel plates. The locating brackets are then removed.

The side edges of the fuel plates are straddle milled with a cutter on a horizontal arbor. Two 8-in.-dia staggered-tooth milling cutters are correctly spaced for straddle cutting to finished fuel plate width of $2.558 \pm 0.002$ in. The ends are then milled on a vertical milling machine using a 4-in.-long side-cutting mill. The lot of plates is clamped to the table over a block. Equal amounts of stainless steel are removed from each end of the fuel plates. Final lengths are $23 \mathrm{in.} \pm 1 / 64 \mathrm{in}$. and $24-3 / 8 \pm 1 / 64 \mathrm{in}$. for short and long plates, respectively.

After degreasing in a vapor degreaser, the machined edges of the fuel plates are lightly deburred by hand filing. Special care is taken to prevent rounding of the edges.

7. Inspection - All fuel plates are fluoroscopically inspected to determine that the machined plate meets the dimensional specifications shown in Fig. 19. The final inspection template is illustrated in Fig. 20. Width inspection slots are spaced $2.28 \mathrm{I}$ in. apart and are $0.039 \mathrm{in}$. wide. The width between the outer edge of the slot and the edge of the template is 0.100 in. Length inspection slots are spaced to determine whether or not the core length lies within the minimum and maximum specifications. Fuel plates with questionable dimensions are radiographed. Core length, core width, and width of inactive stainless steel edging are measured directly from the radiograph. Plates which do not meet dimensional requirements are rejected.

The surfaces of the fuel plates are inspected visually for defects. Inclusions, pits, and scratches deeper than 0.001 in. are cause for rejection. Dents, blisters, and discrete color changes on the surface are also cause for rejection.

\section{G. Flatten Annealing of Machined Fuel Plates}

To facilitate assembling of the fuel plates and to meet plate-spacing dimensions in the brazed fuel unit, it is necessary that the composite plates be flat and fully annealed. Flattening and annealing are accomplished in one operation. Acceptable fuel plates are degreased in a vapor degreaser prior to annealing. Lot size for flatten annealing is twenty-five fuel plates. 


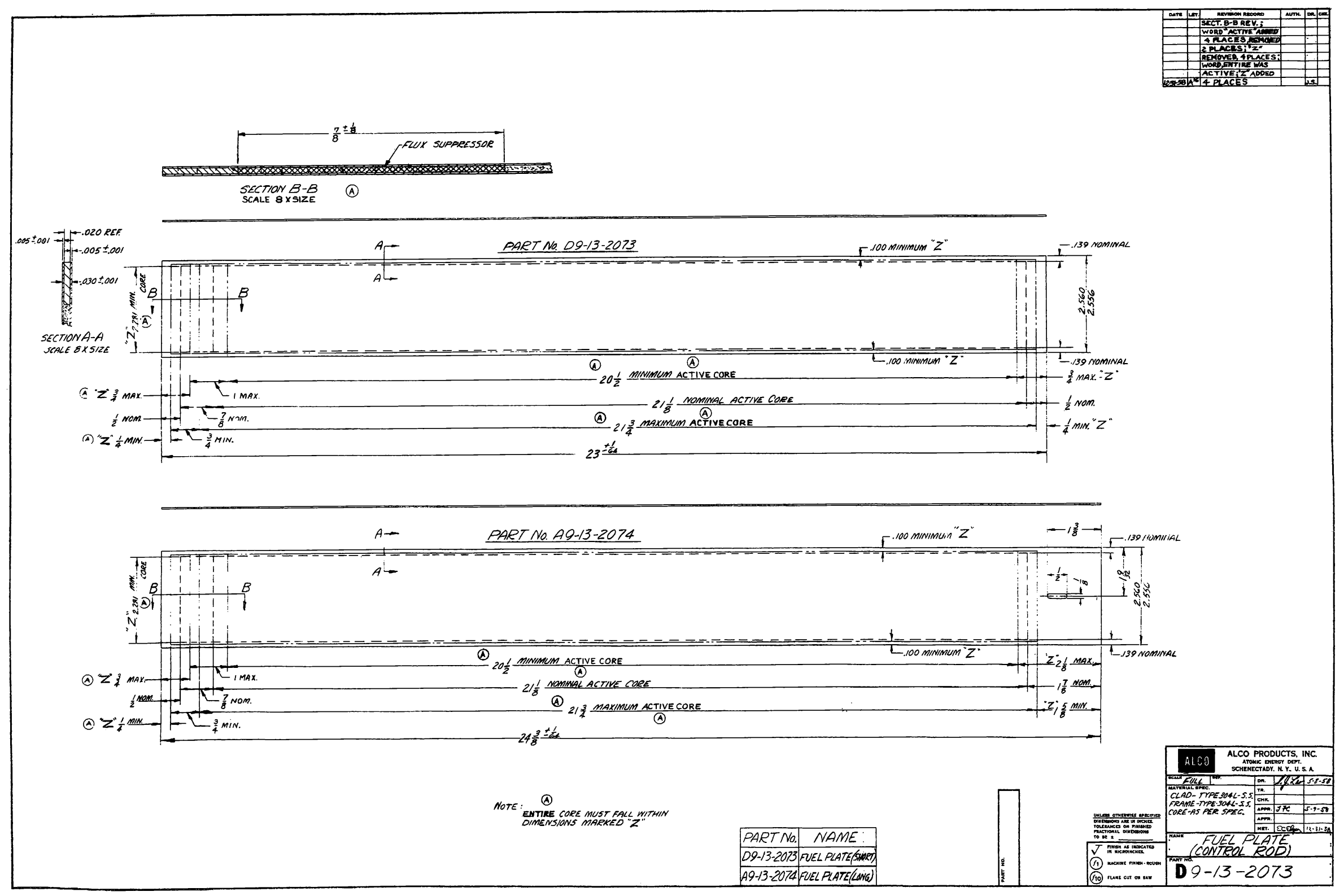

Fig. 19. Control Rod Fuel Plates. 


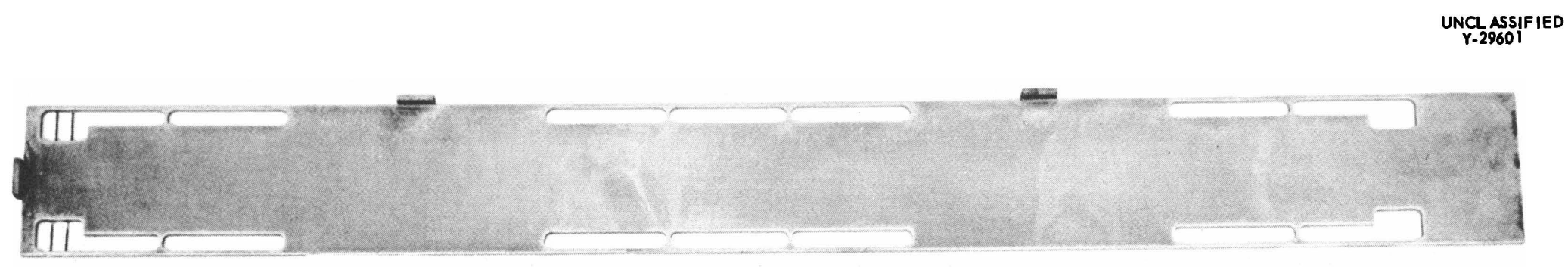

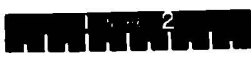

Fig. 20. Final Inspection Template for the Control Rod Fuel Plates. 
Each plate is covered on one side with a thin coat of a mixture containing one part by volume of Fisher 5F Precisionite levigated alumina and ten parts of water. A three-inch camel's hair brush is used to apply an even coating. The coated fuel plates are allowed to dry for at least $1.5 \mathrm{~min}$.

As illustrated in Fig. 2l, a jig composed of two platens for clamping the fuel plates together is used ior this operation. Twenty-five fuel plates are stacked together with the coated side adjacent to the uncoated side. The stack is placed between the platens, and the clamping bolts are firmly tightened. The loaded assembly is dried in an oven at $330^{\circ} \mathrm{F}$ for a minimum of $16 \mathrm{hr}$.

Annealing is accomplished within an Inconel muffle inserted into a 56-kw Globar furnace at a temperature of $2100^{\circ} \mathrm{F} \pm 25^{\circ} \mathrm{F}$. The muffle has a cross sectional dimension of 7 in. $x 9$ in. and is $6 \mathrm{ft}$ in length. Bright annealing of the plates is obtained under dry hydrogen with a dew point of $-80^{\circ} \mathrm{F}$, as measured by an Alnor Dewpointer at the furnace inlet.

Furnace temperature at insertion of the loaded platen assembly ordinarily does not exceed $570^{\circ} \mathrm{F}$. The muffle is purged with helium prior to insertion of the plates and during the period of heating between $570^{\circ} \mathrm{F}$ and $1200^{\circ} \mathrm{F}$. The temperature is raised to $1200^{\circ} \mathrm{F}$ at a rate not exceeding $540^{\circ} \mathrm{F}$ per hour. A.t $1200^{\circ} \mathrm{F}$ the helium atmosphere is replaced by hydrogen. A flow rate sufficient to bright anneal stainless steel is recommended; $240 \mathrm{cfh}$ is used generally. The temperature is raised to $2100^{\circ} \mathrm{F}$ at a rate of approximately $540^{\circ} \mathrm{F}$ per hour. The plates are held at $2100^{\circ} \mathrm{F}$ for two hours, and then furnace cooled to $570^{\circ} \mathrm{F}$. A.t this temperature, the hydrogen atmosphere is replaced with a helium purge. The assembly is then removed from the muffle and air cooled. After disassembly, the fuel plates are scrubbed under flowing water to remove the coating of alumina. Care is exerted in this scrubbing treatment to prevent distortion of the fuel plates. The fuel plates are then either air or oven dried. The surfaces of the fuel plates again are inspected for defects and acceptable plates are stored in a safe. Oxide indentations, pits, and scratches deeper than 0.001 in. are cause for rejection. Dents, blisters, and discrete color changes on the surface are also cause for rejection.

\section{H. Manufacture of Side Plates and Combs}

1. Side Plates

(a) Machining - The side plates are machined from 0.050 in. $\pm 0.003 \mathrm{in}$. stainless steel sheet stock, sheared to $25 \mathrm{in.} \times 2-7 / 8 \mathrm{in} \pm 1 / 16 \mathrm{in}$. 


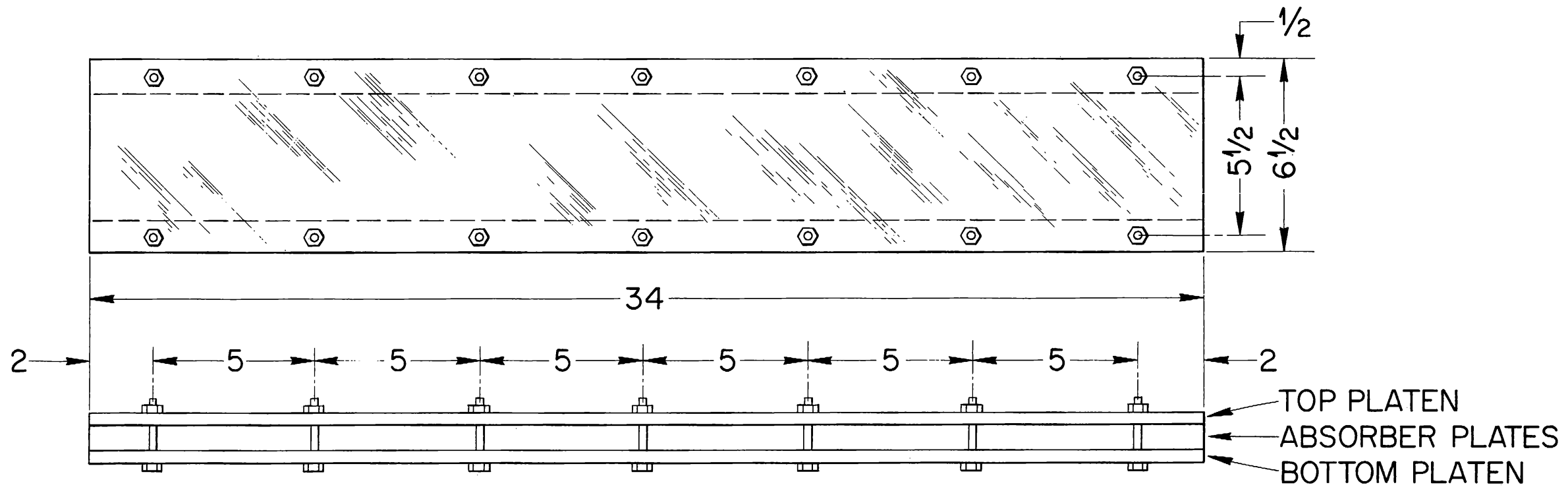

PLATENS - 3/8 304 OR 316 STAINLESS STEEL

BOLTS AND NUTS - $1 / 4-20304$ STAINLESS STEEL

ALL DIMENSIONS IN INCHES

Fig. 21. Assembly Fixture for Flatten Anneal Operation. 
in size. Each plate is deburred with a file after shearing. A stack of twenty plates is sandwiched between two pieces of 1/8-in.-thick aluminum sheet of approximate side-plate dimensions to prevent distortion of the side plates during the milling operation. The assembly is table-clamped lengthwise and straddle milled on a horizontal milling machine. Two 8-in.-dia staggered-tooth steel cutters rotating at approximately $20 \mathrm{rpm}$ with a $1 / 2-\mathrm{in} . / \mathrm{min}$ feed are used to mill the stack of plates to final width in one pass. The assembly is then transferred to a vertical milling machine, and machined to the proper length with a side-cutting mill rotating at $150 \mathrm{rpm}$ with a $1-\mathrm{in} . / \mathrm{min}$ feed. Dimensional requirements are specified on Alco Drawing (D9-13-2011) shown in Fig. 22.

Each side plate is completely deburred with a file to ensure a good grip by the vacuum chuck employed during the grooving operation. The chuck is 36 in. $x 12$ in. with vacuum holes on $1 / 2-i n$. centers. Holes not covered by the side plate are covered with two layers of heavy masking tape. The vacuum for the chuck is supplied by a large industrial vacuum cleaner.

During the grooving operation, the sixteen grooves per plate are cut in one pass on a horizontal milling machine using 3-in.-dia x 0.034-in.-thick carbide-tipped slitting-saw blades. Special care is exercised in establishing the location of the saw blades on the machine arbor to ensure that the dimensions between grooves and edges of the side plates are correct. The cutters rotate at $60 \mathrm{rpm}$ with a feed of about $1-5 / 8 \mathrm{in} . / \mathrm{min}$. A heavy sulphur-base cutting oil is used for lubrication.

(b) Inspection - Subsequent to machining and grooving, the plates are degreased and each is dimensionally inspected. The plate groove depths are determined either by gauge wire with a micrometer or by a thin roller attached to a dial indicator. The groove separations are measured with a micrometer from plates inserted in the grooves or with a disc-type micrometer. All dimensions must fall within the tolerances specified on Alco Drawing (D9-13-2011).

(c) Flatten Annealing - Flatten annealing of the side plates is required to relieve the stresses which result from the grooving operation. The side plates are annealed in a manner identical to that used in annealing the fuel plates described in Item $G$ with the following exceptions:

(1) The individual side plates are separated by 0.030 -in.thick, type 304L stainless steel shim stock.

(2) The alumina mixture is applied to both sides of the shim stock. The side plates are not coated because of the difficulty in removing the alumina from the grooves. 


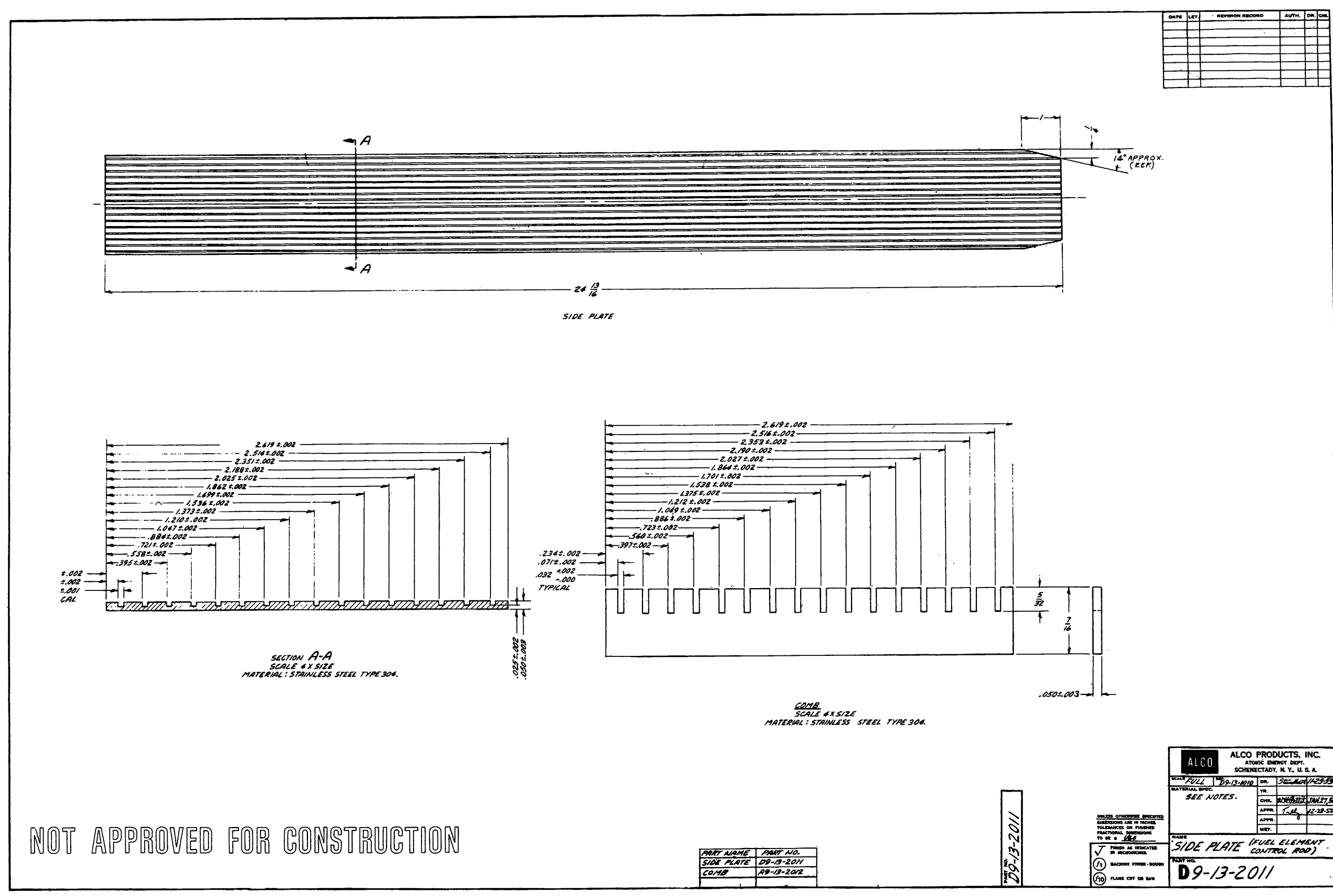

Fig. 22. Dimensional Drawing of Side Plate and Comb. 
(3) A maximum of fifteen side plates are stacked with the alumina-coated shims between each plate.

The plates are degreased and stored for future use.

2. Combs

(a) Machining - The combs are prepared from 0.050-in. \pm 0.003 -thick stainless steel sheet stock sheared to 3 in. $x ~ I$ in $\pm 1 / 16$ in. and machined in accordance with the dimensional specifications shown in Fig. 22. Stock is usually selected from trimmings remaining from side-plate shearing. The length is milled to final size. The width is milled $1 / 4-i n$. oversize to provide sufficient stock for holding during the slotting operation. Slotting of the combs is performed on a horizontal milling machine with a high-speed steel screw-slotting cutter rotating at $60 \mathrm{rpm}$ with a $1 / 2-i n . / \mathrm{min}$ feed. A. group of fifteen to twenty combs is held by the excess material on the width in a precision vise mounted on the table of a milling machine. Each slot is machined individually. After complete slotting, the pieces are mounted in a precision vise and are machined on a shaper to remove the excess width stock.

(b) Inspection - Each comb is dimensionally inspected. The comb groove width and location are checked in the same manner as the side plates. The length, width, and thickness of the combs are checked with conventional micrometers. Combs not meeting the dimensional tolerances specified on Alco Drawing (D9-13-20.1.1) are rejected. Following inspection, the combs are vapor degreased and stored for future use.

3. Attachment of Gusset Plates to Side Plates - As illustrated in Fig. 23 (AIco Drawing D9-13-1011), the gusset plate, which is machined to the specifications listed in Fig. 24 (Alco Drawing A9-13-2078), is attached to the side plate by heliarc welding. The shoulderea end of the gusset, with the channeled side facing the grooved side plate, is centered at the square end of the side plate and held flush with the side plate end by a "C" clamp. A. small. bar $1 / 2$ in. $x 1-1 / 4$ in. $x 1 / 8$ in. is placed over the gusset "U" shaped hole to serve as a base for the "C" clamp. After examining the alignment, the gusset plate is heliarc welded using type 308 stainless steel filler rod at the four gusset-plate side-plate joints.

\section{Assembly of Fuel Unit}

1. Brazing Jig - A combination assembly and brazing jig is utilized for assembling the fuel plates, side plates, and combs into a fuel assembly. 


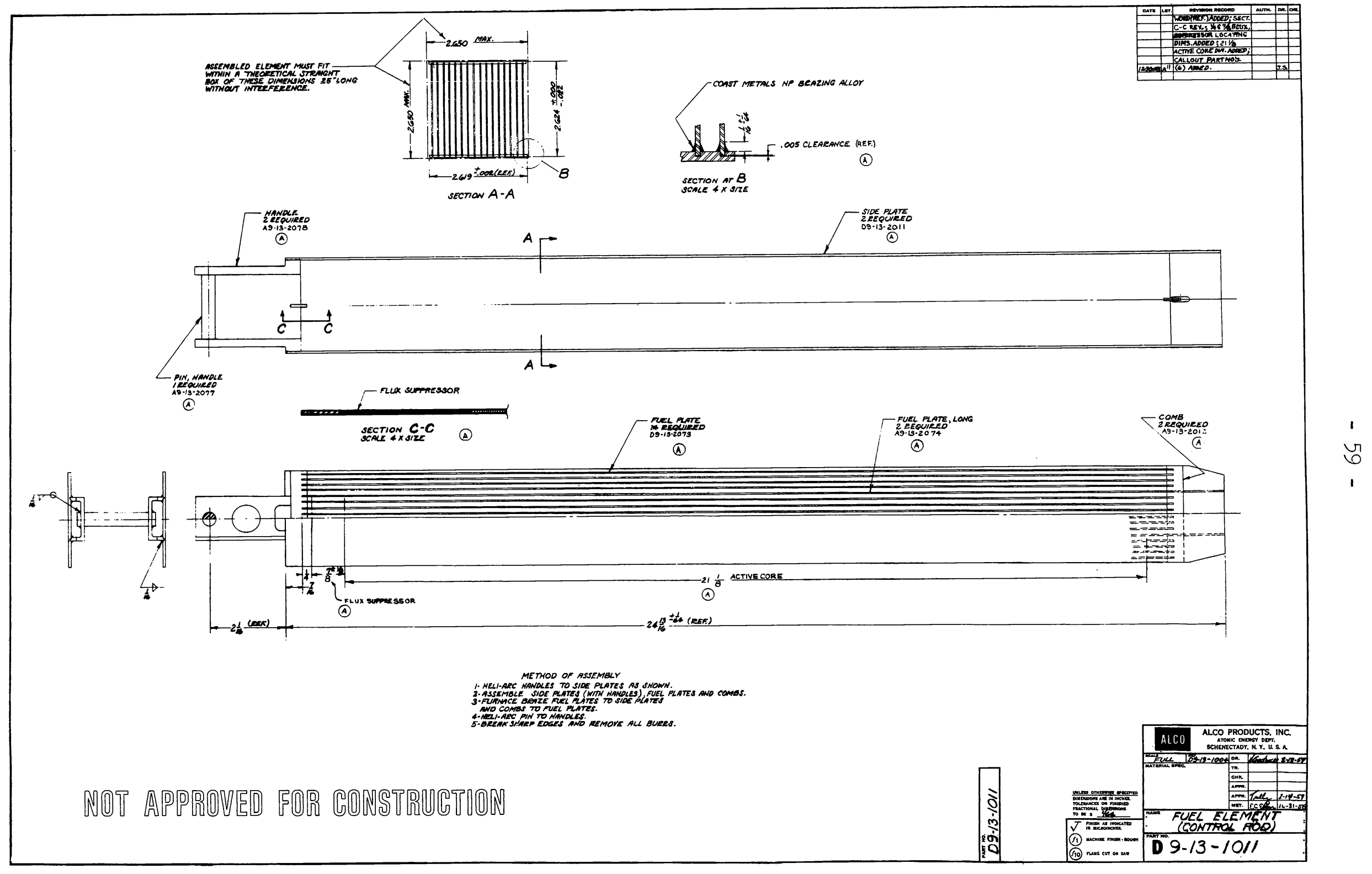

Fig. 23. Control Rod Fuel Element. 

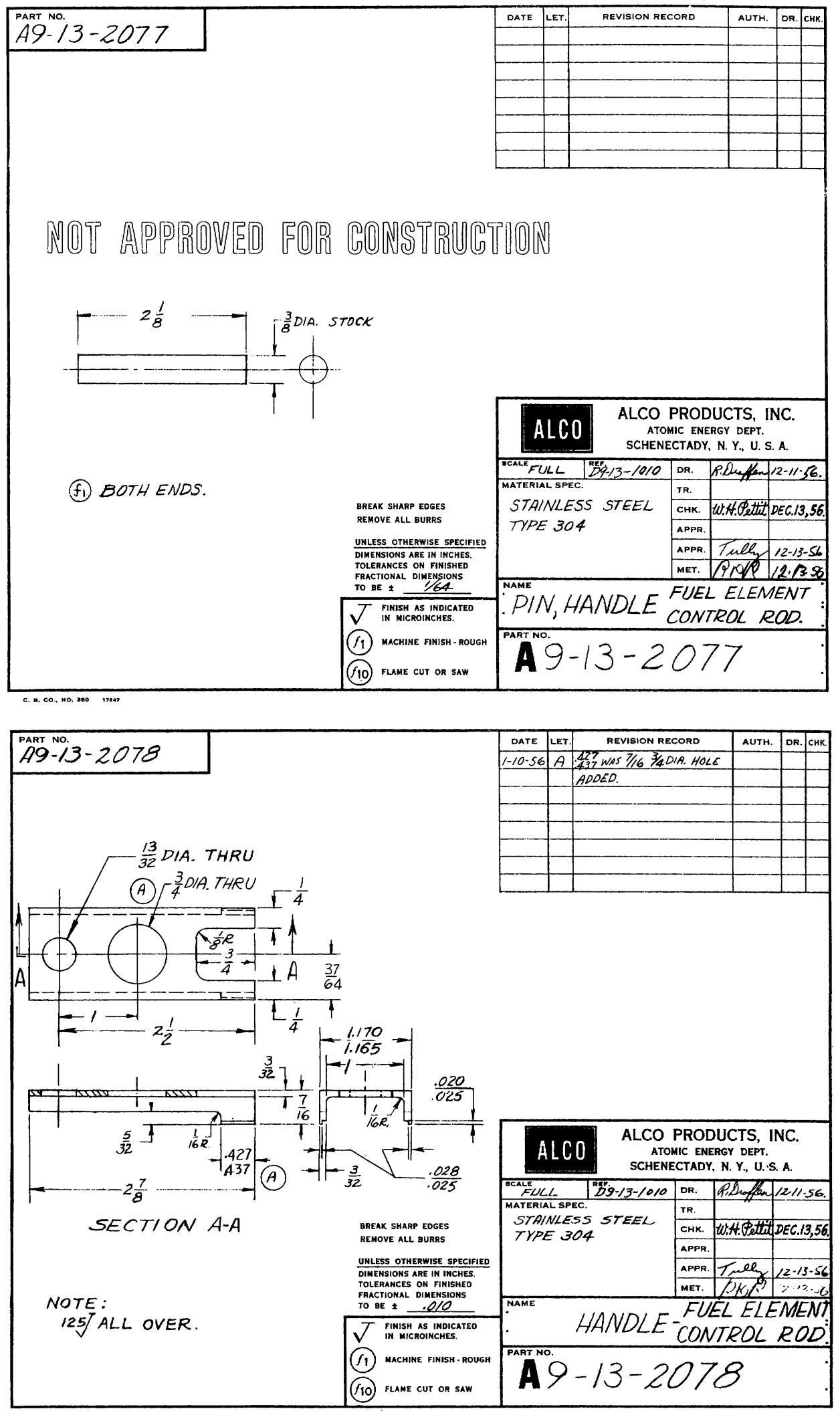

Fig. 24. Pin and Gusset Plate. 
Any type of 300-series stainless steel with expansion characteristics approximating that of type $304 \mathrm{I}$ stainless is satisfactory as the jig materiaI.

As shown in Fig. 25, the base plate of the jig is made from 1-in. plate to which longitudinal bottom skids are attached. Five "U" shaped supports are located in a shallow groove machined in the base plate and are attached to the base plate by means of dowel pins and screws. To allow for flexibility in assembly, the inside dimension of the "U" supports is approximately 0.100 in. larger than the actual finished width of the brazed assembly. A shim plate inserted between each side of the " $U$ " support and the respective side plate compensates for the gap. The thickness of the shims used in assembling an individual fuel assembly is determined prior to assembling. A sample calculation is shown as follow:

Inside dimension of brazing $j i g{ }^{~}{ }^{89}$ supports: $\quad 2.715 \mathrm{in.} \pm 0.001 \mathrm{in}$. Fuel plate width: 2.552 in. \pm 0.001 in.

Side-plate thickness (measured from base of grooves ):

$$
2.025 \text { in. } \pm 0.001 \text { in. }
$$

Braze metal clearance (measured from bottom of side-plate grooves to edge of inserted fuel plate):

Total shim thickness $=a-(b+2 c+2 d)$

$$
\begin{aligned}
& =2.715 \mathrm{in.}-[2.552 \mathrm{in.}+2(0.025 \mathrm{in.})+2(0.005 \mathrm{in.})] \\
& =0.103 \mathrm{in.}
\end{aligned}
$$

A removable comb holder located by two dowel pins at one end of the jig is attached to the base plate with machine screws. This holder is removed prior to insertion of the jigged fuel element into the brazing furnace.

2. Procedure - Immediately prior to assembly, all component parts of the assembly are visually inspected and degreased to ensure cleanliness. The following: operations are performed in sequence:

(a) The size of the shims to be used is determined.

(b) The two selected shim plates are then positioned, one against each side of the "U" uprights.

(c) Two side plates, with grooved sides facing each other, are placed adjacent to the shim plates and the ends with the gusset plates positioned snug against the mounting plate of the comb holder. A scrap piece of stainless steel sheet stock is inserted to hold the side plates flat against the jig sugports. 


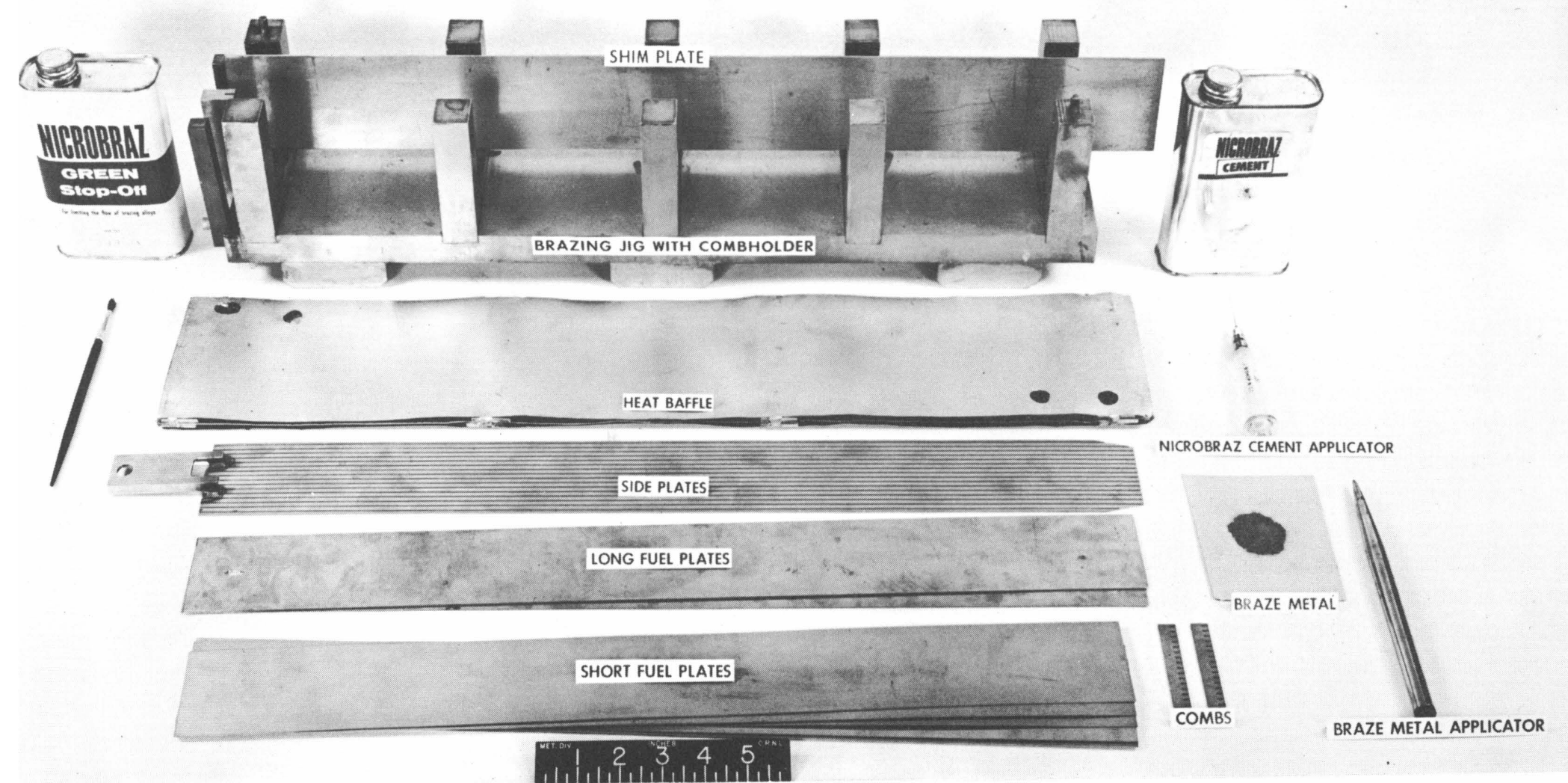

Fig. 25. Components for Brazing the Control Rod Fuel Element Assembly. 
(d) A comb is placed in the comb holder, and a short plate is inserted in the bottom row of side-plate grooves and firmly placed in the comb groove. It is very important that the end of the plate containing the flux suppressor be inserted into the comb which is at the gusset end of the assembly.

(e) Braze powder is applied at the comb-fuel plate joints, glued into place with Nicrobraz Cement followed with a stripe of Green Stop-Off to prevent flow of braze metal across the fuel plate. This operation is repeated immediately after insertion of subsequent plates.

(f) The $j i g$ is tilted about the horizontal axis to faclititate placing of the braze metal, cement, and stop-off. This is accomplished by using a 1.5-in.-thick piece of wood to elevate one side of the assembly.

(g) The dry Coast Metals N. P. braze metal is applied by gravity from a stainless steel pointed tube resembling the barrel of a mechanical pencil. It is important that the braze metal be confined to the inactive edge of the plate and not be preplaced on the cladding surface above the fuel core. Since the minimum width of the inactive stainless steel edge of the fuel plate is $0.100 \mathrm{in}$. and $0.025 \mathrm{in}$. is the maximum distance the plate can be inserted in the side plate groove, a mere 0.075-in.-wide strip of inactive stainless steel, remains for preplacement of braze powder. It is recommended that the width occupied by the braze powder be less than $0.050 \mathrm{in}$.

(h) The dry braze metal powder is cemented into place with Colmonoy Nicrobraz Cement. A. 19-gauge hypodermic needle attached to a 5-cc syringe permits the cement to drip by gravity onto the fuel plate adjacent to the braze metal fillet. The cement is allowed to dry for $30 \mathrm{sec}$.

(i) A. 1/4-in.-wide stripe of Colmonoy Green Stop-Off is applied with a camel's hair brush directly adjacent to the braze metal on the active portion of the plate. The stop-off is used to prevent the braze metal from flowing laterally onto the stainless steel cladding of the active core section during the subsequent brazing operation.

(j) The wood tilting block is then moved to the opposite side of the $j i g$, and operations " $g$ " through " $i$ " are repeated for the opposite fuel-plate sideplate joint.

(k) The plates are inserted from bottom to top, and each joint of all sixteen plates is properly prepared with braze powder, cement, and stop-off. Attention is called to the fact that there are two long plates in the assembly. Care is to be exercised to ensure that they are inserted in the locations shown in Fig. 23. 
(1) The second comb is attached to the unit after inserting all of the plates into the side-plate grooves. All comb-fuel-plate joints are filled with braze metal, cement, and stop-off.

(m) The comb holder is removed from the jig.

(n) A heat baffle is placed on top of the jig to minimize temperature gradients during the heating and cooling cycle. This baffle consists of three 0.050-in.-thick 18-8 stainless steel plates, separated 1/8 in. by spacers and welded to form an integral unit. The assembled unit is shown within the brazing fixture in Fig. 26.

(o) The disposition of the fuel plates is identified with the fuel element number in the master log.

\section{J. Brazing of Fuel Assemblies}

1. Procedure - Brazing of fuel elements is accomplished in the identical furnace equipment utilized for annealing fuel plates. The furnace is equipped with a leak-tight muffle for maintaining a dry hydrogen atmosphere and is capable of maintaining a maximum gradient of $5^{\circ} \mathrm{F}$ along the entire fuel assembly length at the brazing temperature.

Two calibrated chromel-alumel thermocouples are attached (one to the front and the other to the rear) to the assembly. Each thermocouple is recalibrated prior to future use. The rear thermocouple leads extend along the base plate between the jig skids, and the junction is inserted a distance of two inches from the rear of the fuel element between the midale fuel plates. The front thermocouple is similarly located between the middle fuel plates by inserting the leads directly into the front of the element.

The jig containing the assembled fuel unit, complete with thermocouples, is placed in the furnace at a maximum temperature of $570^{\circ} \mathrm{F}$. A dry helium atmosphere, with a minimum dew point of $-40^{\circ} \mathrm{F}$, as measured by an A.Inor Dewpointer at the inlet end, is introduced as the atmosphere at low temperatures. A pair of stainless steel reflector shields is placed in front of the jig to minimize thermal gradients along the fuel element. The thermocouple leads on the fuel element are threaded through the furnace door entry port.

The furnace temperature is raised to $1200^{\circ} \mathrm{F}$ at a rate not to exceed $370^{\circ} \mathrm{F}$ per hour. The furnace is held at this temperature until the temperature gradient, as measured by the thermocouples, is less than $45^{\circ} \mathrm{F}$. At this time, dry hydrogen with a dew point of at least $-80^{\circ} \mathrm{F}$, as measured by. an Alnor Dewpointer, is 
$-65-$

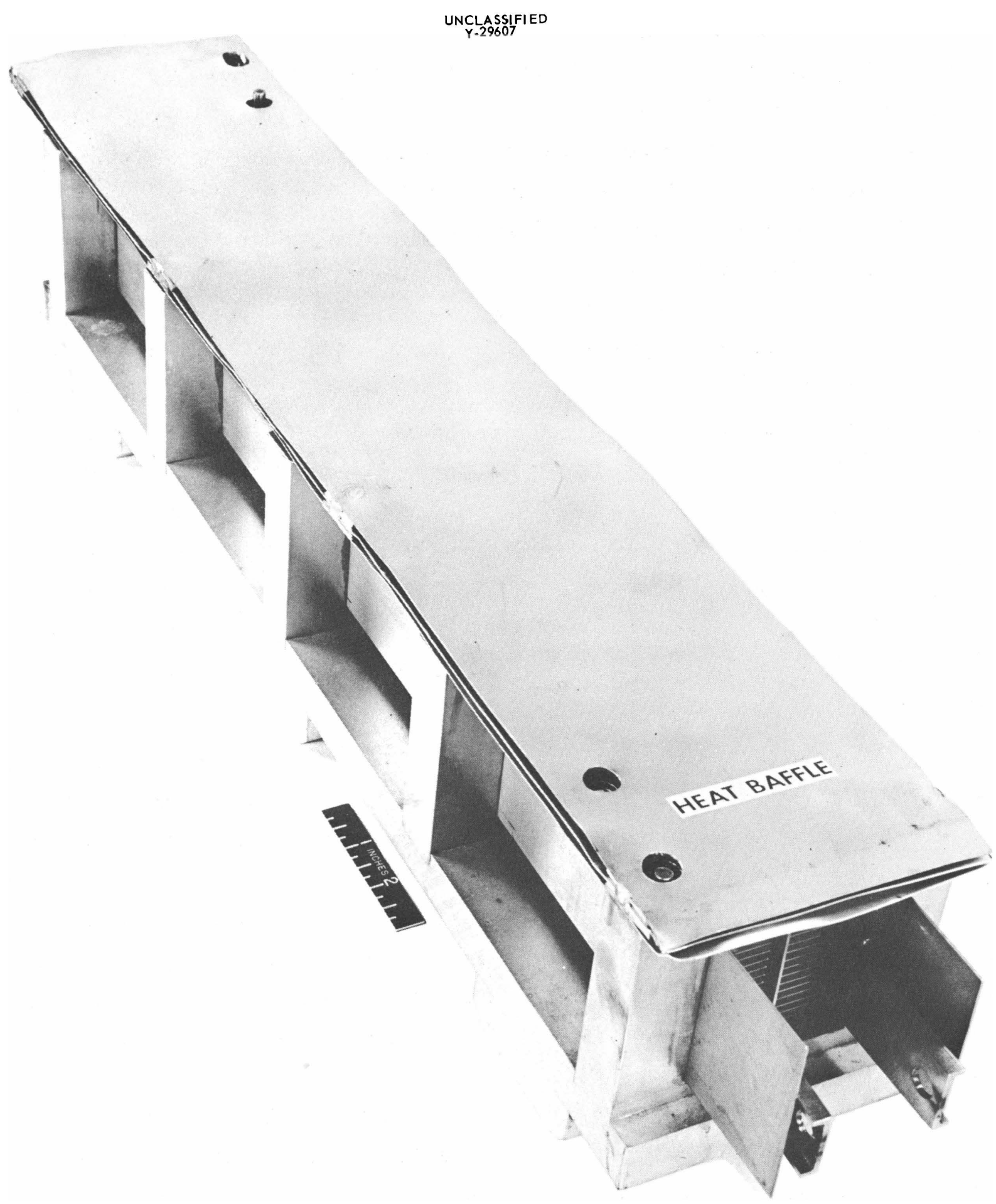

Fig. 26. Completely Assembled Control Rod Fuel Element. 
introduced and the helium purge discontinued. The temperature is raised to $1830^{\circ} \mathrm{F}$, and is held until the temperature gradient is less than $18^{\circ} \mathrm{F}$ and outlet hydrogen dew point is at least $-50^{\circ} \mathrm{F}$. The furnace temperature is raised to $2010^{\circ} \mathrm{F}$ and the fuel element is held at this temperature until the temperature gradient is less than $5^{\circ} \mathrm{F}$.

Above $2010^{\circ} \mathrm{F}$, the furnace temperature is slowly raised by careful manual control. Temperature readings are taken on both the thermocouples every minute. The temperature gradient is maintained as low as possible, with a maximum of $5^{\circ} \mathrm{F}$. When the thermocouple temperatures reach $2071^{\circ} \mathrm{F}$, the furnace is shut off. The total time for the fuel assembly above $2066^{\circ} \mathrm{F}$, as measured by the thermocouplies, does not exceed eight minutes. The brazed fuel assembly is furnace cooled to $570^{\circ} \mathrm{F}$, at which temperature the furnace is purged with helium. After thorough purging, the furnace is opened and the assembly air cooled to room temperature. The total time for one complete brazing cycle is approximately twenty-four hours.

After the brazing operation, each completed assembly is identified with numbers approximately 1/2 in. high scribed by a Burgess V1bro tool on the gusset end of one side plate. Completed fuel assemblies are consecutively marked starting with "I" for the first assembly. Appropriate records are maintained in the master log.

2. Dimensional Inspection - The brazed fuel assemblies are dimensionally inspected for squareness, plate spacing, element width, and sag or distortion of top and bottom plates. The data for each assembly are recorded on an appropriate inspection form.

Plate spaclngs are measured at the centers of fuel plates at distances of 2-1/2 in., 10 in., 17 in., and 22 in. from the numbered end. Sixty readings per fuel element are obtained. Maximum allowable deviation is $\pm 10 \%$ of the nominal spacing, or $0.013 \mathrm{in}$. Fuel elements with deviations greater than 0.013 in. are subject to rejection.

Air gauging to measure plate spacings is not acceptable. As shown in Fig. 27, a special measuring device incorporating a calibrated elliptical prołe... has been successfully used. A steel ellipsoid, having 0.100-in. minor and 0,150-in. major axes, is rounted on the end of a 0.100-in.-dia tube approximately 27 in. long. A l-in.-thick plastic block, 3 in. $x 6$ in., with a hole in the center allowing tube rotation, is mounted near the other end of the tube. A needle indicator is rigidly mounted on the tube near the plastic block parallel 


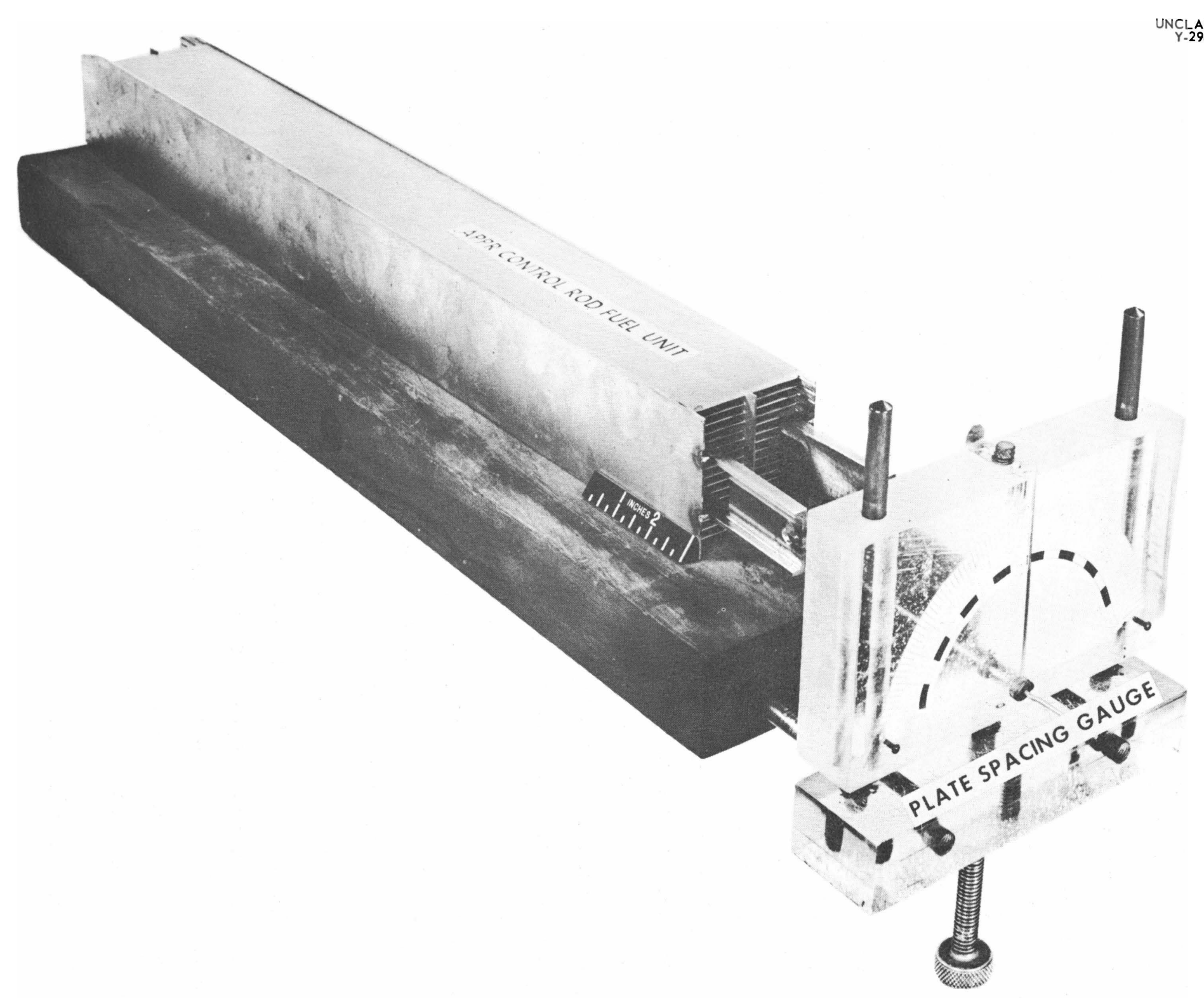

Fig. 27. Plate Spacing Gauge. 
with the ellipsoid minor axis. The needle is calibrated by rotating the ellipsoid between gauge blocks and the width of space between gauge blocks marked on a piece of polar graph paper. The calibrated graph paper is properly oriented and permanently fixed to the face of the plastic block.

The width of the assembly is measured with a 3 -in. micrometer at six locations along the top and bottom of the side plates for a total of twelve measurements per assembly. Measurements are taken at distances of 1, 5, 10, 14, 19, and $21 \mathrm{in}$. from the numbered end of the element. Fuel assemblies with width dimensions outside the width limits of $2.624 \mathrm{in.,}-0.022 \mathrm{in} .+0.000 \mathrm{in}$. are cause for rejection.

The dimensions from the outside center of the top and bottom fuel plates to the edges of the side plates are measured with a depth micrometer at locations of $4,9,1$, and $22 \mathrm{in}$. from the numbered end of the fuel assembly for a total of eight measurements. Fuel assemblies with measurements outside the limits of $0.072 \mathrm{in.} \pm 0.013 \mathrm{in}$. are cause for rejection.

The unit is measured for squareness on a surface plate. Any evidence of twist or other manifestations of out-of-squareness requires that the element be passed through the final inspection straight box with inside dimensions of $2.650 \mathrm{in.} x 2.650 \mathrm{in}$. and 26-1/16 in. long. Binding at any point is cause for rejection.

3. Cleaning - The fuel assemblies are cleaned under hot water to remove the stop-off residue by scrubbing with a 1/8-in.-dia stainless steel wire brush. Care must be exercised to prevent damage to the fuel plates.

4. Visual Inspection - The fuel plates and the brazed joints are visually inspected for defects such as blisters, dents, scratches, and pits which are obviously deeper than 0.001 in., splatter and excessive lateral spread of braze metal over the fuel section of the plate, and a total discontinuity of more than 2 in. in any brazed joint. The presence of any of these defects is cause for rejection.

\section{K. Attachment of Handle}

The handle pin machined to the dimensions shown on Alco Drawing (A.9-13-2077) is positioned in the holes provided into the gusset plates and the handle heliarc welded as shown on Alco Drawing (D9-13-1011). 
VII. PREPARATION FOR SHIPMENT

Prior to storage and/or shipment, the control rod fuel elements are vapor degreased and enclosed in a plastic sheath which is thermally sealed to protect the component. The control rod fuel elements are packaged in suitable shipping containers which are designed to protect the units against damage or contamination during shipment and to meet AEC requirements with respect to criticality.

\section{ACKNOWLEDGMENTS}

The publication of this report was made possible through the co-operation and combined efforts of many people. The authors wish to acknowledge

R. D. Robertson and E. C. Edgar of Alco Products, Inc., for their assistance in preparing this report and I. Meem, J. F. Haines, J. Tully, and J. G. Gallagher of Alco Products, Inc., for their work on the finalization of design and the preparation of engineering drawings. The contributions of various members of the Army Reactors Branch of the Division of Reactor Development, AEC, Washington, and the AEC Operations Offices in Oak Ridge and Schenectady in administrating the program are gratefully appreciated. The authors are also indebted to the following staff members of ORNL: A. L. Boch, H. C. McCurdy, L。D. Schaffer, F. F. Neill, and E. E. Gross of the Package Reactor Group for technical advice and guidance; E. R. Turnbill of the Metallurgy Division for his assistance in the fabrication and development of Core II control rod fuel elements; and R. C. Waugh of the Metallurgy Division for his efforts during development of Core I fuel elements. Special thanks are due also to the ORNL Graphic Arts Group for the illustrations, the Metallographic Section of the Metallurgy Division for the metallography, photomicrographs, and photographs, and the Reports Office of the Metallurgy Division for the fine stenographic work and other help furnished on the report. 


\section{BIBLIOGRAPHY}

I. J. A. Kyger, F. Kerze, and W. H. Wilson, Cam-Type Plate Spacing Gage for the Materials Testing Reactor Fuel Assemblies, ORNL-255 (July, 1949).

2. R. J. Beaver et ai., Specifications for Army Package Power Reactor (APPR-1) Fuel and Control. Rod Components, GRNL-22.25 (July, 1957).

3. R. J. Beaver et al., Investigation of the Factors Affecting Sensitization of Army Package Power Reactor (APPR-I) Fuel Elements, ORNL-2312 (September, 1957).

4. J. E. Cunnirgham et a.l., "Fuel Dispersions in Stainless Steel Components for Power Reactors, "FueI Elements Conference, Faris, France, November, 1957, Book I, MID-7546, p 24.3 (March, I.958).

5. J. E, Cunningham and R, J. Beaver, "APPR Fuel Technology," Proceedings of the Seccnd. Intermational Conference on Peacerul Uses of Atomic Energy, September, 1958, UN Paper 1925.

6. J. T. Cunnirgham and Ro J. Beaver, "Stainiess Steel-Uranium Dioxide Fuel. Components," IMD Special Report Series, Nucleax Metailurgy 2, AIMF Fal.1 Meeting, Cleveland, Ohio, (October, 1958) Synposium on the Fabrication of Fue I Ellements.

7. R. G. Cardwel.1, "Fuel Element, Faorication," Nuclear Materials Management, Chapter VTr. (In press)

8. Bxitish Journaid of Radiology, Suppiement No. 6 (1955).

9. "Stainless anả Heat-Resisting SteeIs," Steel Proaucts Manual, Section 24, American Iron and Steel. Institute (Nay, 1946)。

10. J. E. Cunningham et al., Specifications and Fabrication Procedures for APPR-I Core II, Stationary Fuel Ejements, OrivL-2649 (January 29, 1959).

11. A. L. Boch, Army Package Power Reactor Project Progress Report, ORNL-2703 (March 24, 1959). Classifieả

12. C.F. Leitten, Jr. et a.., Specifications and Fabrication Procedures for APPR-I Core II Absorber Sections, ORNI,-2733. (To be published) 


\section{APPENDIX A}

Sample calculation illustrating the method utilized in determining the quantities of $\mathrm{Eu}_{2} \mathrm{O}_{3}$ and stainless steel required in the make-up of the suppressor compact.

\section{Data Required}

1. Weight of europium per plate

$=1.0 .8$

2. Average weight per cent europium in $\mathrm{Eu}_{2} \mathrm{O}_{3}=85.0$

3. Coined compact densification

$=84 \%$

4. Theoretical density of $\mathrm{Eu}_{2} \mathrm{O}_{3}$

$=7.42 \mathrm{~g} / \mathrm{cm}^{3}$

5. Theoretical density of stainless steel

$=7.9 \mathrm{~g} / \mathrm{cm}^{3}$

An individual suppressor compact size of 2.180 in. $x 0.274$ in. $x 0.068$ in. was experimentally determined. Based on the required data, the compact contained 28.96 vol $\% \mathrm{Eu}_{2} \mathrm{O}_{3}$ or the equivalent of $1 \mathrm{~g} \mathrm{Eu}$. These individual compacts were machined from a "master compact" to facilitate preparation. A sample calculation to determine the amount of each base constituent required in the master compact is as follows:

1. Total volume of master compact:

2.180 in. $x] .832$ in. $x 0.068$ in. $x 16.38 \frac{\mathrm{cm}^{3}}{\text { in. }{ }^{3}}=4.454 \mathrm{~cm}^{3}$

2. Actual material volume:

$4.454 \mathrm{~cm}^{3} \times 84=3.751 \mathrm{~cm}^{3}$

3. Volume of $\mathrm{Eu}_{2} \mathrm{O}_{3}$ in coined compact:

$3.751 \mathrm{~cm}^{3} \times \frac{28.96}{100}=1.086 \mathrm{~cm}^{3}$

4. Volume of stainless steel in coined compact:

$3.751-1.086=2.665 \mathrm{~cm}^{3}$

5. Weight of $\mathrm{Eu}_{2} \mathrm{O}_{3}$ and stainless steel in master compact:

$\mathrm{Eu}_{2} \mathrm{O}_{3}: 1.086 \mathrm{~cm}^{3} \times 7.42 \mathrm{~g} / \mathrm{cm}^{3}=8.058 \mathrm{~g}$

SS: $2.665 \mathrm{~cm}^{3} \times 7.9 \mathrm{~g} / \mathrm{cm}^{3}=21.053 \mathrm{~g}$ 
6. The stainless steel results in sintering elemental $\mathrm{Fe}, \mathrm{Ni}$, and $\mathrm{Cr}$ powders in the weight ratio $71,11,18$, respectively. The charge of each constituent is:

Fe: $21.053 \mathrm{~g} \times \frac{71}{100}=14.948 \mathrm{~g}$

$\mathrm{Ni}: 21.053 \mathrm{~g} \times \frac{11}{100}=2.316 \mathrm{~g}$

Cr: $21.053 \mathrm{~g} \times \frac{18}{100}=3.789 \mathrm{~g}$

7. Weight per cent $\mathrm{Eu}_{2} \mathrm{O}_{3}$ and stainless steel in compact:

$\mathrm{Eu}_{2} \mathrm{O}_{3}: \frac{8.058}{29.111} \times 100=27.68 \%$

SS: $\frac{21.053}{29.111} \times 100=72.32 \%$

8. Weight per cent of europium:

$8.058 \mathrm{~g} \times \frac{85}{100}=6.849 \mathrm{~g}$

6.849

$\overline{29.111} \times 100=23.53 \%$ 


\section{APPENDIX B}

The following drawings are included to furnish potential fabricators with additional information not covered in the main body of the report:

Description of Item

Powder Metal Die

Details Sheet No. 1

Powder Metal Die

Details Sheet No. 2

Blanking Die

Details Sheet No. I

Blanking Die

Details Sheet No. 2

Blanking Die

Details Sheet No. 3

Control Rod Fuel Element Braze Jig

Assembly and Details
Dwg. No.

$\underline{\text { Page }}$

D-27220

74

D-26295

75

$D-28951$

76

D-28952

77

D-28953

78

D-23422

79 



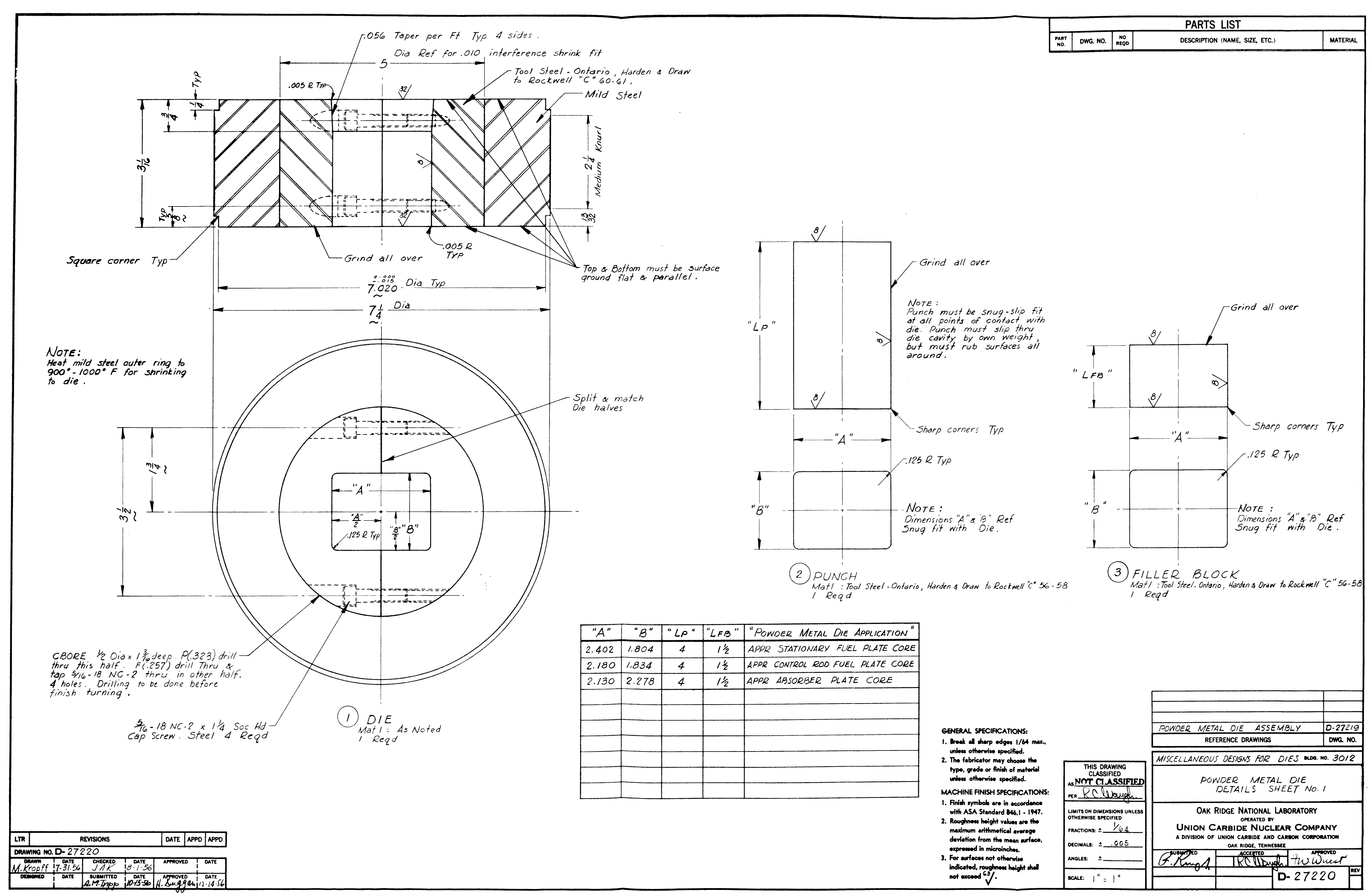





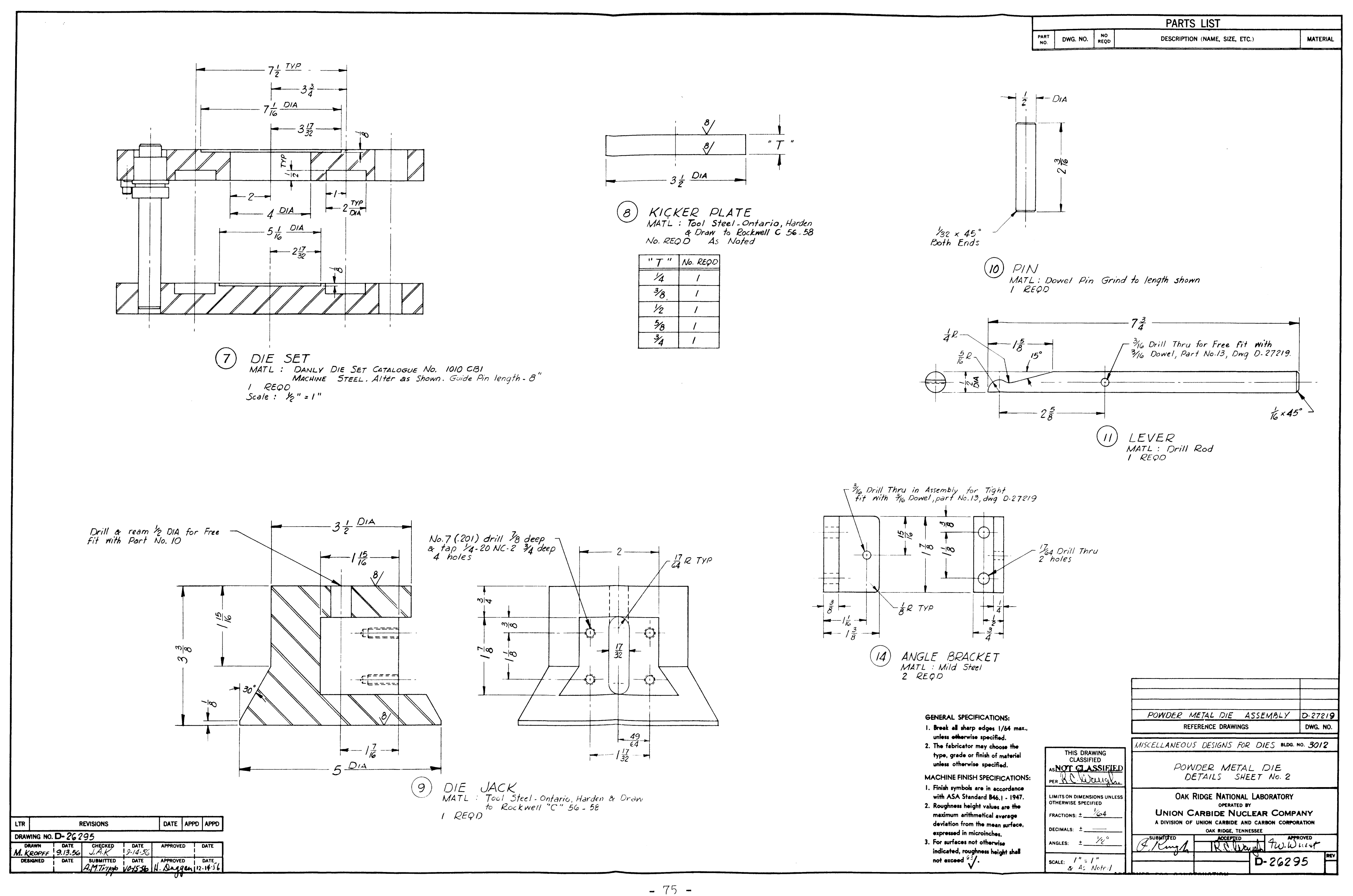




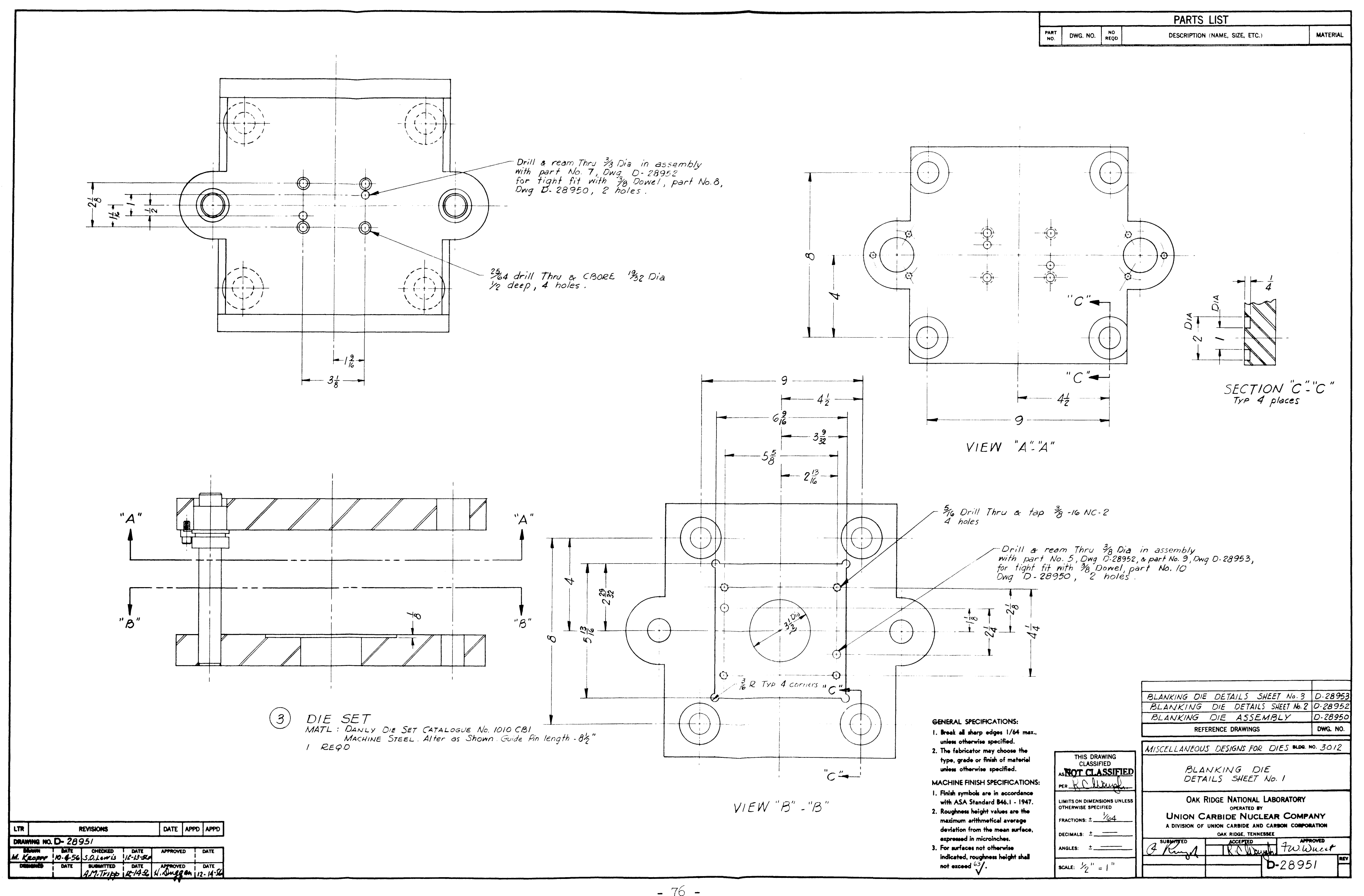




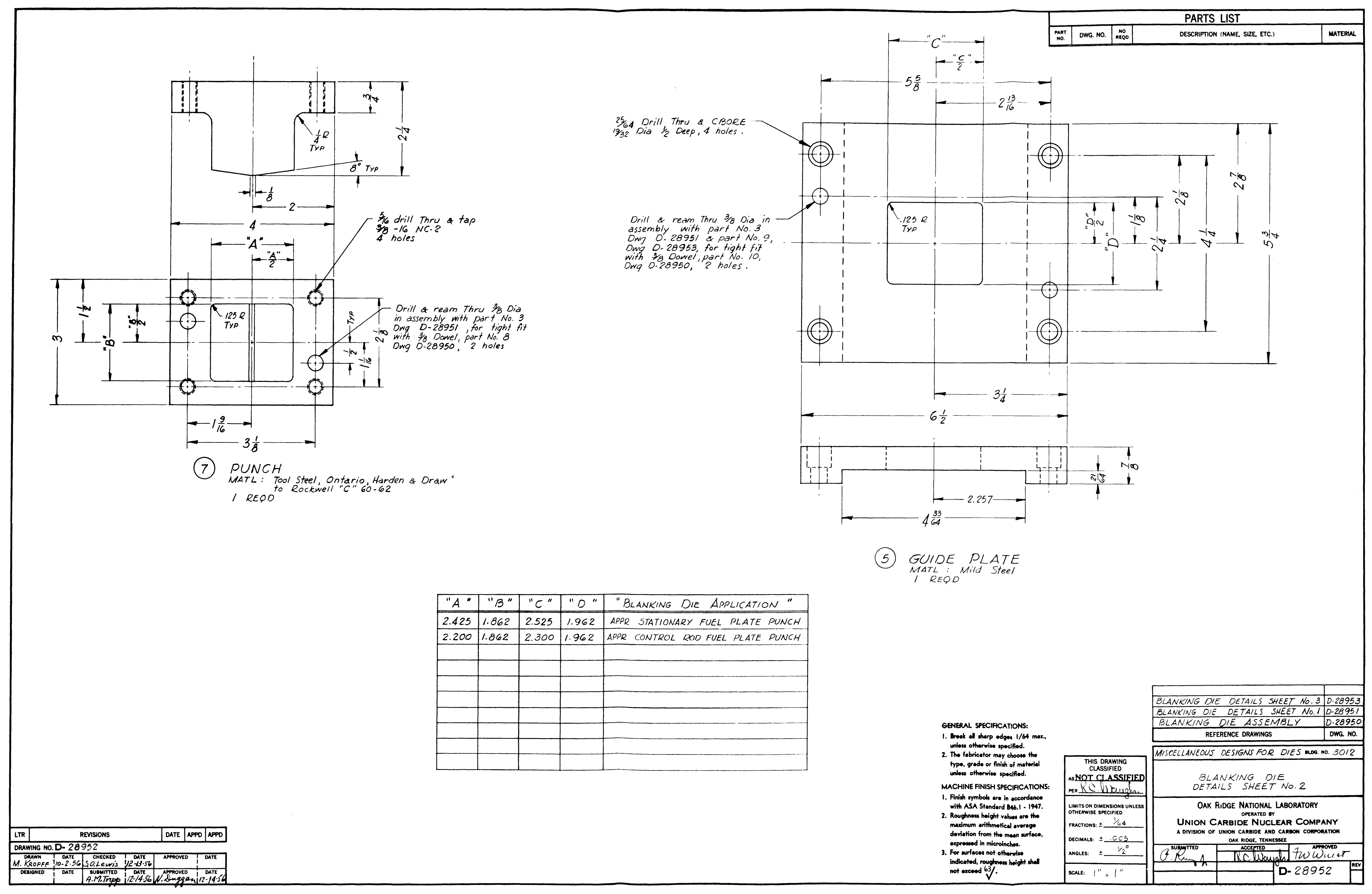




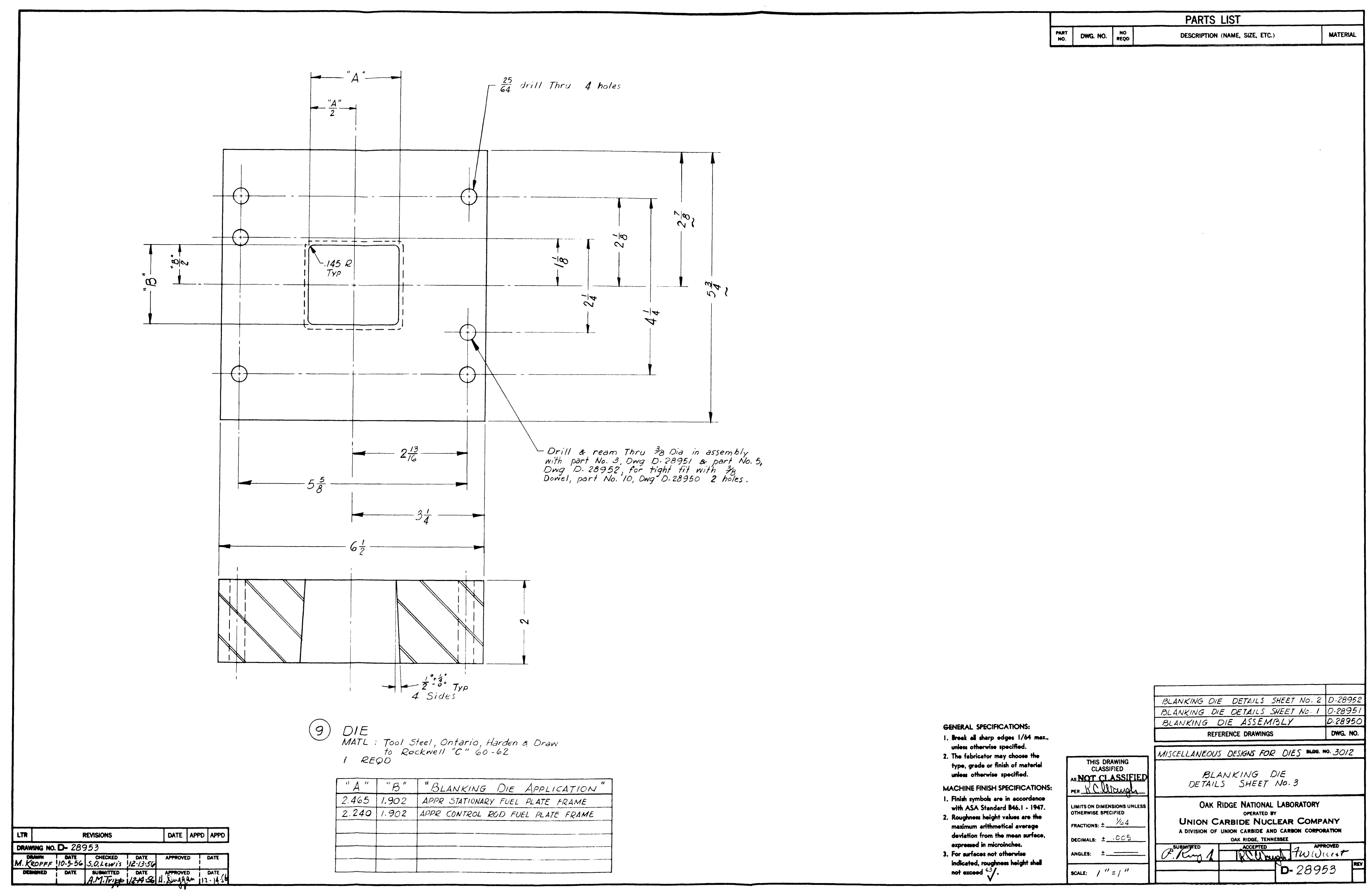




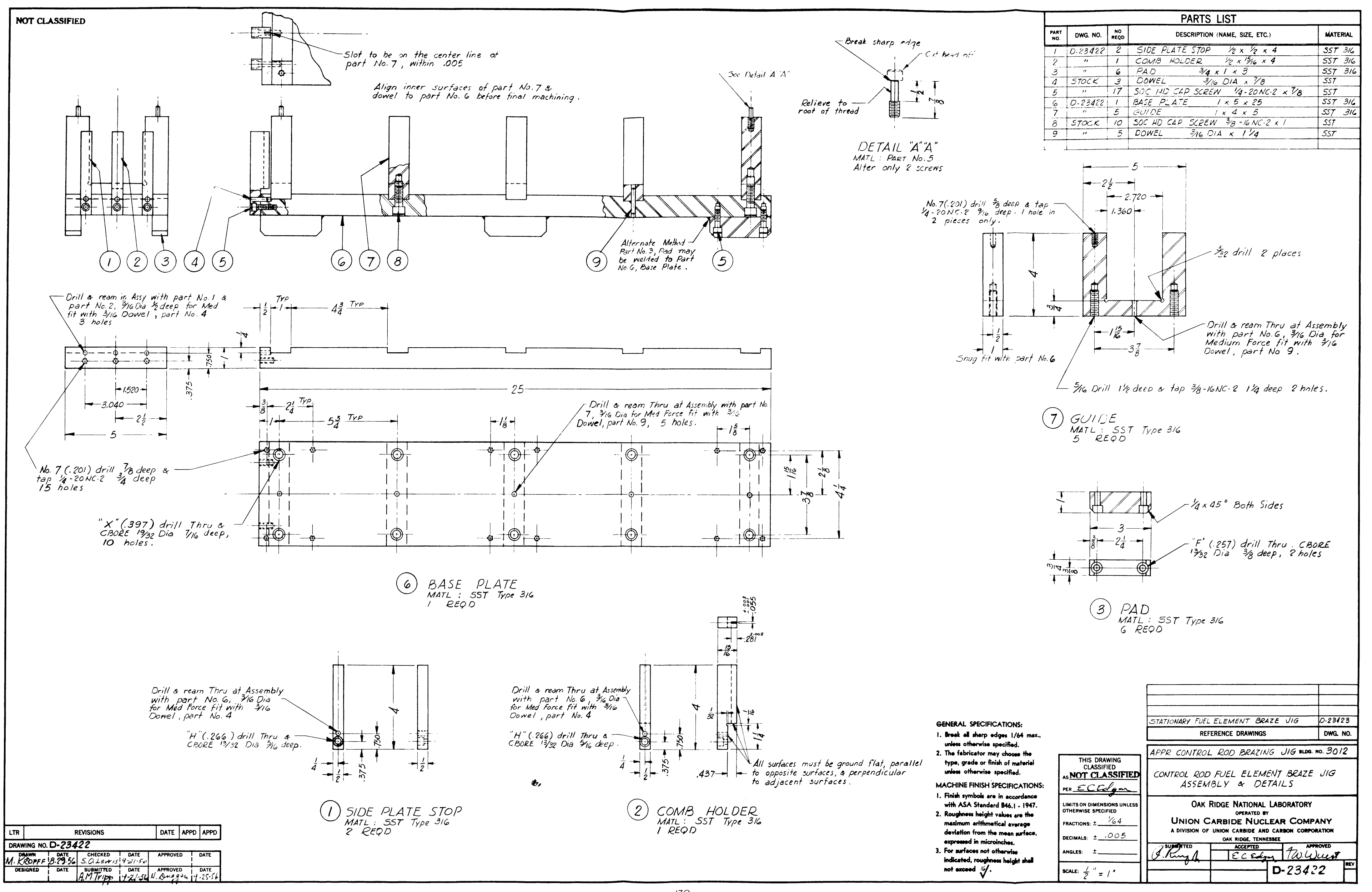

- 79 - 



\section{APPENDIX C}

Copies of the following forms are included to serve as a guide in helping potential fabricators maintain proper metallurgical history, fuel accountability, and other pertinent data requiring permanent record:

Form Identification

Powder Metallurgy Core Order Form

Rare Earth. Powder Metallurgy Core Order Form

Powder Metallurgy Fabrication Form

Flux Suppressor Core Inspection Sheet

Rolling Schedule

Fuel Plate Fabrication Record

Radiographic Inspection Sheet of Fuel Plates

Assembly Record Card

Inspection Record $\underline{\text { Page }}$

81

84

87

88

89

90

91

92

93 

Core Order \#

No. of Cores Ordered
Order Date

Order Completed

Uranium Dioxide Specifications per core:

1. Identification

2. Enrichment

3. Weight per cent

4. Grams per core

5. Particle size range

Boron Carbide Specifications per core:

1. Identification

2. Weight per cent

3. Grams per core

4. Particle size range

Stainless Steel Specifications per core:

1. Identification

2. Weight per cent

3. Grams per core

4. Particle size range

Theoretical Total Core Weight, grams

Desired Core Size:

Special Instructions: 
POWDER METALLURGY CORE ORDER FORM

Data for Core Order \#

A. Blending Operation

1. Total weight of core components to be batch blended for cores.

a. Uranium dioxide: grams .

b. Boron carbide: grams .

c. Stainless steel: grams.

2. Identification of blending container:

3. Blending device to be used:

4. Initial dry blending time:

5. Type of alcohol to be added: ; volume to add:

6. Method of alcohol addition:

7. Alcohol to be added:

8. Final reblending time:

B. Cold Pressing Operation

1. Pressure to be used:

C. Sintering Operation

1. Sinter for hours at ${ }^{\circ} \mathrm{F}$.

D. Coining Operation

1. Pressure to be used:

E. Other Operations 
POWDER METALLURGY CORE ORDER FORM

Data for Core Order \#

Deviations from the specified core composition or fabrication procedure:

Record of individual core weight and thickness: (To be completed unless otherwise specified.)

Weight in
grams

Thickness in
inches

Weight in
grams

Thickness in
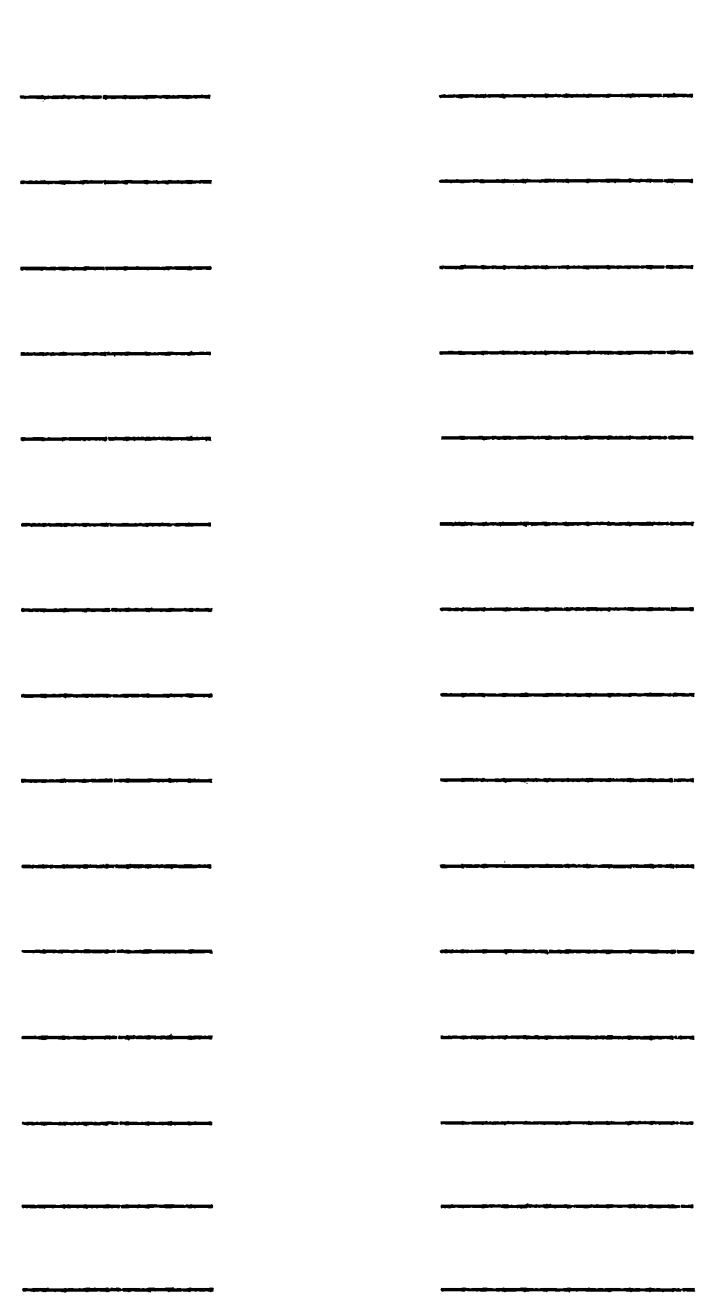

Average Core Weight
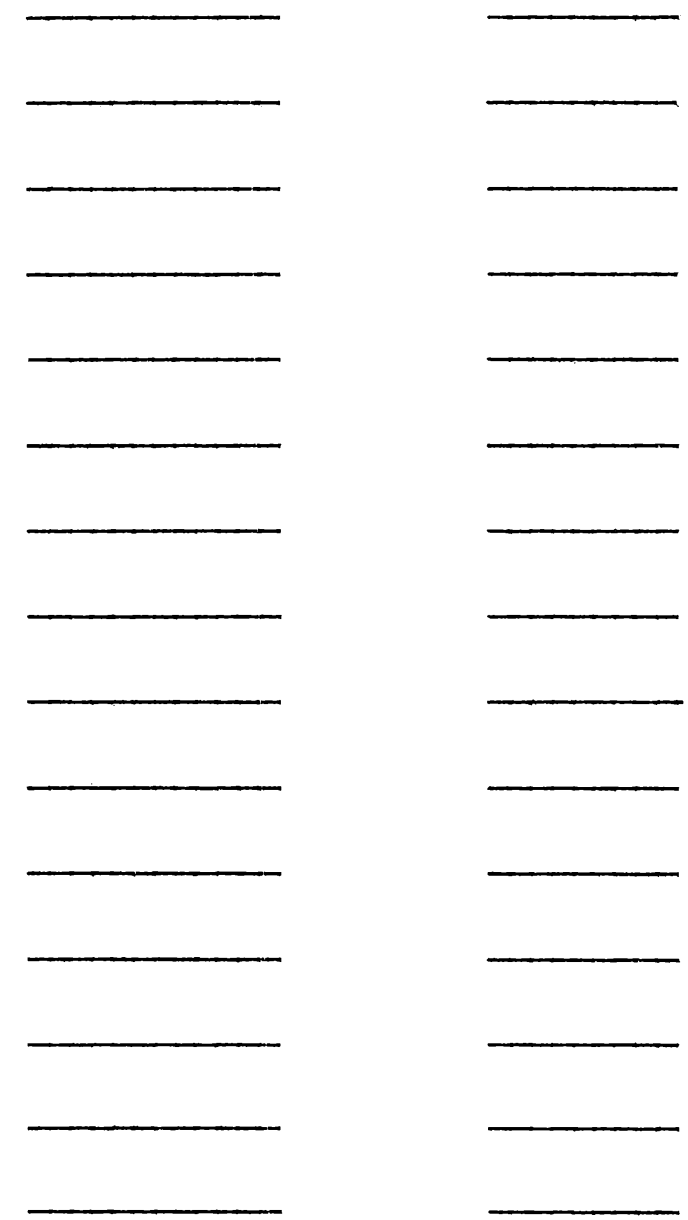

inches

No deviations from the specified core composition or fabrication procedure are to be made without the prior approval of 
RARE EARTH POWDER METAILURGY CORE ORDER FORM

Core Order \#

No. of Cores Ordered

Rare Earth Specifications per core:

1. Type Material

2. Identification

3. Weight per cent

4. Grams per core

5. Particle size

Matrix Material Specifications per core:

1. Type Material

2. Base Constituents

3. Identification of Constituents

4. Weight per cent

5. Grams per core

6. Particle size
Order Date

Order Completed 
RARE EARTH POWDER METAILURGY CORE ORDER FORM

Data for Core Order \#

A. Blending Operation

1. Identification of blending container

2. Blending device to be used

3. Blending time desired

Special Instructions:

\section{B. Core Processing Operations}

1. Initial cold pressing operation:

a. Pressure Tsi

b. Load T

2. Initial sintering operation:

a. A.tmosphere

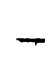

, Dew Point ${ }^{\circ} \mathrm{F}$

b. Sintering time $\mathrm{Hr}$, Temperature ${ }^{\circ} \mathrm{F}$

3. Final pressing operation:
a. Pressure Tsi
b. Load $\mathrm{T}$

4. Final sintering operation:
a. A.tmosphere
, Dew Point ${ }^{\circ} \mathrm{F}$
b. Sintering time
Hr, Temperature ${ }^{\circ} \mathrm{F}$

5. Coining operation:
a. Pressure Tsi
b. Load $\mathrm{T}$

6. Other operations 
RARE EARTH POWDER METAILURGY CORE ORDER FORM

Data for Core Order \#

Deviations from the specified core composition or fabrication procedure:

Record of individual core weight and thickness:

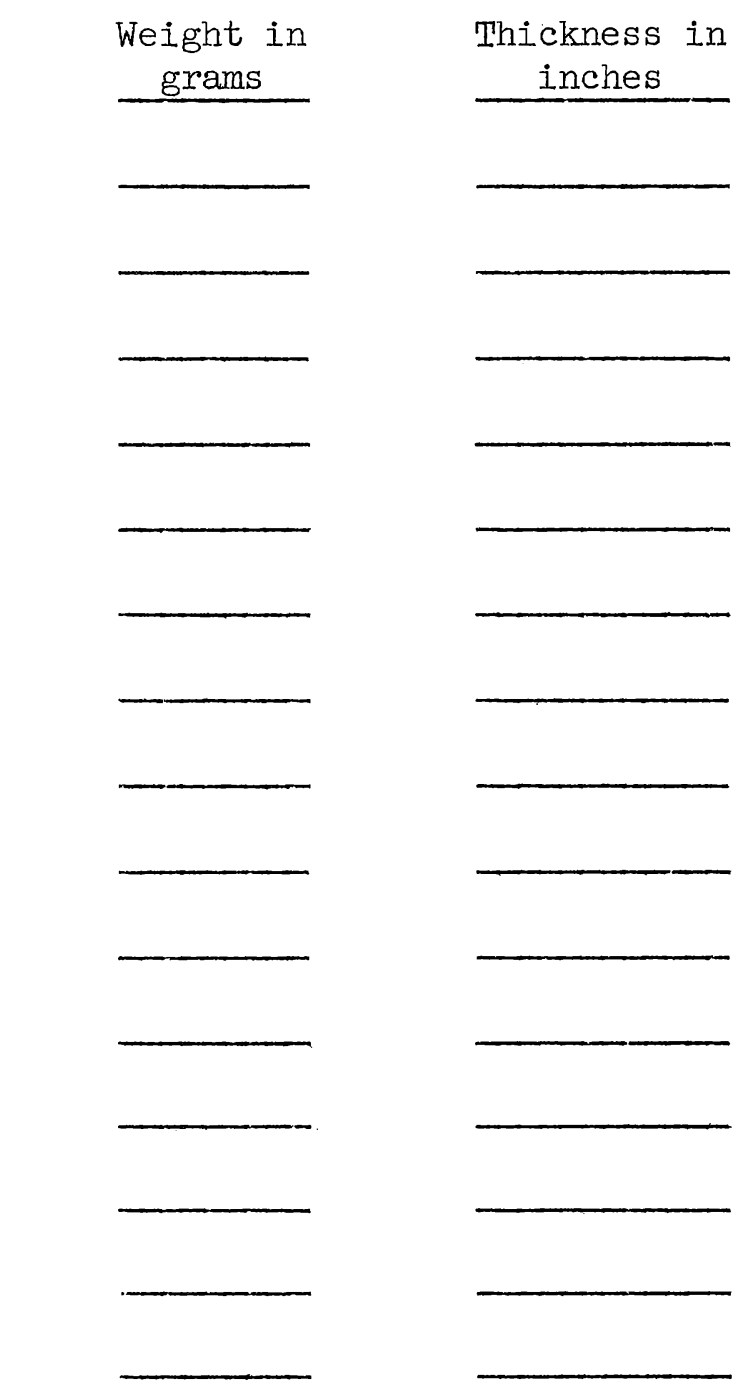

Average Core Weight

Weight in
grams $\quad \begin{gathered}\text { Thickness in } \\ \text { inches }\end{gathered}$

grams

inches

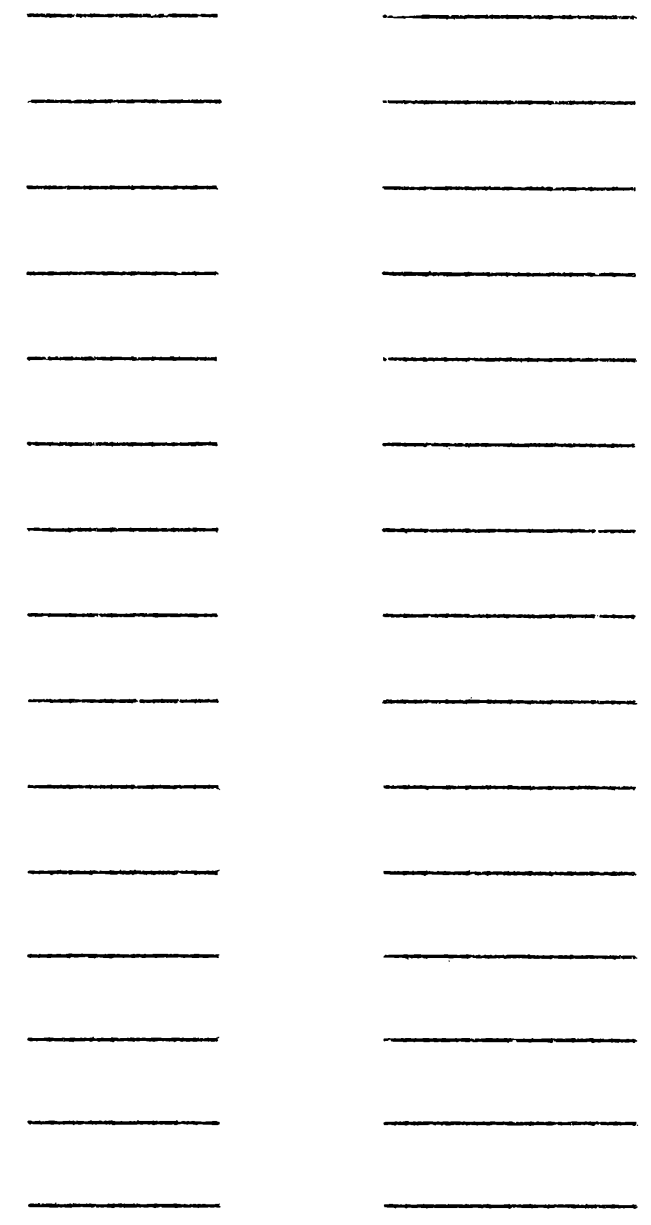

Average Core Thickness

No deviations from the specified core composition or fabrication procedure are to be made without the prior approval of 
Shipment Number Typo Material

Total Wt Material

Type Cores

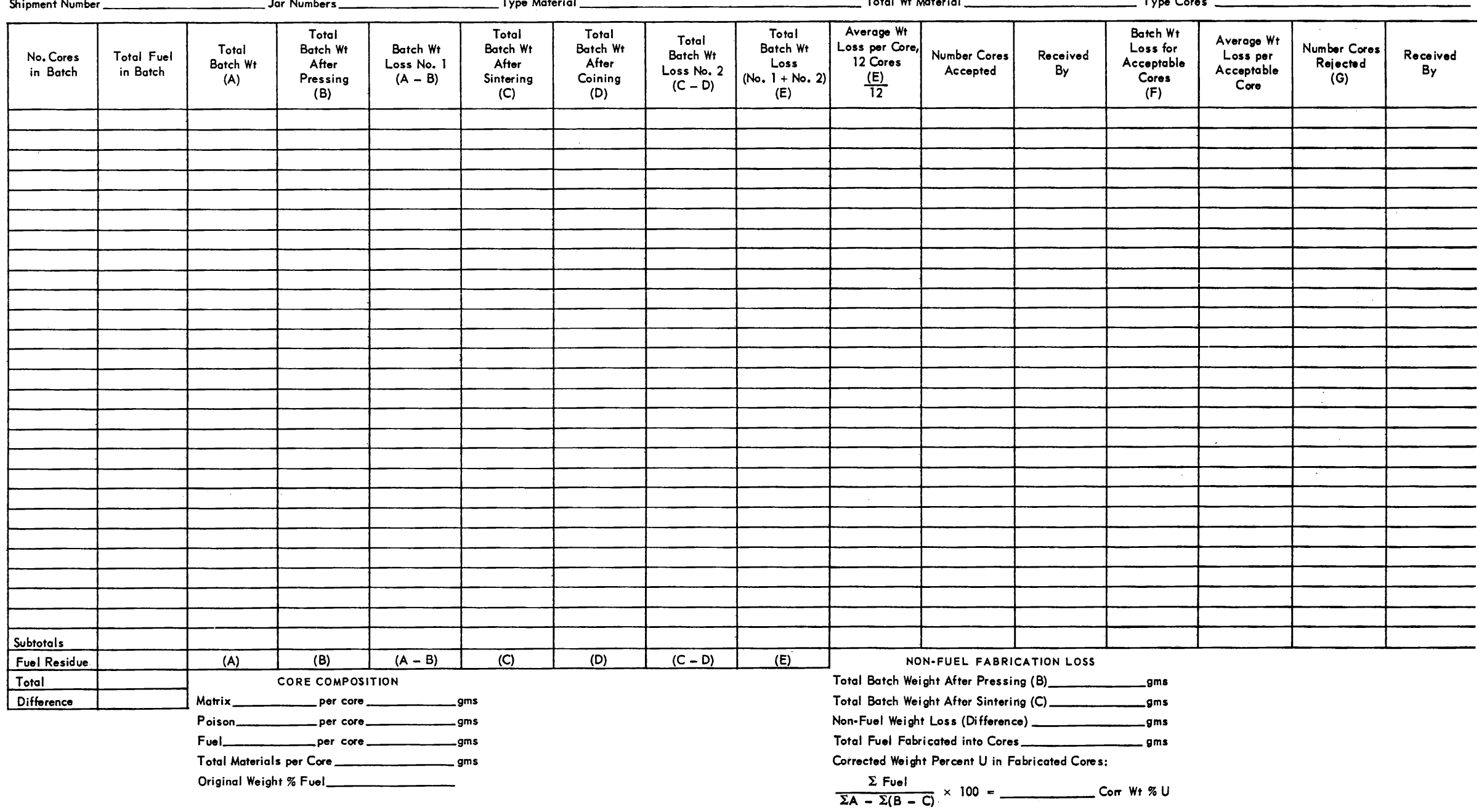


$-88-$

FLUX SUPPRESSOR CORE INSPECTIION SHEET

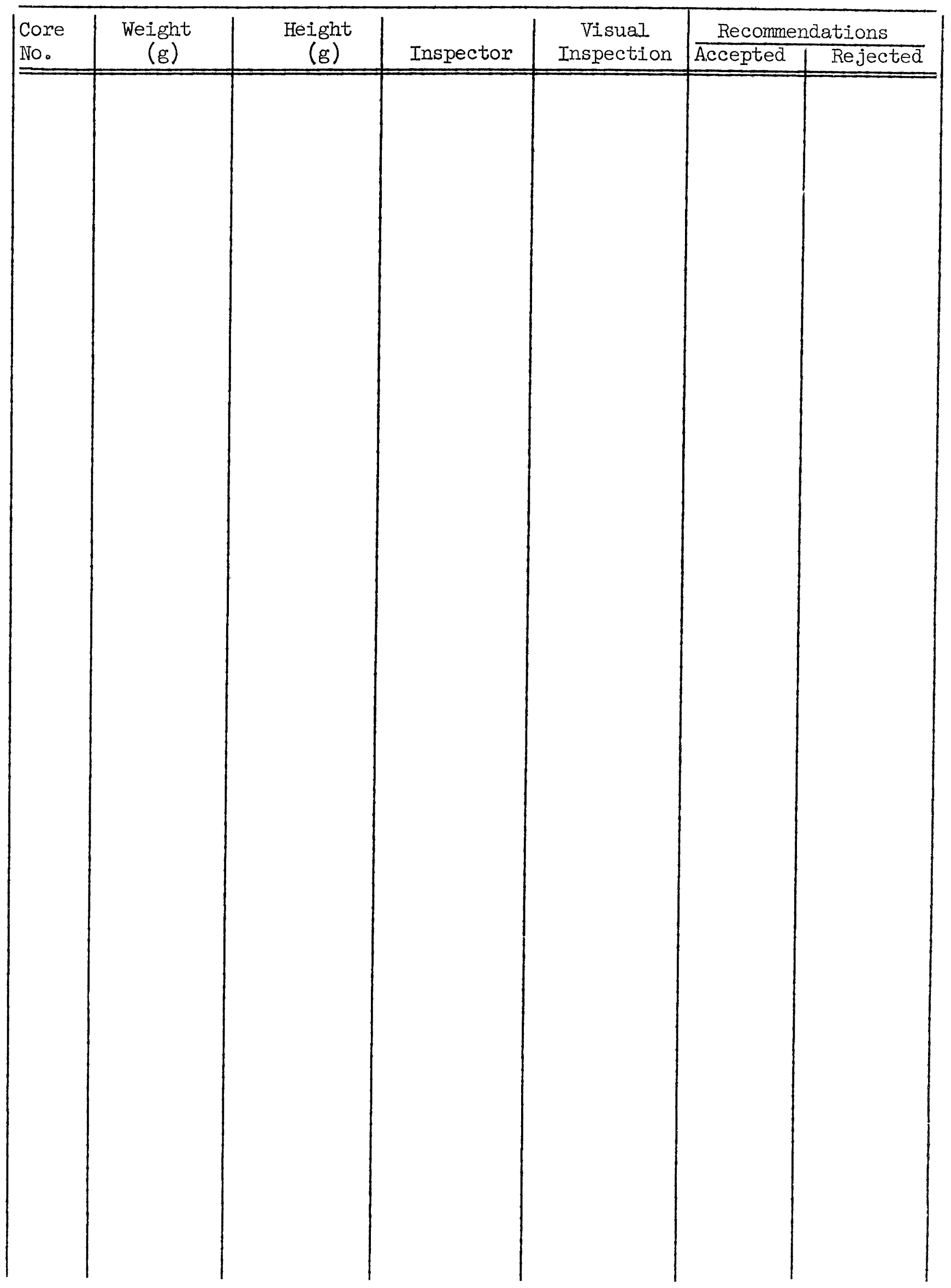




\section{ROLCING SCHEDULE}

\section{MIIL SETTINGS:}

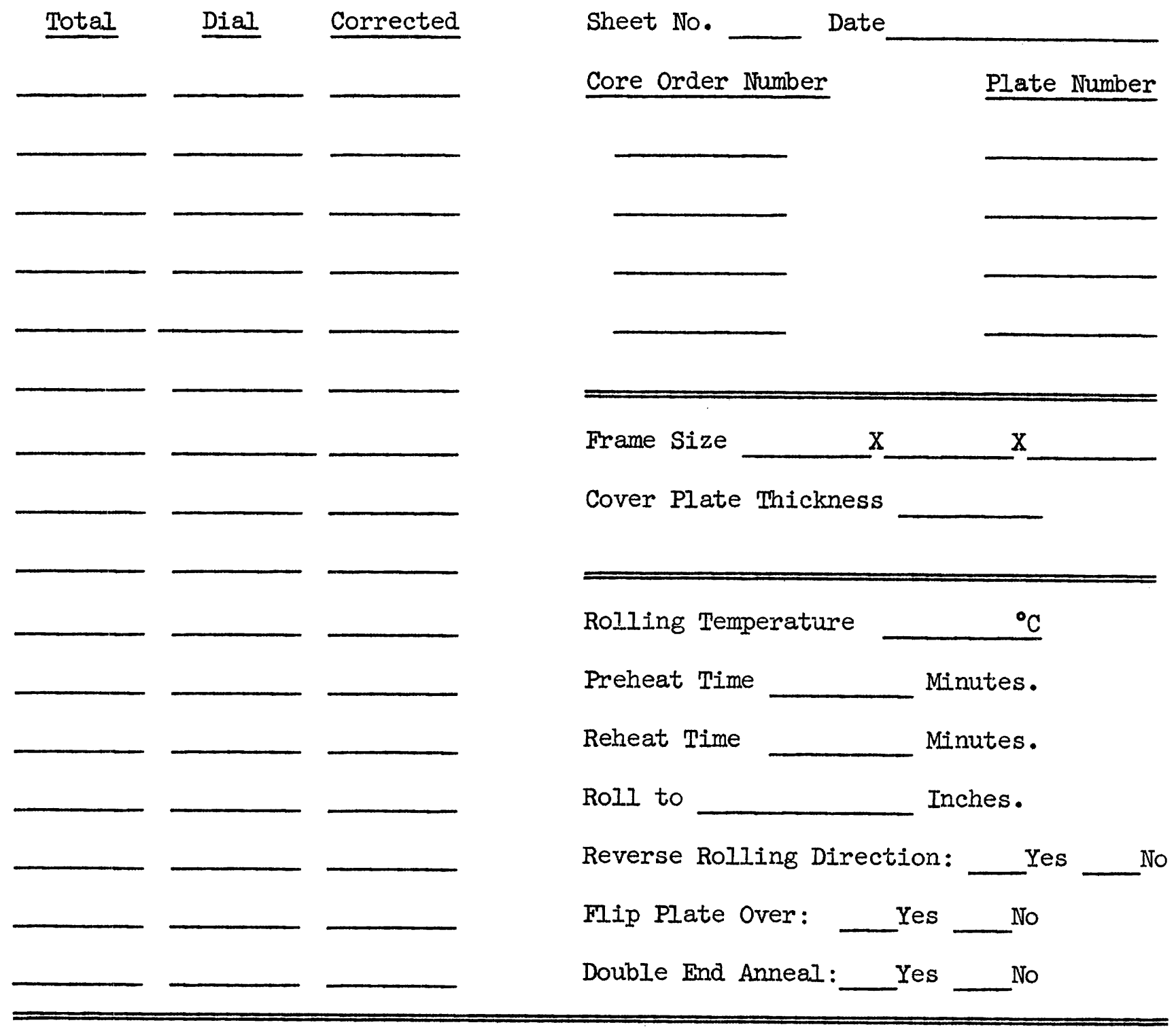

C O M M N T S:

Billet Rolling Direction: 
FUEL PLATE FABRICATION RECORD

\begin{tabular}{|c|c|c|c|c|c|c|c|c|c|}
\hline \multirow[b]{2}{*}{$\begin{array}{l}\text { PLATE } \\
\text { No. }\end{array}$} & \multicolumn{2}{|c|}{ TYPE OF FUEL PLATE } & \multirow[b]{2}{*}{ 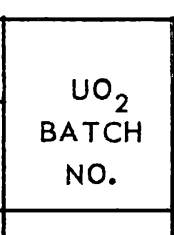 } & \multicolumn{5}{|c|}{ DESCRPPTION OF REEECTION } & \multirow{2}{*}{\begin{tabular}{|c|c|} 
TRANSERRE \\
BRRARING \\
FRR \\
\end{tabular}} \\
\hline & 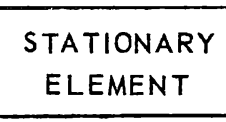 & 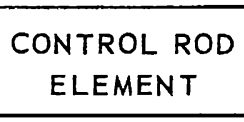 & & \begin{tabular}{|c|c|} 
HOT \\
ROLLNG
\end{tabular} & PITS & $\begin{array}{l}\text { COLD ROLL } \\
\text { BOW }\end{array}$ & LING & MISCELLANEOUS & \\
\hline & & & & & & & & & \\
\hline & & & & & & & & & \\
\hline & & & & & & & & & \\
\hline & & & & & & & & & \\
\hline & & & & & & & & & \\
\hline & & & & & & & & & \\
\hline & & & & & & & & & \\
\hline & & & & & & & & & \\
\hline & & & & & & & & & \\
\hline & & & & & & & & & \\
\hline & & & & & & & & & \\
\hline & & & & & & & & & \\
\hline & & & & & & & & & \\
\hline & & & & & & & & & \\
\hline & & & & & & & & & \\
\hline
\end{tabular}


RADIOGRAPHIC INSPECTION SHEET OF FUEL PLATES

\begin{tabular}{|c|c|c|c|c|c|c|c|c|}
\hline $\begin{array}{l}\text { PLATE } \\
\text { NO. }\end{array}$ & $\begin{array}{c}\text { DATE } \\
\text { DELIVERED }\end{array}$ & $\begin{array}{c}\text { DATE } \\
\text { RECEIVED }\end{array}$ & $\begin{array}{l}\text { QUALITY } \\
\text { COLTROL } \\
\text { CHECK }\end{array}$ & $\begin{array}{l}\text { QUALITY } \\
\text { O.K. }\end{array}$ & $\begin{array}{l}\text { MINIMUM END } \\
\text { STAINLESS, INCHES }\end{array}$ & \begin{tabular}{|c} 
POSSIBLE \\
EXCESSIVE \\
BOWING \\
\end{tabular} & $\begin{array}{l}\text { MIN. EDGE } \\
\text { STAINLESS, } \\
\text { INCHES }\end{array}$ & \begin{tabular}{|c|c|} 
RECOMMENDATION \\
ACCEPTED REJECTED
\end{tabular} \\
\hline & & & & & & & & \\
\hline & & & & & & & & \\
\hline & & & & & & & & \\
\hline & & & & & & & & \\
\hline & & & & & & & & \\
\hline & & & & & & & & \\
\hline & & & & & & & & \\
\hline & & & & & & & & \\
\hline & & & & & & & & \\
\hline & & & & & & & & \\
\hline & & & & & & & & \\
\hline & & & & & & & & \\
\hline & & & & & & & & \\
\hline & & & & & & & & \\
\hline & & & & & & & & \\
\hline & & & & & & & & \\
\hline & & & & & & & & \\
\hline & & & & & & & & \\
\hline & & & & & & & & \\
\hline & & & & & & & & \\
\hline & & & & & & & & \\
\hline & & & & & & & & \\
\hline & & & & & & & & \\
\hline & & & & & & & & \\
\hline
\end{tabular}




\section{ASSEMBLY RECORD CARD}

Jig Number-an-

Inside Diameter of Jig Measured with an Inside Micrometerma

Width of Shim Plate \#I (As Coated)

Width of Shim Plate \#2 (As Coated) -

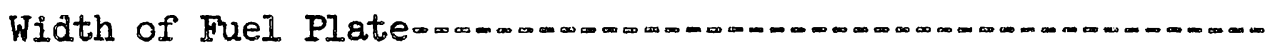

Material Left Behind Side Plate Groove (Randomly Checked)--Space Remaining in Jig

Inside Dimensions of Jignman-m-nomon

Maximum Metal Remaining Behind Groove-

Thickness of Shim Plates

Calculated Clearance-......................

Theoretical Width of Assembly-.........

Maximum Actual Brazed Width-.......-.

Maximum Lean of Assembly 
INSPECTION RECORD

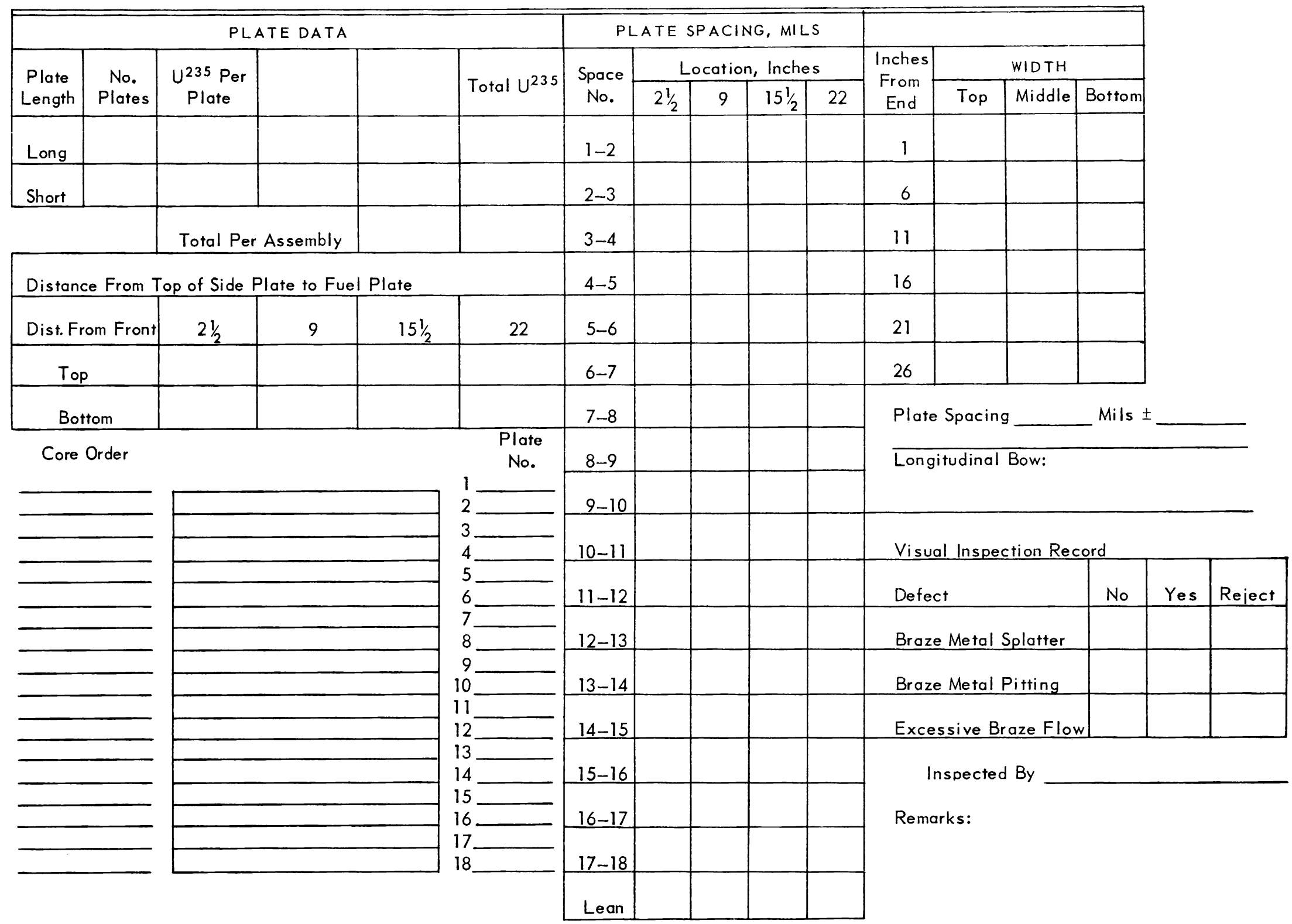




\author{
ORNL -2726 \\ Reactors-Power \\ TID -4500 ( 14 th ed.)
}

INTERNAL DISTRIBUTION

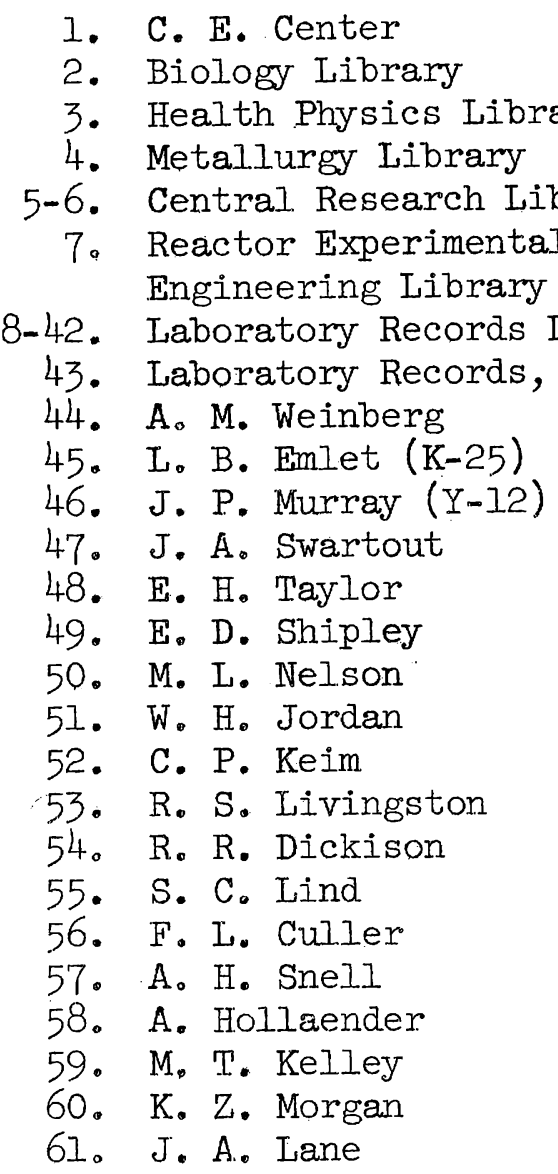

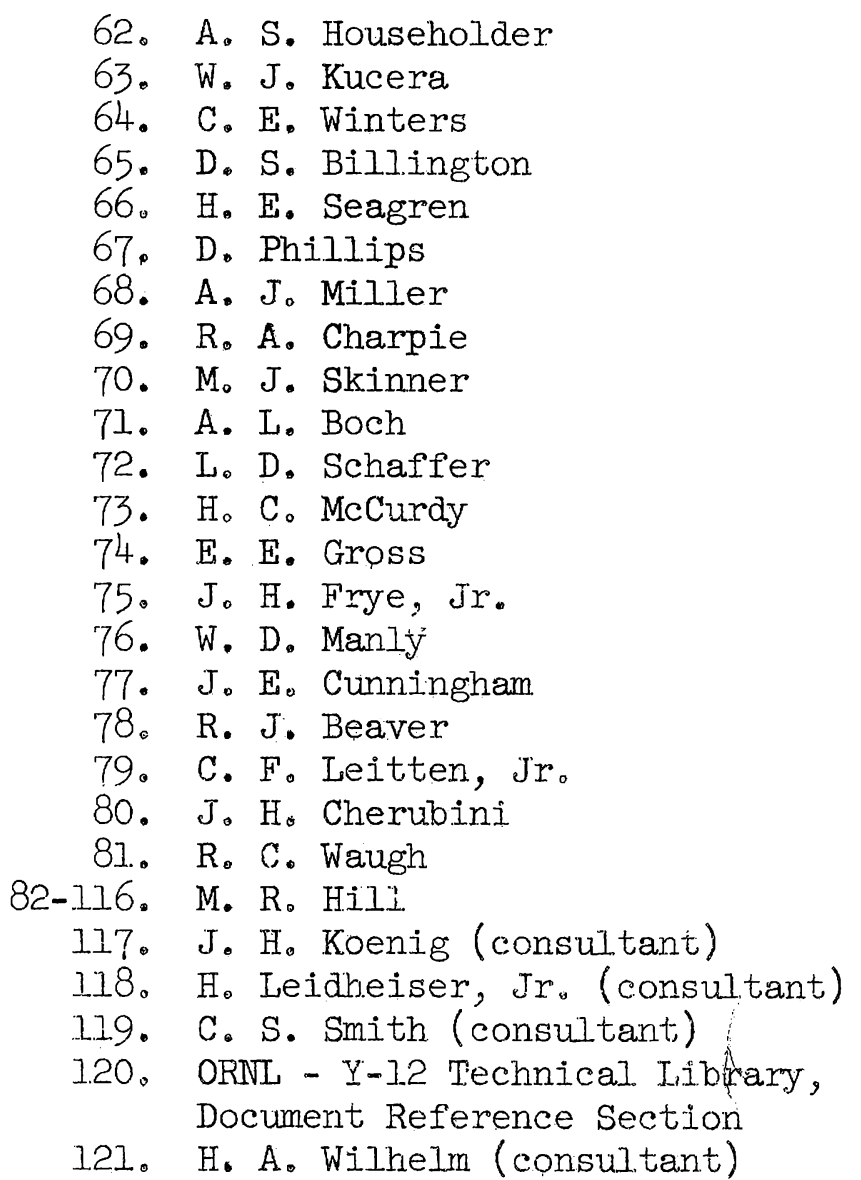

EXTERNAL DISTRIBUTION

122. Division of Research and Development, AEC, ORO

123-129. AEC, Washington (3 copies to Col. D. G. Williams, APB-DRD, I copy ea to Capt. E. D. Peixotto, APB-DRD, Lt. D. A. Pistenma, APB-DRD, M。 A。 Rosen, APB-DRD, Capt. L. P. Crocker, APB-DRD)

130-132. NYO-AEC, New York (1 copy ea. to M. Eisenbud, W. M. Johnson, and Capt. R. L. Harris)

133-137. Alco Products, Inc. (I copy ea. to K. Kasschaw, J. F。 Haines, J. G. Gallaher, R. D. Robertson, and E. C. Edgar)

138-139. DRD-AEC, Washington (I copy ea. to J. M. Simmons and R. Co Dalzell)

140. Brig. Gen. K. A. McCrimmon, OCE, US Army, Washington

141-142. Maj. J. T. Rhett, OCE, US Army, Washington

143. Maj. W. E. Ray, NPFO, EROL, Ft. Belvoir, Va。

144-725. Given distribution as shown in TID-4500 (14th ed.) under Reactors-Power category ( 75 copies - OTS)

726-740. Capt. James W. Barnette, US Am. Engrs. Dist., Eastern Ocean, 345 Broadway, New York 13, N. Y。 


.

. 
